Danusa Haick Tavares

\title{
ANÁLISE TEÓRICA E EXPERIMENTAL DE VIGAS DE CONCRETO ARMADAS COM BARRAS NÃO METÁLICAS DE GFRP
}

Dissertação apresentada à Escola de Engenharia de São Carlos da Universidade de São Paulo, como parte dos requisitos para a obtenção do Título de Mestre em Engenharia de Estruturas.

Orientador: José Samuel Giongo

São Carlos

2006 
A minha mãe e meu pai pelo seu amor, carinho, dedicação, paciência, ajuda e confiança. Aos meus irmãos pelo amor e companheirismo em todos os momentos da minha vida.

Aos meus avós maternos, Jamile e Abraão (in memorian) e minha avó paterna, Maria Francisca, pelo exemplo de coragem e amor e pelos mimos e ensinamentos.

Ao Professor José Samuel Giongo, pela sua orientação atenciosa, paciência e principalmente pela amizade e o apoio para me ajudar a conquistar meus objetivos.

Aos amigos que convivi no Mestrado, Tatiane, Alice, Rafaelle, Ricardo, Anselmo, Sudano, Abner e em especial, Rodrigo Delalibera e Antônio Peruzzi que tiveram uma grande participação nesta pesquisa, com conversas, troca de conhecimentos e apoio moral.

A galera das Pimentas, praticamente minha família em São Carlos: Kenneth, Fernanda, Thaís e o agregado da república Danilo, pela amizade, pela enorme força e pelos melhores momentos que passei durante esses anos.

A galera da Purguero que me acolheu nestes momentos finais, pelo apoio e amizade. Ao pessoal que conheci no esporte, em especial ao time masculino de handebol do CAASO que me aceitou como parte do grupo, possibilitando momentos de descontração.

Aos professores do Departamento de Estruturas da EESC-USP, que contribuíram no meu crescimento pessoal e profissional.

A todos os funcionários do Departamento de Estruturas da EESC-USP, pela competência na execução dos seus serviços. 
A toda equipe do Laboratório de Estruturas: Amaury, Luiz Vareda, Mário, Maury, Fabiano Caio e Romeo pelo apoio, paciência, dedicação e competência com que realizaram os serviços para o desenvolvimento da pesquisa experimental.

A CAPES, pelo apoio financeiro da bolsa.

Aos funcionários da Marcenaria da EESC-USP, pela confecção das fôrmas.

A Hughes Brothers e a Owen's Corning pela doação e importação das barras da armadura não metálica. 


\section{SUMÁRIO}

RESUMO

I

ABSTRACT .II

1 INTRODUÇÃO .1

2 FUNDAMENTOS TEÓRICOS........................................................11

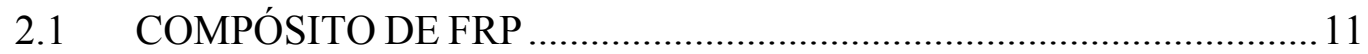

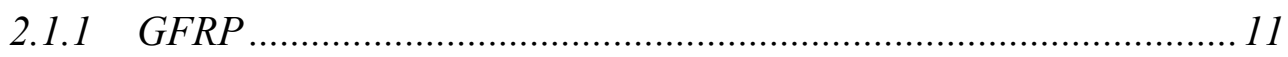

2.1.1.1 Matriz Polimérica .................................................................... 12

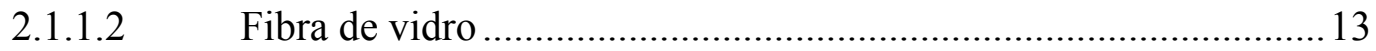

2.1.1.3 Processo de produção das barras.................................................. 14

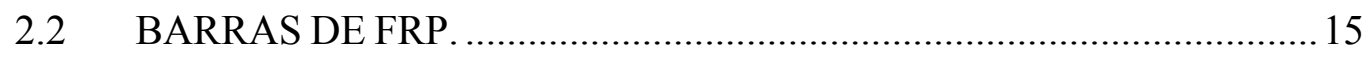

2.2.1 Classificação das barras de FRP................................................. 15

2.2.2 Propriedades das barras de FRP............................................. 16

2.2.2.1 Propriedades físicas das barras de GFRP................................... 17

2.2.2.2 Propriedades mecânicas das barras de GFRP.............................. 18

2.3 DURABILIDADE DAS BARRAS DE GFRP. ...................................20

2.4 DIMENSIONAMENTO DE VIGAS ARMADAS COM BARRAS DE FRP. 
2.4.2.1 Coeficiente de segurança da barra de FRP..................................28

2.4.3 Tensões Normais - Dimensionamento à flexão...............................31

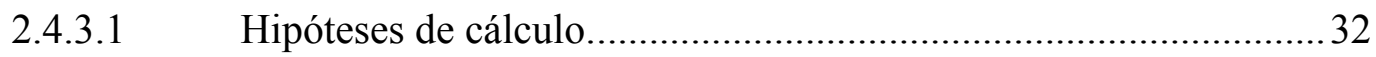

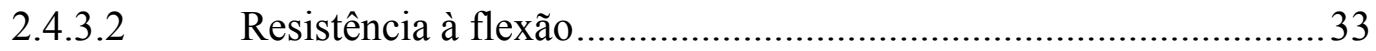

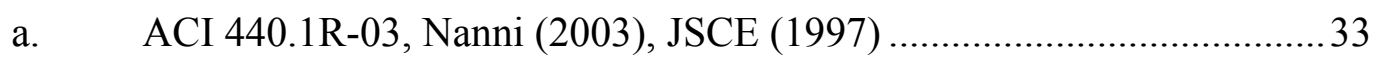

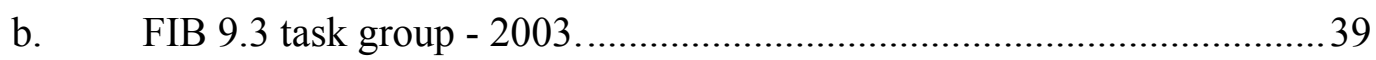

2.5 ELS - ESTADO LIMITE DE SERVIÇO..........................................4 42

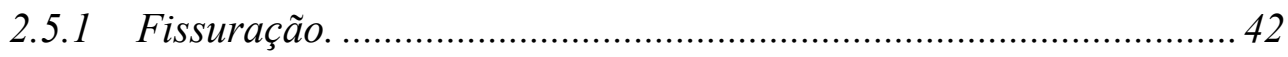

2.5.1.1 Deformação....................................................................... 44

3 DIMENSIONAMENTO À FLEXÃO DE ELEMENTOS ARMADOS

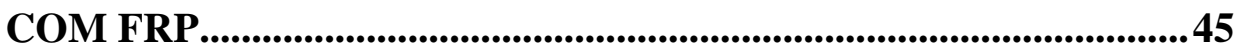

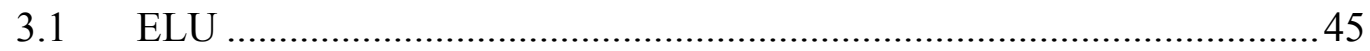

3.1.1 Coeficiente de segurança da barra de FRP $\left(\gamma_{\text {FRP }}\right)$....................... 46

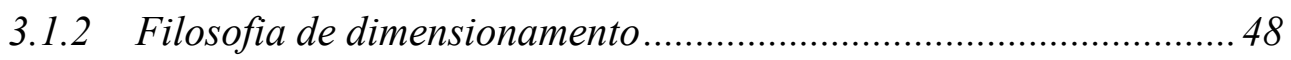

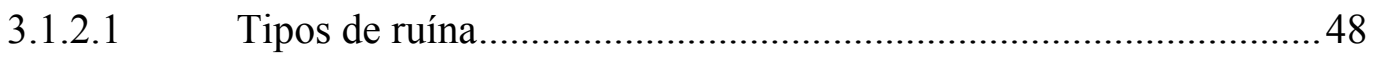

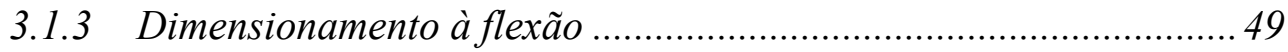

3.1.3.1 Equação de equilíbrio:............................................................. 50

3.1.3.2 Equação de compatibilidade das deformações:..............................50

3.1.3.3 Cálculo da Posição da linha neutra: .............................................50

3.1.3.4 Cálculo da deformação na armadura de FRP:.............................5 51 
3.1.3.5 Cálculo do braço de alavanca e do momento resistente.

3.1.3.6 Análise dos diagramas de deformação para os casos propostos de dimensionamento.

3.2 ELS 53

3.2.1 Fissuração 53

3.2.2 Deformação 53

3.2.2.1 Momento de inércia efetivo 53

3.2.2.2 Cálculo da deformação 54

4 INVESTIGAÇÃO EXPERIMENTAL .55

4.1 DEFINIÇÃO DAS VARIÁVEIS 55

4.2 DIMENSIONAMENTO E DETALHAMENTO DAS ARMADURAS. 57

4.2.1 Dimensionamento 57

4.2.2 Detalhamento. 58

\subsection{PROGRAMA EXPERIMENTAL} .65

4.3.1 Instrumentação 65

4.3.2 Construção dos elementos e montagem dos protótipos....... 67

4.3.3 Propriedades dos materiais. 69

4.3.3.1 Concreto 69

4.3.3.2 Armaduras. 71

4.3.4 Procedimento de ensaio das vigas. 74

4.3.5 Dispositivos, Instrumentos e equipamentos utilizados nos ensaios. 76 


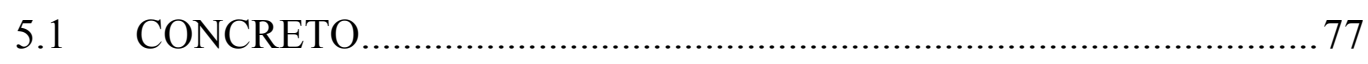

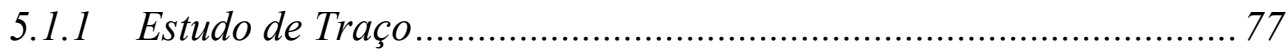

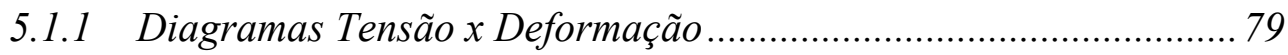

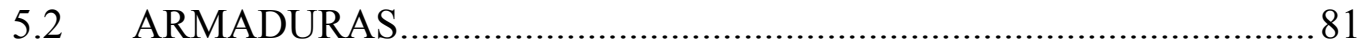

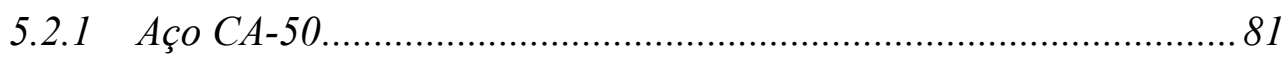

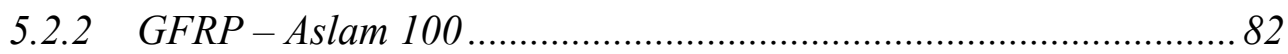

5.3 RESULTADOS E ANÁLISES DOS MODELOS ................................ 83

5.3.1 Deformação na armadura de tração..............................................8 83

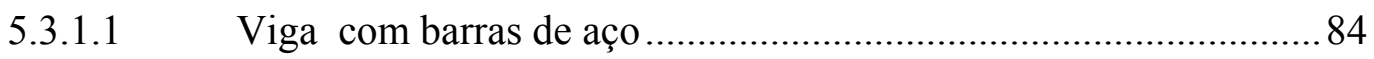

5.3.1.2 Vigas com equivalência de resistência......................................... 85

Vigas com equivalência de deformação.............................................................. 87

5.3.2 Deslocamentos observados nos modelos........................................ 89

Viga com barras de aço ............................................................................. 90

Vigas com equivalência de resistência.............................................................91

Vigas com equivalência de deformação.............................................................. 91

5.3.3 Deformações nas extremidades das barras dos modelos e efetividade dos ganchos ................................................................ 93

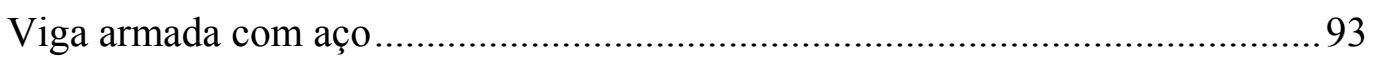

Viga de GFRP armada com equivalência de capacidade resistente.....................94

Viga de GFRP armada com equivalência de deformação última .......................97 


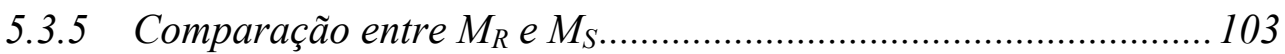

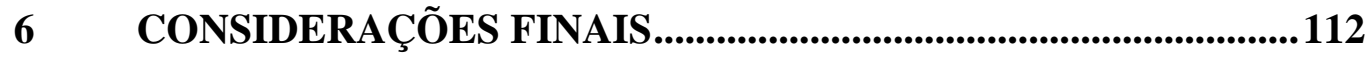

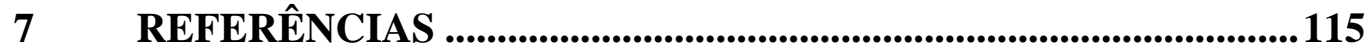




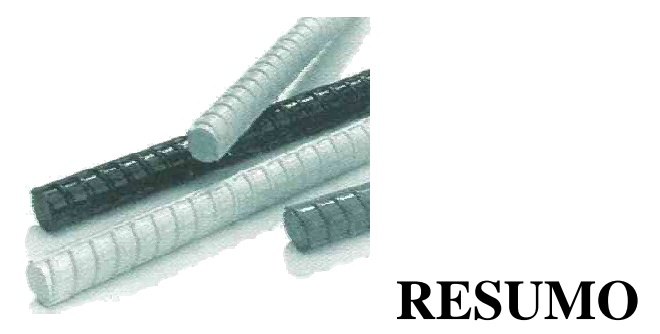

TAVARES, D. H. (2006). Análise teórica e experimental de vigas de concreto armadas com barras não metálicas de GFRP. Dissertação (Mestrado) - Escola de Engenharia de São Carlos, Universidade de São Paulo, São Carlos, 2006.

A substituição do aço pela armadura não metálica objetiva o aumento da durabilidade de estruturas sujeitas à corrosão e a campos eletromagnéticos. Mas, a inserção de um novo material na construção civil demanda especificação de sua composição, comportamento e procedimentos de sua utilização. Este trabalho analisa o comportamento à flexão de vigas de concreto armadas com barras não metálicas. Para esta finalidade foram realizados, uma revisão bibliográfica considerando os trabalhos publicados desde o início das pesquisas até os mais recentes e ensaios dos materiais e de vigas de concreto armado. Os ensaios de determinação das propriedades das barras da armadura não metálica de GFRP (glass fiber polymer polímero reforçado com fibra de vidro) englobam a determinação do diagrama tensãodeformação e capacidade resistente. As vigas armadas com barras de GFRP foram ensaiadas à flexão em quatro pontos e os resultados comparados com o de uma viga armada com barras de aço CA-50 também ensaiada a flexão. Nos modelos pôde-se perceber a influência das propriedades das barras de GFRP no comportamento geral da estrutura. Por exemplo, as grandes deformações nas barras longitudinais e os deslocamentos dos modelos foram determinados pelo baixo módulo de elasticidade das barras de GFRP. É evidente a necessidade de continuação dos estudos envolvendo barras de GFRP. Estas pesquisas poderão desenvolver meios de se utilizar as propriedades do material em favor do melhor funcionamento da estrutura.

Palavras-chave: FRP, GFRP, Armadura não metálica, vigas de concreto armadas com FRP, flexão de vigas de GFRP. 
ABSTRACT

TAVARES, D. H. (2006). Theoretical and experimental analysis of beams reinforced with non metallic GFRP bars. M.Sc. Dissertation - Escola de Engenharia de São Carlos, Universidade de São Paulo, São Carlos, 2006.

Steel reinforcement replacement aims an increase at the durability of structures with corrosion and electrical magnetic problems. But, inserting a new material at the civil construction industry demands specifications of its composition, behavior and procedures for its utilization. This work is a flexural behavior analysis of reinforced concrete beams reinforced with GFRP bars. To make this, a technical literature research was made considering the pioneer until the most recent researches, and components and concrete reinforced beams tests were done. GFRP bars properties tests went from the determination of its strains $X$ stress diagram to its tension resistance. GFRP reinforced beams were submitted to four points flexural tests and the results compared with a CA-50 steel reinforced beam also submitted to the flexural test. The specimens showed the influence of GFRP properties at the behavior of the structure. For example, longitudinal bars large strains and the large displacement of the beam were determined by GFRP bars low longitudinal elastic modulus. Continuing the studies evolving GFRP bars is certainly a need. New researches might be able to design a way to use the composite properties to improve the structure behavior.

Key words: FRP, GFRP, non metallic reinforcement, concrete beams reinforced with FRP, Flexural behavior of FRP reinforced beams. 


\section{INTRODUÇÃO}

\subsection{CONSIDERAÇÕES INICIAIS}

A construção civil remonta desde 10.000 anos a.C., muitos materiais foram introduzidos nesse tempo desde a madeira até as novas tecnologias que surgem a cada dia. A Figura 1.1 mostra a evolução dos materiais até a década de 40.

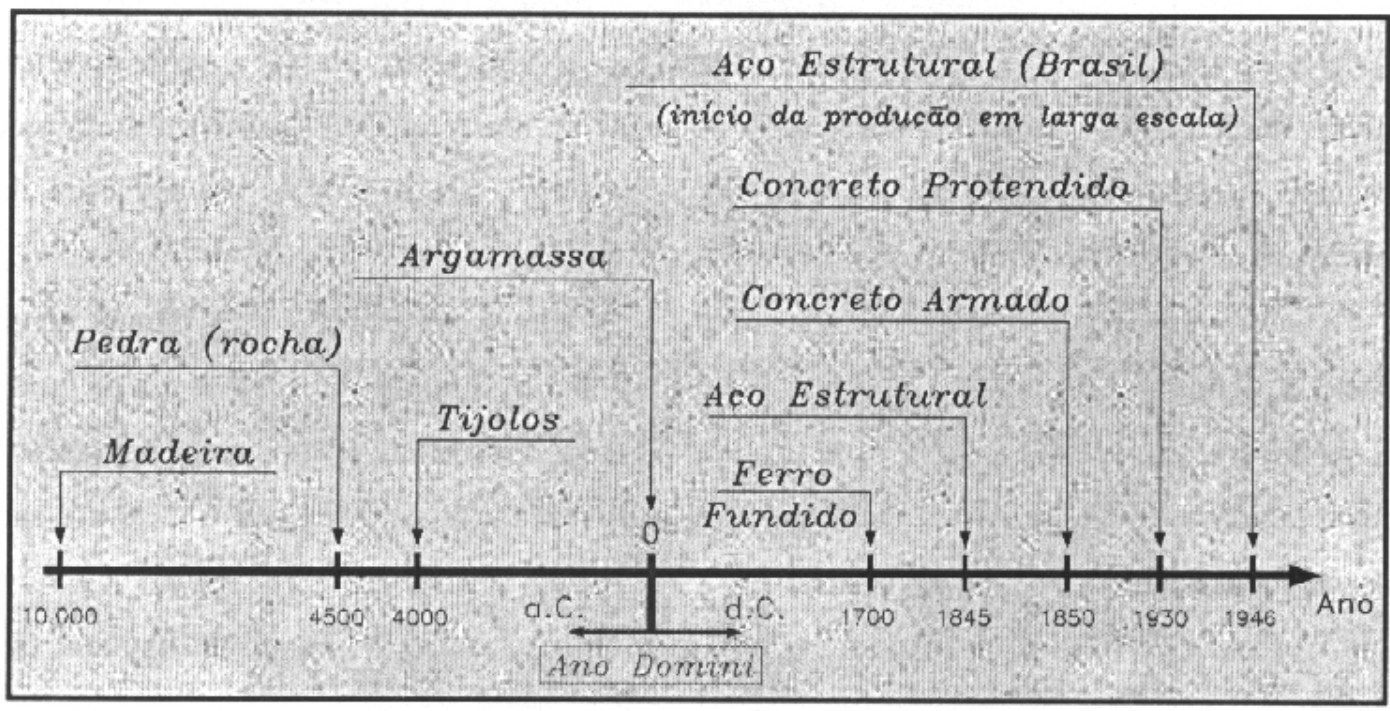

Figura 1.1 - Materiais utilizados na construção civil em ordem cronológica - Segurança nas estruturas, Gonçalves et al. 2005. 
A tecnologia em todas as áreas está sempre sendo atualizada com novos sistemas produtivos, novos materiais e novos produtos são colocados à disposição do mercado. A indústria da construção civil é considerada atrasada quando comparada a outros ramos industriais. A fama se dá pelo fato de a indústria apresentar pouca produtividade, grande desperdício de materiais, morosidade e baixo controle de qualidade. Sua participação no mercado foi sempre marcada por absorver a mão-deobra menos qualificada. Os principais sistemas estruturais são construídos de madeira, concreto (podendo este ser armado, protendido, pré-moldado) e aço. O que se pode notar é que ocorreram poucas mudanças com relação às estruturas de concreto desde a década de 30.

Especificamente para $\circ$ concreto armado existem muitos problemas relacionados com o custo de manutenção e vida útil de algumas estruturas com problemas relacionados à durabilidade. Estruturas litorâneas, pontes, metrôs, muros de contenção de taludes são exemplos de casos críticos.

Tendo em mente a solução deste problema está sendo pesquisada uma armadura constituída de materiais inertes à corrosão e a formação de campos eletromagnéticos. Essa armadura consiste de um compósito formado por fibras impregnadas com resina, as FRP (fiber reinforced polymer). As barras possuem propriedades que favorecem a sua utilização como armadura de estruturas expostas a intempéries capazes de prejudicar o desempenho da armadura metálica em estruturas de concreto armado.

Antigamente, os materiais se inseriam no âmbito daqueles utilizados para a construção de estruturas em geral, sem que houvesse comprovação científica da real segurança e eficácia do material para este fim; era o chamado Método Indutivo. Atualmente não se pode pensar em inserir um material de importância primária em uma estrutura, como são as barras de FRP, sem que primeiramente tenham sido realizados estudos que garantam os aspectos de segurança e durabilidade inerentes a todas as estruturas.

Este estudo reflete o início dos estudos de vigas simplesmente armadas com GFRP, tratando-se de uma análise do comportamento destas vigas submetidas a solicitações normais. 


\subsection{BREVE HISTÓRICO}

A utilização de compósitos do tipo FRP remonta ao final da Segunda Guerra Mundial, quando foram utilizados na construção dos "Spitfires" ingleses. Desde então os compósitos vêm sendo utilizados na indústria naval e na indústria aeronáutica. Esta última transformou, por meio de muitas pesquisas, o compósito FRP num material muito competitivo.

$\mathrm{Na}$ indústria da construção civil, conhecidamente resistente à inovações, a inserção de compósitos formados por FRP foi bem mais lenta. A primeira aplicação de FRP para estruturas de concreto foi realizada em meados dos anos 50 (Rubinsky e Rubinsky, 1954 e Wines, 1966). Pesquisas isoladas foram realizadas nos anos 60 nos EUA e nos anos 70 na Europa e no Japão. Porém, somente no final da década de 80 , com o aumento dos problemas de corrosão das armaduras de aço, é que as pesquisas começaram a atrair investidores e pesquisadores em todo o mundo.

Na Figura 1.2 pode-se observar que em 1987, iniciaram-se os trabalhos de um conjunto de pesquisadores japoneses, algumas indústrias e construtoras e o Ministério da Construção. O projeto incluía diversas pesquisas, entre elas as que envolviam armaduras não metálicas. Foi um projeto que durou 5 anos e produziu trabalhos científicos importantes (SONOBE 1993).

Em 1991 iniciaram-se nos Estados Unidos da América, os trabalhos dos comitês $\mathrm{ACl} 440$, formados pelo Instituto Americano de Concreto ( $\mathrm{ACl}$ - American Concrete Institute) que obtiveram como produto duas normas publicadas, uma apresentando o Estado da Arte em FRP (ACl 440R-1996) e outra os procedimentos para dimensionamento de elementos estruturais utilizando-se FRP (ACI 440.1R-2003).

Em 1991 iniciou-se na Inglaterra outro projeto de pesquisas em FRP o BRITE EURAM Project, em 1993 iniciou-se o EUROCRETE Project que futuramente deu início aos trabalhos do grupo de pesquisa FIB TG 9.3 que está finalizando o rascunho do que será a futura norma da FIB para estruturas de concreto com armaduras de FRP. 


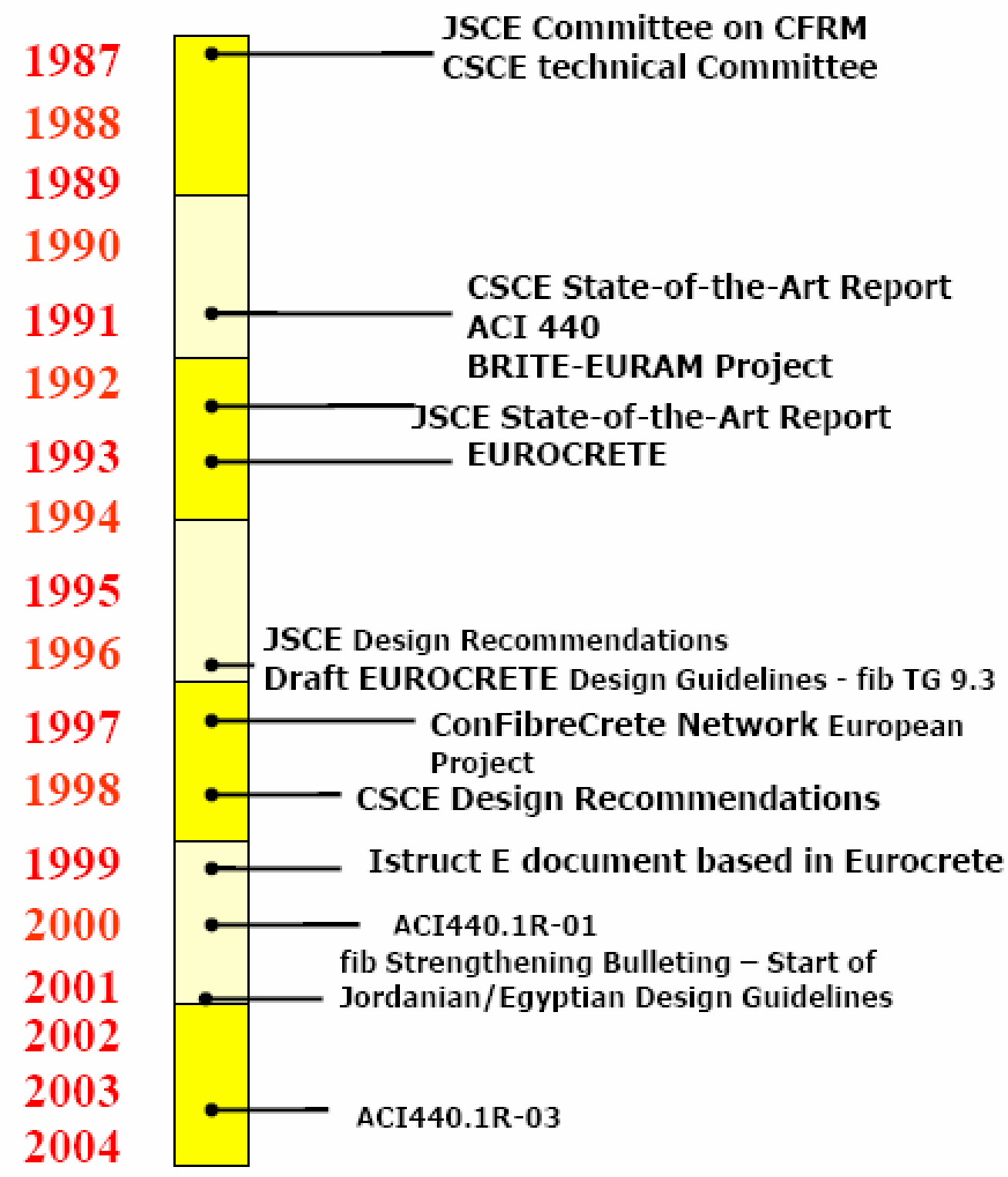

Figura 1.2 - Histórico internacional de pesquisas em FRP - Design Guidelines for FRP reinforced concrete; Pilakoutas e Guadagnini.

A partir das iniciativas as pesquisas em armaduras de barras de FRP se espalharam por todo o mundo. No Brasil existem registros de pesquisas isoladas iniciais em meados da década de 90 em Fortaleza -CE, seguidas de dois artigos apresentados no III Congresso de Engenharia Civil em Juiz de Fora: Barras de Armação em FRP: Discussão de parâmetros para normalização (ALVES, A. B. e CASTRO, P. F. - 1998) e Comportamento de Vigas de Concreto de Alta Resistência com Armadura Não Metálica Tipo FRP (RAYOL, J. O. e MELO, G. S. 1998). Sendo que este segundo artigo tratava de uma introdução a uma dissertação de mestrado do mesmo autor com o mesmo título. Mas, ainda há muito a ser feito para que se possa chegar a um ponto ideal com um grupo de estudos nacional e assim realmente inserir este material como disponível para a construção civil. 


\subsection{OBJETIVO}

Estudar barras de armaduras não metálicas, especificamente, barras de fibra de vidro polimerizadas, as GFRP, centrando este estudo no seu comportamento quando submetida a tensões normais.

Analisar o comportamento de vigas simplesmente armadas com armadura de GFRP utilizando uma viga armada com barras de aço com as mesmas propriedades geométricas dos modelos como referência. Sendo esta análise resumida a solicitações normais.

Como objetivo secundário esta pesquisa abre precedentes para outros trabalhos, com o fim maior de viabilizar a utilização das barras de GFRP como alternativa para soluções estruturais em concreto armado.

\subsection{JUSTIFICATIVA}

A indústria da construção civil ainda é carente de avanços com relação a novos materiais e sistemas construtivos. Muitos são os problemas, o que remonta à necessidade de novas tecnologias para o concreto armado visando a melhoria de algumas propriedades das estruturas. A utilização de armaduras não metálicas pode solucionar alguns desses, principalmente a melhoria da durabilidade de algumas estruturas críticas.

O litoral brasileiro é extenso e muitas das capitais são localizadas no litoral. Uma das principais razões de manutenção mais extensiva de algumas estruturas é a corrosão da armadura metálica. Essa é uma das possíveis aplicações das barras de FRP. Além disso, existem problemas relatados de corrosão da armadura metálica causada por ondas eletromagnéticas nos metrôs, outra possível aplicação das barras de FRP. No mundo todo existe uma preocupação em diminuir o custo global das estruturas em geral, dentre as diversas alternativas, as barras de FRP estão sendo estudadas em vários países, desde o início dos anos 80 . É preciso diminuir a diferença de conhecimento nesta área da comunidade acadêmica no Brasil, em relação a outros países, para o avanço tecnológico das estruturas de concreto brasileiras.

Participar do início das pesquisas desta nova tecnologia é um privilegio. Desenvolver uma dissertação, cujo tema é inédito no Departamento de Engenharia de 
Estruturas - EESC - USP pode proporcionar o desenvolvimento de trabalhos futuros, aprofundando e ampliando estudos nessa área.

\subsection{MÉTODO EMPREGADO}

Este trabalho científico se inicia com extensa revisão bibliográfica englobando diversas pesquisas, normas e diretrizes relativas às barras de FRP em todo o mundo. Baseando-se na literatura científica disponível, é proposta rotina para dimensionamento à flexão adaptada à realidade brasileira e aos moldes da NBR 6118:2003, para facilitar a inserção deste novo material no mercado brasileiro.

Posteriormente a esta análise teórica das barras de FRP, a pesquisa se estende a sua fase experimental com o ensaio de seis vigas de concreto. O programa experimental inicial comtemplou a realização dos seguintes ensaios:

- Ensaios para determinar as propriedades dos materiais: cimento, agregados, barras de aço e de GFRP;

- Ensaios preliminares para dosagem do concreto: resistência à compressão e a tração, módulo de deformação longitudinal e consistência;

- Ensaios de seis corpos-de-prova cilíndricos de 100 mm de diâmetro e 200 mm de altura, por série de concretagem, para controle da resistência e determinação do módulo de elasticidade dos concretos dos modelos;

- Ensaio de flexão (quatro pontos) de seis vigas: Figura 1.3, uma armada com aço para controle V1 e as outras armadas com GFRP, a V2 e a V3 armadas com barras de GFRP para que haja equivalência da capacidade resistente, na V4 a equivalência será na deformação da viga. A V5 e a V6 serão reproduções da $\mathrm{V} 2$ e V3, mas armadas somente com barras retas sem ganchos nas extremidades.

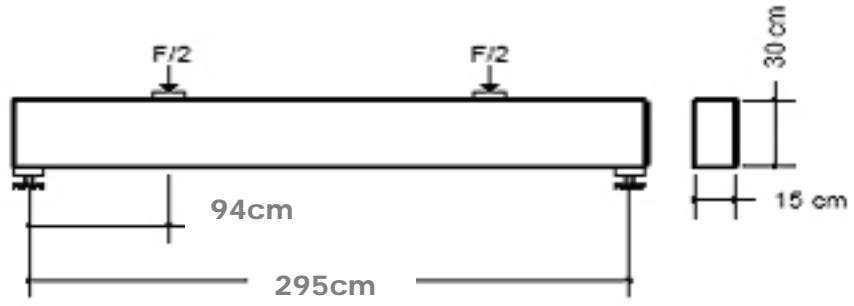

Figura 1.3 Esquema do modelo experimental de viga de concreto armado. 


\subsection{APLICAÇÕES}

A aplicação das barras de FRP é na substituição das armaduras de aço em estruturas de concreto armado, tornando-se uma alternativa com propriedades semelhantes, e algumas vantagens: maior durabilidade, menor massa, e a não existência de campo eletromagnético. Dependendo da região do mundo, os estudos de FRP foram iniciados por diversos motivos. A Figura 1.4 exemplifica os motivos do estudo desta alternativa de armadura.

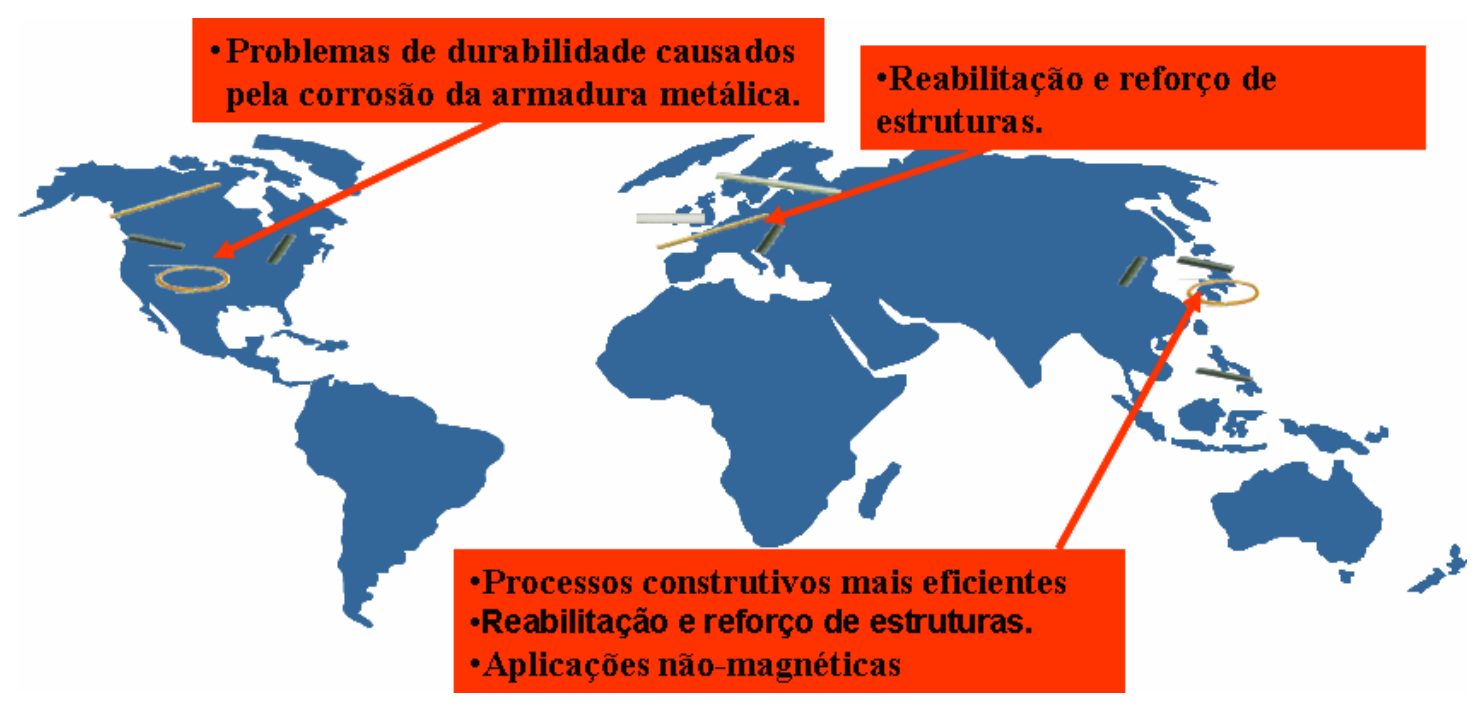

Figura 1.4 Motivação do início dos estudos das armaduras de FRP - Adaptado da apresentação de Pilakoutas 2000.

Existe um crescimento na utilização deste novo material, como mostra a

Figura 1.5 desde a década de 80 até o ano de 2001. 


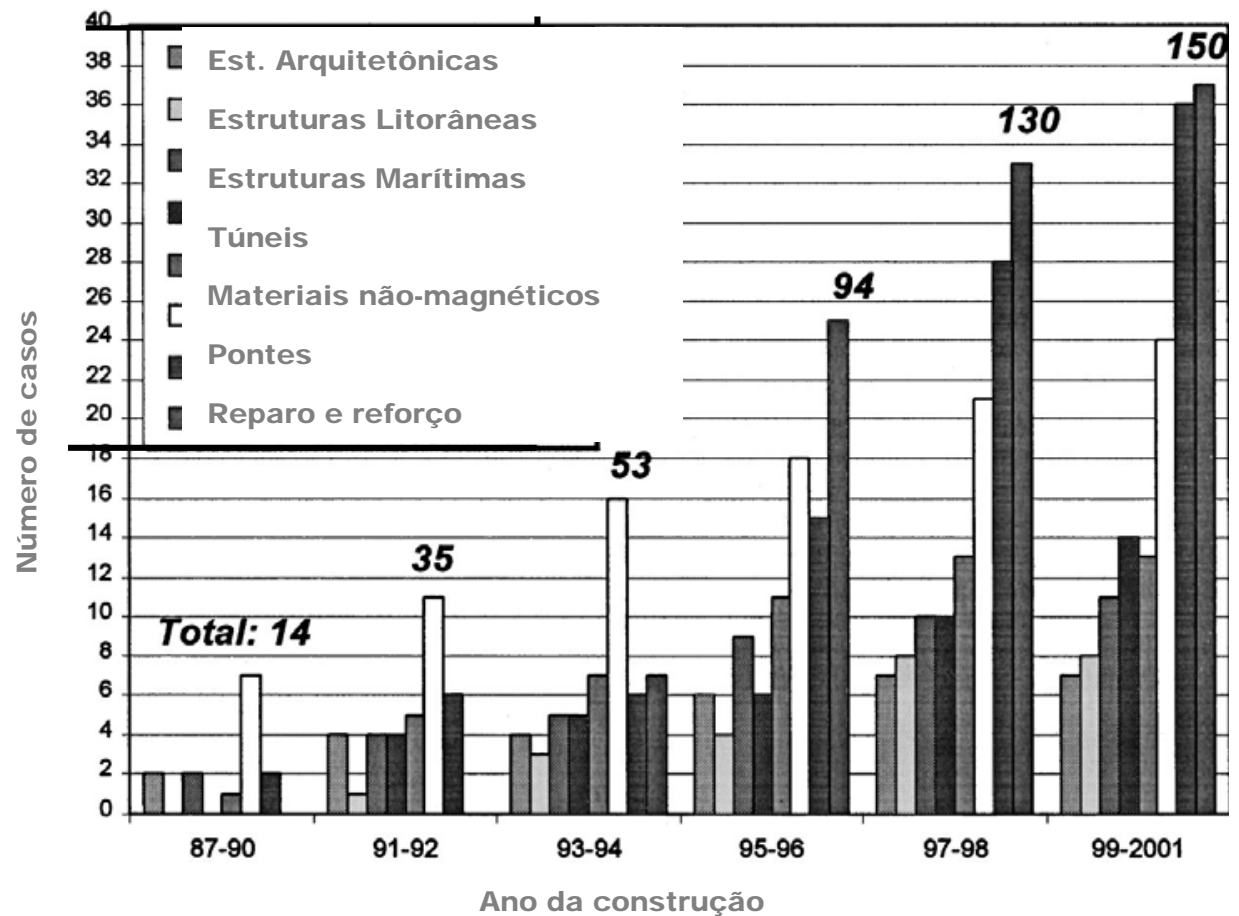

Figura 1.5 Crescimento da utilização de FRP

Dentre as principais aplicações, algumas são citadas na Figura 1.6, a primeira refere-se a vigas de suporte em contato direto com a agua; na Figura 1.6-b, o exemplo refere-se a utilização da armadura não metálica no reforço de taludes, onde a agressão do ambiente é muito alta; nos Estados Unidos da América, o uso de GFRP é mais comum para armadura de tabuleiro de pontes, face a maior agressividade do meio a que as pontes em algumas regiões do país estão sugeitas; finalmente a Figura 1.6-d e Figura 1.6-e referem-se a obras realizadas no Japão: a primeira utilizando-se da transparência eletromagnética do material e a segunda da capacidade resistente das barras de GFRP. 


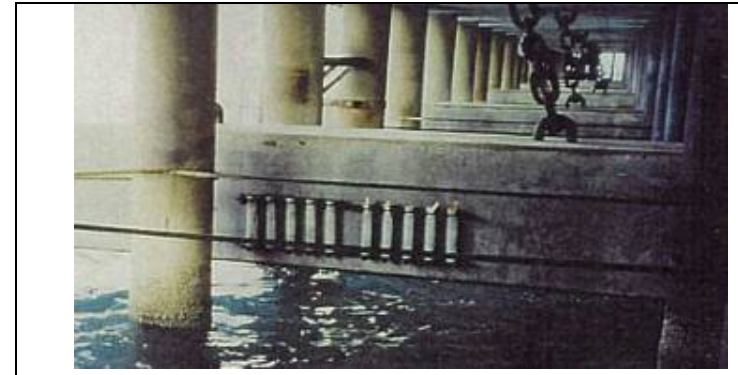

a) Viga de suporte de pontes (the Qatar Fertiliser Company)

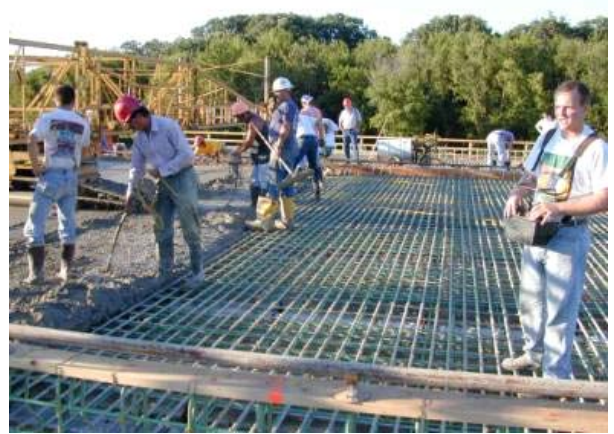

c) Tabuleiros de Pontes

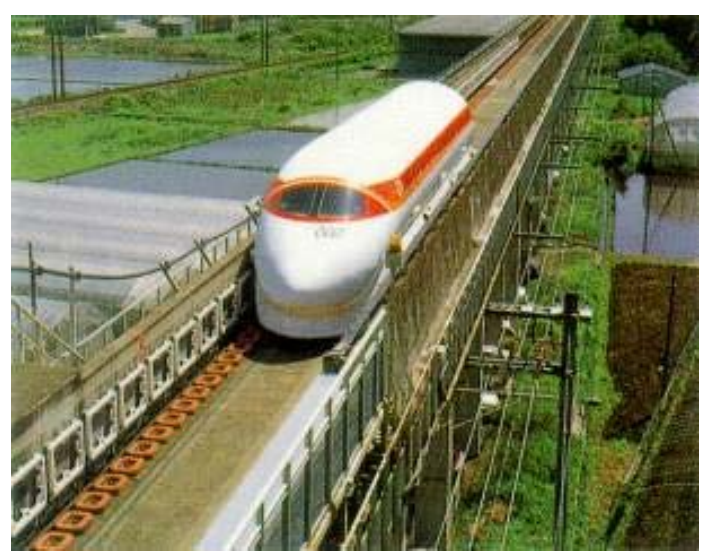

d) Estruturas magneticamente inertes

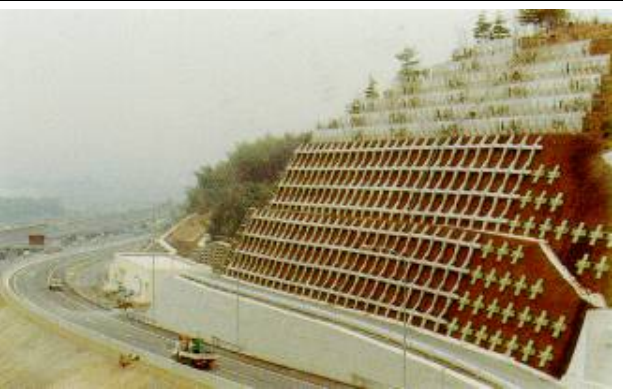

b) Reforço de Talude
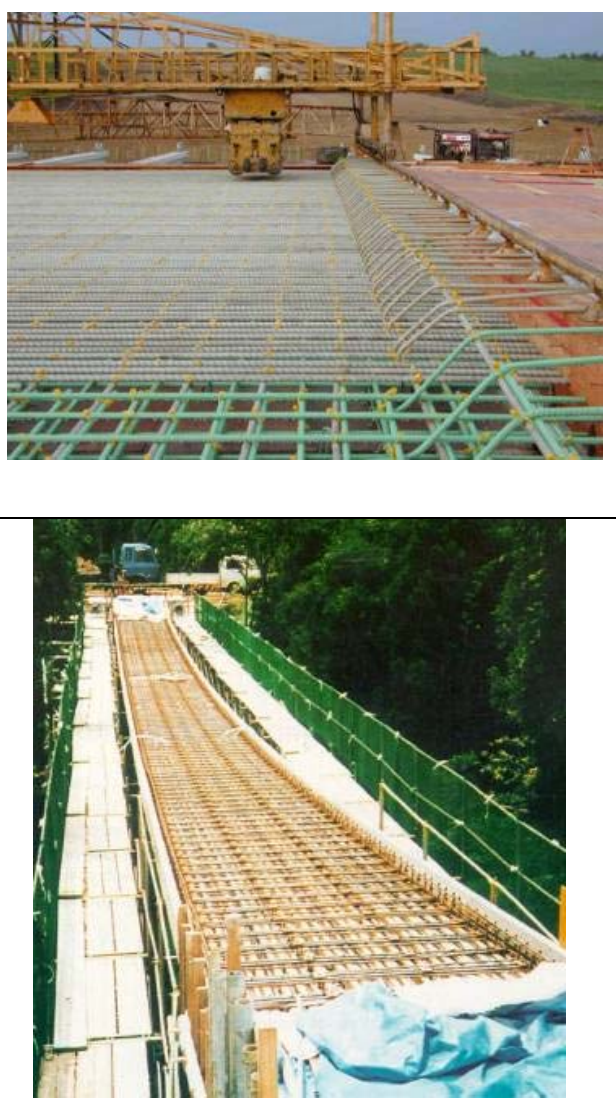

e) Alta resistência

Figura 1.6 Exemplos de aplicação das barras de GFRP - uso de GFRP no mundo - Adaptado da apresentação de Pilakoutas 2000.

\subsection{ESTRUTURA DA DISSERTAÇÃO}

O primeiro capítulo da dissertação traz a introdução do trabalho, iniciando com algumas considerações iniciais e um breve histórico, para chegar até os objetivos e a justificativa do estudo. O método empregado trata dos meios utilizados para se alcançar o tópico anterior: o objetivo. Para exemplificar as utilizações possíveis do material, algumas obras e algumas informações sobre as aplicações no mundo são apresentadas no item 1.6. O primeiro capítulo termina com a apresentação desta estrutura da dissertação. 
Para mostrar as propriedades do material e as normas e diretrizes desenvolvidas para sua aplicação, o segundo capítulo reúne informações sobre os compósitos de FRP, com ênfase na armadura de GFRP, sobre as principais propriedades mecânicas das barras de FRP e finalmente as diretrizes de dimensionamento de estruturas utilizando essas barras.

O terceiro capítulo trata-se de uma adaptação das informações coletadas no capítulo anterior para a realidade brasileira. Nada mais é do que uma tentativa de facilitar o entendimento e a utilização das barras de FRP no Brasil.

Essa tradução da linguagem das diretrizes para aquela utilizada no dimensionamento de estruturas de concreto no Brasil encerra a parte de revisão da literatura técnica do trabalho, e no capítulo 4, inicia-se a parte experimental deste trabalho. Neste capítulo estão descritas as etapas de determinação das propriedades dos materiais utilizados (concreto e armaduras), a montagem dos modelos e finalmente o ensaio de flexão de quatro pontos das seis vigas de concerto armadas com GFRP.

O capítulo 5 apresenta resultados e analisa todos os estudos descritos no capítulo anterior. O capítulo contempla desde o estudo de traço e a determinação das propriedades do concreto, a determinação das propriedades das armaduras e finalmente a análise da viga armada com barras de aço CA-50 ( viga 01) e demais vigas armadas com barras de GFRP.

Para terminar esta dissertação no capítulo 6 são apresentadas as conclusões gerais e as conclusões tiradas dos modelos experimentais seguidas de algumas sugestões de trabalhos de possível realização futura, para continuar e aprofundar o estudo das barras de FRP.

As referências deste estudo são apresentadas no capítulo 7 . 


\section{FUNDAMENTOS TEÓRICOS}

\subsection{COMPÓSITO DE FRP}

As barras de FRP são formadas por fibras impregnadas com resina, atualmente produzidas com o processo de pultrusão. As fibras utilizadas são: fibra de carbono, aramida e vidro. A Tabela 2.1 exemplifica as propriedades de algumas das fibras utilizadas na fabricação de barras de FRP.

\begin{tabular}{|c|c|c|c|c|c|c|c|c|c|}
\hline & \multicolumn{4}{|c|}{ Fibra de Carbono } & \multirow{2}{*}{\multicolumn{2}{|c|}{$\begin{array}{l}\text { Fibra de } \\
\text { Aramida }\end{array}$}} & \multirow{2}{*}{\multicolumn{2}{|c|}{ Fibra de Vidro }} & \multirow{3}{*}{$\begin{array}{l}\text { Fibra de } \\
\text { álcool } \\
\text { Polivinil } \\
\text { (alta } \\
\text { resistência) }\end{array}$} \\
\hline & \multicolumn{2}{|c|}{$\begin{array}{c}\text { Carbono Poliacrílico } \\
\text { Nitril } \\
\end{array}$} & \multicolumn{2}{|c|}{ Carbono Pitch } & & & & & \\
\hline & $\begin{array}{c}\text { Alta } \\
\text { resistência }\end{array}$ & $\begin{array}{c}\text { Alto } \\
\text { módulo } \\
\text { de Young }\end{array}$ & Comum & $\begin{array}{c}\text { Alto } \\
\text { módulo } \\
\text { de Young }\end{array}$ & $\begin{array}{l}\text { Kevlar } \\
49 \\
\text { Twaron }\end{array}$ & $\begin{array}{l}\text { Tech } \\
\text {-nora }\end{array}$ & Vidro-E & $\begin{array}{c}\text { Vidro } \\
\text { Álcali } \\
\text { resistente }\end{array}$ & \\
\hline $\begin{array}{c}\text { Resistência a } \\
\text { tração } \\
(\mathrm{MPa})\end{array}$ & 3430 & $2450-3920$ & $764-980$ & $2940-3430$ & 2744 & 3430 & $3430-3528$ & $1764-3430$ & 2254 \\
\hline $\begin{array}{l}\text { Módulo de } \\
\text { Young } \\
(\mathrm{GPa})\end{array}$ & $196-235$ & $343-637$ & $37-39$ & 392-784 & 127 & 72,5 & $72,5-73,5$ & $68,6-70$ & 59,8 \\
\hline $\begin{array}{c}\text { Alongamento } \\
(\%)\end{array}$ & $1,3-1,8$ & $0,4-0,8$ & $2,1-2,5$ & $0,4-1,5$ & 2,3 & 4,6 & 4,8 & $\begin{array}{l}4-5 \\
2-3\end{array}$ & 5,0 \\
\hline $\begin{array}{l}\text { Densidade } \\
\left(\mathrm{g} / \mathrm{cm}^{3}\right)\end{array}$ & $1,7-1,8$ & $1,8-2,0$ & $1,6-1,7$ & $1,9-2,1$ & 1,45 & 1,39 & 2,6 & 2,27 & 1,30 \\
\hline $\begin{array}{l}\text { Diâmetro } \\
(\mathrm{mm})\end{array}$ & & & & & 12 & & & & 14 \\
\hline
\end{tabular}

\subsubsection{GFRP}

Segundo o ACl 440R-96, a barra de fibra de vidro polimerizada, em particular, é um compósito formado por uma matriz de polímero e fibra de vidro com uma alta razão entre raio e comprimento. No caso das armaduras contínuas de GFRP, as fibras 
devem ser contínuas e mais rígidas e resistentes que a matriz. Portanto se trata de um tipo de compósito, no sentido macroestrutural da palavra.

O comportamento do compósito depende dos materiais constituintes, o arranjo das fibras e a interação entre os materiais. Os fatores que mais afetam o comportamento físico das GFRP dependem das propriedades mecânicas, orientação, comprimento, forma e composição das fibras de vidro e das propriedades mecânicas da resina matriz e da aderência entre as fibras e a matriz polimérica.

\subsubsection{Matriz Polimérica}

O polímero no compósito de GFRP permite a transferência de tensões entre as fibras e para a estrutura ao redor e protege as fibras de danos mecânicos e causados pelo ambiente. A Figura 2.1 esquematiza a distribuição de um compósito de FRP, sendo o agente de aderência na interface normalmente uma proteção extra às fibras.

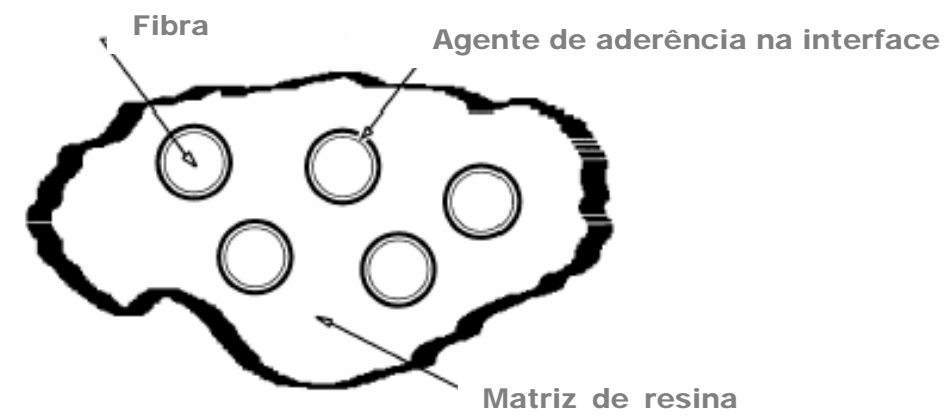

Figura 2.1 - Compósito de GFRP. - Fonte ACI 440.1R-03.

As matrizes utilizadas na produção das barras não metálicas são, na sua maioria, as termoestáticas pela maior facilidade de manuseio dessas resinas, pois ao contrário das termoplásticas, essas resinas são manuseadas em estado líquido viscoso. Nesse estado é possível obter boa impregnação das fibras. Dentre as resinas termoestáticas as mais utilizadas, cujas propriedades estão descritas na Tabela 2.2, são as de poliéster, vinil éster e as de epóxi (UOMOTO et al. 2002). 
Tabela 2.2 Propriedades das matrizes poliméricas do compósito de FRP - FIB 9.3 TG - 2003.

\begin{tabular}{|l|c|c|c|}
\hline \multicolumn{1}{|c|}{ Propriedades } & \multicolumn{3}{c|}{ Matriz } \\
\cline { 2 - 4 } & poliéster & epóxi & vinil éster \\
\hline Densidade $\left(\mathrm{kg} / \mathrm{m}^{3}\right)$ & $1200-1400$ & $1200-1400$ & $1150-1350$ \\
\hline Resistência a tração (MPa) & $34,5-104$ & $55-130$ & $73-81$ \\
\hline Módulo longitudinal (GPa) & $2,1-3,45$ & $2,75-4,10$ & $3,0-3,5$ \\
\hline Coeficiente de Poisson & $0,35-0,39$ & $0,38-0,40$ & $0,36-0,39$ \\
\hline Coeficiente de expansão térmica $\left(10^{-6} /{ }^{\circ} \mathrm{C}\right)$ & $55-100$ & $45-65$ & $50-75$ \\
\hline Conteúdo da mistura (\%) & $0,15-0,60$ & $0,08-0,15$ & $0,24-0,30$ \\
\hline
\end{tabular}

\subsubsection{Fibra de vidro}

O comportamento estrutural da fibra submetida a uma força de tração é elástico linear, sem apresentar fadiga em ambientes secos. As fibras reagem com a água e sua superfície é extremamente reagente. Desse modo, as fibras de vidro podem facilmente ser danificadas durante o manuseio, por isso um filme protetor é aplicado o que também aumenta o poder de adesividade da fibra na matriz.

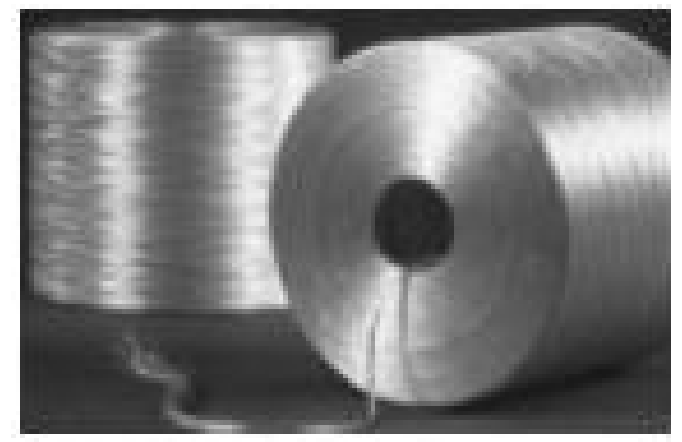

Figura 2.2 - Fibra de vidro em forma de fio. - ACI 440R-96.

Essa susceptibilidade ao meio ambiente deve ser levada em consideração mesmo depois das fibras estarem envolvidas com o polímero, pois qualquer falha no processo de produção pode acarretar danos nos produtos (ACl 440R-96).

Levando em consideração o custo em relação ao benefício da utilização da fibra de vidro, esta tem sido a mais utilizada pela indústria da construção civil. As fibras comercialmente disponíveis mais utilizadas para formação das GFRP são as fibras: vidro-S, vidro-E e vidro álcali resistente (FIB TG 9.3), cujas propriedades estão descritas na Tabela 2.3. 
Tabela 2.3 Propriedades das diversas fibras de vidro utilizadas nas barras de GFRP - Adaptado da FIB TG 9.3 - 2003.

\begin{tabular}{|c|c|c|c|c|c|c|}
\hline \multirow[t]{2}{*}{ Tipo de fibra } & $\begin{array}{l}\frac{0}{0} \\
\frac{\pi}{0} \\
. \frac{0}{0} \\
\frac{D}{0} \\
0\end{array}$ & 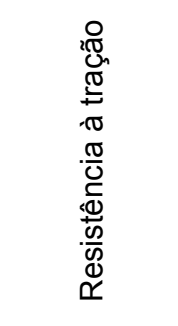 & $\begin{array}{l}0 \\
\frac{0}{3} \\
0 \\
\frac{0}{0} \\
\frac{0}{0} \\
0 \\
\frac{0}{5} \\
\frac{0}{2} \\
\sum\end{array}$ & 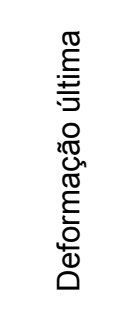 & 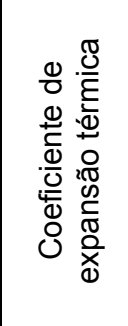 & \multirow[t]{2}{*}{ 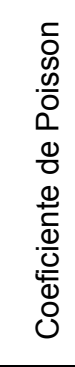 } \\
\hline & $\mathrm{kg} / \mathrm{m}^{3}$ & $\mathrm{MPa}$ & $\mathrm{GPa}$ & $\%$ & $10^{-6} /{ }^{\circ} \mathrm{C}$ & \\
\hline Vidro-E & 2500 & 3450 & 72,4 & 2,4 & 5 & 0,22 \\
\hline Vidro-S & 2500 & 4580 & 85,5 & 3,3 & 2,9 & 0,22 \\
\hline Vidro álcali resistente & 2270 & $1800-3500$ & $70-76$ & $2,0-3,0$ & - & - \\
\hline
\end{tabular}

\subsubsection{Processo de produção das barras}

O ACl 440R-96 descreve três tipos de processos produtivos para componentes estruturais de FRP. O processo chamado de "Filament Winding" para a fabricação de tubos, tanques e outros materiais normalmente cilíndricos; o processo de compactação a vácuo para a fabricação de laminados e o processo de pultrusão. Barras de FRP, ou elementos de FRP de uma dimensão predominante são produzidos normalmente pelo processo de pultrusão ou uma variância deste. Este é o método escolhido tanto pela consistência do produto quanto pela economia proporcionada (Bakis et al. 2002). A Figura 2.3 mostra esquematicamente como funciona o processo de pultrusão.

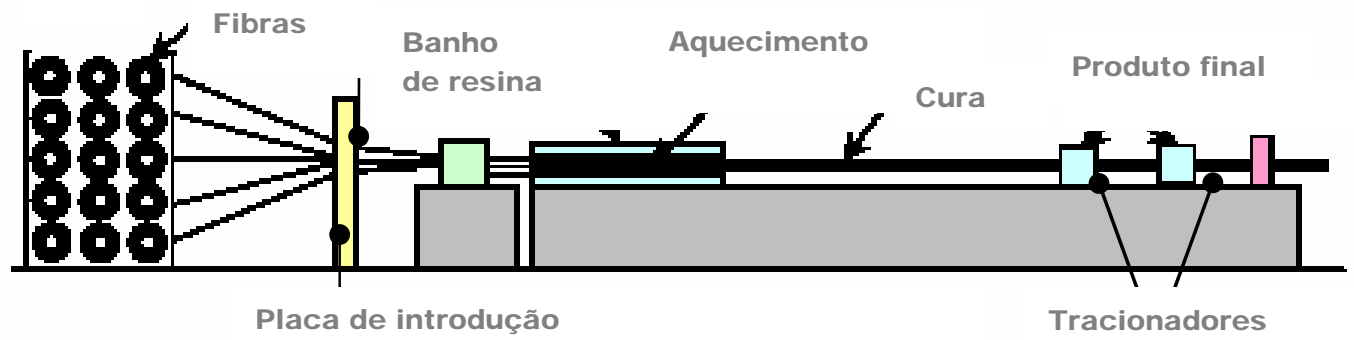

Figura 2.3 - Diagrama básico do processo de pultrusão (MAJI et al., )

A barra produzida possui comprimento ilimitado, sendo o tamanho do galpão e o transporte as únicas restrições envolvidas. Os filamentos de fibras são levados a um banho que contém a resina e outros aditivos antes de serem estirados para a formação do perfil. Um comprimento de $0,9 m-1,3 m$ de fibra é mergulhado na solução e aquecido eletronicamente por um óleo quente para a impregnação. O processo consiste em estirar fibras impregnadas por resina a uma velocidade de $0,9 \mathrm{~m} / \mathrm{min}$, dependendo do tamanho e complexidade do produto (ACl 440R-96). Bakis et al. 
(2002) indica que a velocidade de produção do processo de pultrusão pode chegar a $3 \mathrm{~m} / \mathrm{min}$ de acordo com o produto.

O volume de fibras da seção transversal produzida varia de $35-50 \%$ (BAKIS et al. 2002), e as resinas mais utilizadas são as de poliéster e vinil éster.

\subsection{BARRAS DE FRP.}

\subsubsection{Classificação das barras de FRP.}

Yamasaki et al. (1993) classifica as barras de FRP de acordo com os materiais constituintes e a conformação superficial. A Figura 2.4 e a Figura 2.5 mostram a classificação proposta de acordo com os materiais constituintes.

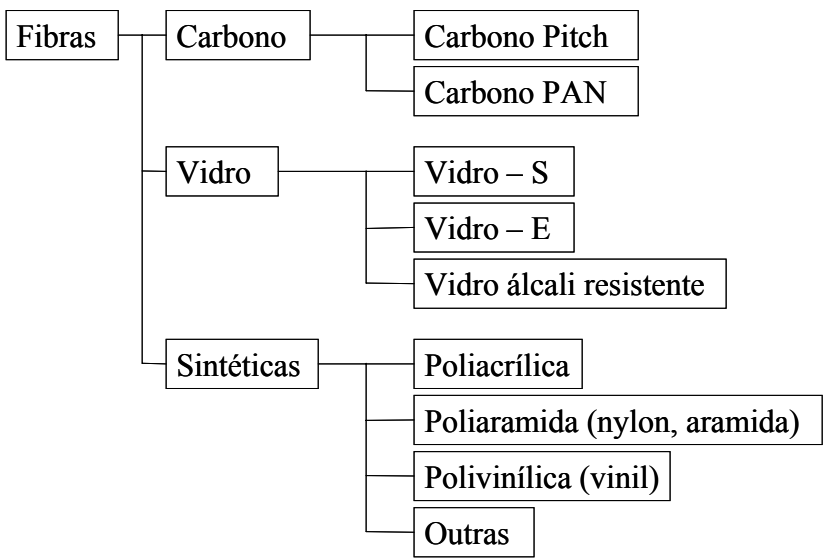

Figura 2.4 - Classificação das barras de FRP de acordo com o tipo de fibra - Yamasaki et al. 2003 (Adaptado).

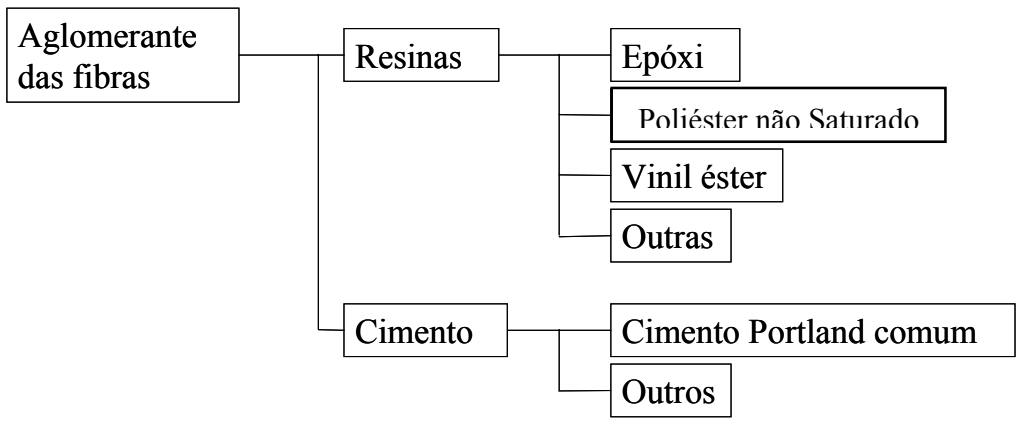

Figura 2.5 - Classificação das barras de FRP de acordo com o tipo de aglomerante - Yamasaki et al. 2003 (Adaptado).

A Figura 2.6 mostra a classificação das barras de FRP de acordo com a sua superfície e a Figura 2.7 exemplifica algumas combinações possíveis. 


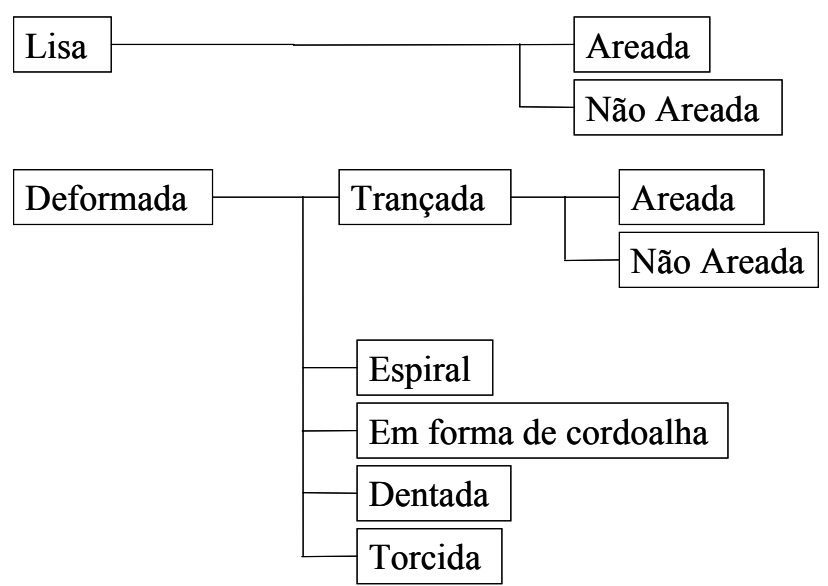

Figura 2.6 - Classificação das barras de FRP de acordo com o tipo conformação superficial - Yamasaki et al. 2003 (Adaptado).

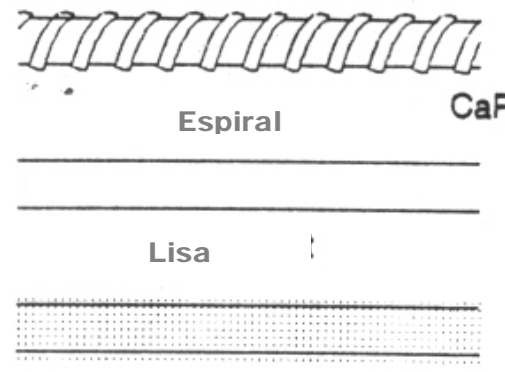

Lisa e areada

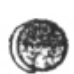

$\mathrm{CaR}, \mathrm{AR}, \mathrm{GR}$

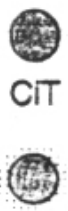

GS

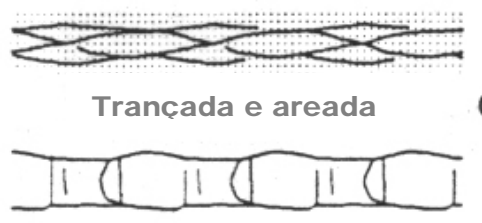

Dentada

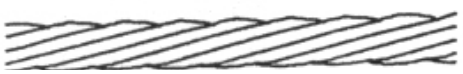

Em forma de cordoalha de 7 fios

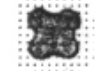

$\mathrm{CaB}, \mathrm{AB}$

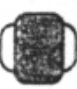

$\mathrm{CaE}$

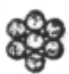

$\mathrm{Ca7}$

Figura 2.7 - Exemplos de conformações superficiais - Yamasaki et al. 2003 (Adaptado).

A rápida evolução da indústria de barras de FRP as produz a partir de outros materiais e com outras conformações superficiais que podem não estar contempladas no fluxograma pelo lapso de tempo entre a publicação do artigo e deste trabalho.

\subsubsection{Propriedades das barras de FRP.}

A utilização de todo material estrutural é intimamente relacionada com as propriedades físicas e mecânicas do material. Para as barras de FRP as variáveis envolvidas incluem a escolha dos constituintes, a quantidade da fração de fibra e matriz, a orientação das fibras e o processo de produção. Efeitos dimensionais e o controle de qualidade na produção também representam importantes fatores na determinação das propriedades das barras. Estas propriedades são sujeitas também às condições de carregamento, temperatura e umidade da estrutura em questão. A Tabela 2.4 compara as propriedades das barras e cordoalhas de aço e as de fibra 
polimerizada e a Figura 2.8 mostra o diagrama tensão $X$ deformação das diversas armaduras.

\begin{tabular}{|c|c|c|c|c|c|c|}
\hline & $\begin{array}{l}\text { Armadura } \\
\text { de aço }\end{array}$ & $\begin{array}{c}\text { Cordoalha } \\
\text { de aço }\end{array}$ & $\begin{array}{l}\text { Barra de } \\
\text { GFRP }\end{array}$ & $\begin{array}{l}\text { Cordoalha } \\
\text { de GFRP }\end{array}$ & $\begin{array}{l}\text { Cordoalha } \\
\text { de CFRP }\end{array}$ & $\begin{array}{l}\text { Cordoalha } \\
\text { de AFRP }\end{array}$ \\
\hline $\begin{array}{l}\text { Resistência à tração } \\
\text { (MPa) }\end{array}$ & $483-690$ & $1379-1862$ & $517-1207$ & $1379-1724$ & $1650-2410$ & $1200-2068$ \\
\hline $\begin{array}{l}\text { Tensão de escoamento } \\
(\mathrm{MPa})\end{array}$ & $276-414$ & $1034-1396$ & \multicolumn{4}{|c|}{ Não se Aplica (N/A) } \\
\hline $\begin{array}{l}\text { Módulo de elasticidade } \\
\qquad(\mathrm{GPa})\end{array}$ & 200 & $186-200$ & $41-55$ & $48-62$ & $152-165$ & $50-74$ \\
\hline $\begin{array}{l}\text { Alongamento máximo } \\
\qquad(\mathrm{mm} / \mathrm{m})\end{array}$ & $>0,10$ & $>0,04$ & $0,035-0,05$ & $0,03-0,045$ & $0,01-0,015$ & $0,02-0,026$ \\
\hline $\begin{array}{l}\text { Resistência à compressão } \\
\text { (MPa) }\end{array}$ & $276-414$ & $\mathrm{~N} / \mathrm{A}$ & $310-482$ & $\mathrm{~N} / \mathrm{A}$ & $\mathrm{N} / \mathrm{A}$ & $\mathrm{N} / \mathrm{A}$ \\
\hline $\begin{array}{l}\text { Coeficiente de expansão } \\
\text { térmica }\left(10^{-6} / \mathrm{C}\right)\end{array}$ & 11,7 & 11,7 & 9,9 & 9,9 & 0,0 & $-1,0$ \\
\hline Peso específico & 7,9 & 7,9 & $1,5-2,0$ & 2,4 & $1,5-1,6$ & 1,25 \\
\hline
\end{tabular}

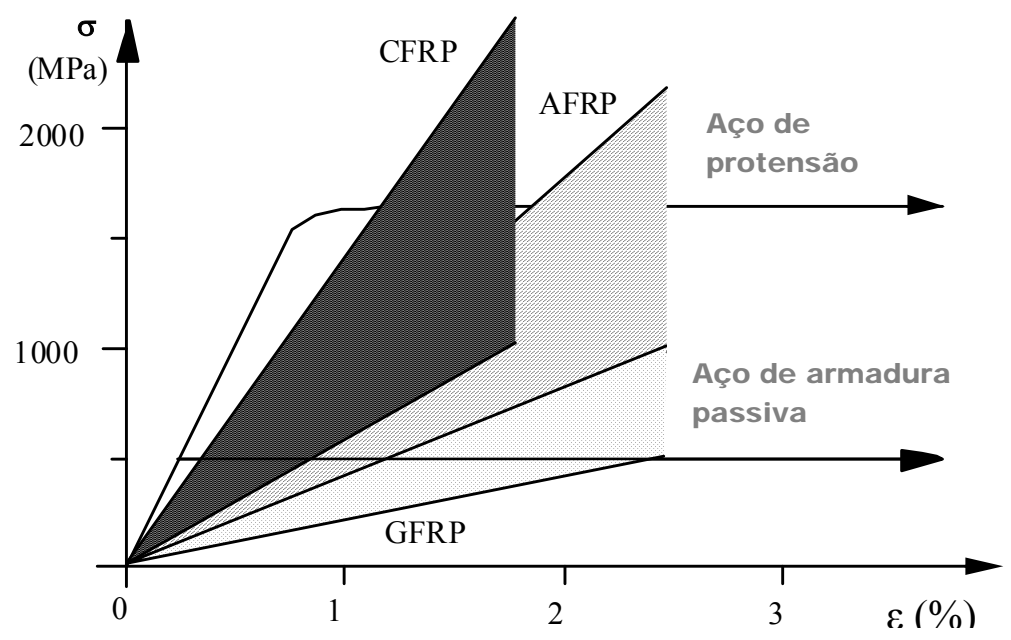

Figura 2.8 - Diagrama Tensão e Deformação dos diversos tipos de armaduras - Design Guidelines for FRP reinforced concrete, Pilakoutas e Guadagnini (2003).

Como o enfoque principal do presente trabalho é a utilização de barras de GFRP, mesmo sendo apresentadas propriedades das barras de FRP, estas serão as únicas comentadas.

\subsubsection{Propriedades fisicas das barras de GFRP.}

Densidade - A densidade do compósito pode ser obtida em termos das densidades e a fração da quantidade de cada constituinte conforme a equação 2-1 (FIB TG 9.3-2003). A Tabela 2.5 mostra a densidade de barras com variação do volume das fibras de $50-70 \%$.

$\rho_{c}=\rho_{f} \cdot V_{f}+\rho_{m} \cdot V_{m}$ 
Tabela 2.5 Densidade típica para barras com volume de fibras entre 50-70\% (kg/m $\left.{ }^{3}\right)$ - FIB TG 9.3-2003 (Adaptado).

\begin{tabular}{|c|c|}
\hline Matriz & GFRP \\
\hline Poliéster & $1750-2170$ \\
\hline Epóxi & $1760-2180$ \\
\hline Vinil éster & $1730-2150$ \\
\hline
\end{tabular}

Coeficiente de expansão térmica - O coeficiente de expansão térmica é um fator dependente do tipo de fibra e a fração de volume dos constituintes da barra de GFRP. É imperativo que o comportamento entre dois materiais sob tensão originadas pela mudança de temperatura seja semelhante para que tensões diferenciais sejam minimizadas. Dependendo do traço da mistura o coeficiente linear de expansão térmica do concreto varia de $(6-11) \times 10^{-6} /{ }^{\circ} \mathrm{C}$ ( $\left.\mathrm{ACl} 440 \mathrm{R}-96\right)$. Na Tabela 2.6 pode-se observar os valores típicos de coeficientes de expansão térmica para barras de GFRP.

Tabela 2.6 Coeficiente de expansão térmica - FIB TG 9.3-2003
\begin{tabular}{|c|c|}
\hline Direção & GFRP $\left(10^{-6} /{ }^{\circ} \mathrm{C}\right)$ \\
\hline Longitudinal & $6,0-10,0$ \\
\hline Transversal & $21,0-23,0$ \\
\hline
\end{tabular}

\subsubsection{Propriedades mecânicas das barras de GFRP.}

Propriedades à tração - O principais fatores de influência nas propriedades à tração das barras de FRP (resistência e módulo de elasticidade) são as propriedades dos constituintes, a fração de volume, distribuição, interações físicas e químicas, procedimento de fabricação e controle de qualidade.

A resistência à tração varia de acordo com a seção transversal da barra. Para barras de GFRP de 9,5mm e 22mm de diâmetro a resistência cai até em 40\% (FIB TG 9.3-2003). Este fato ocorre em virtude do aumento da área de interface entre as fibras e a resina com o aumento da seção transversal da barra. Os testes de resistência à tração são muito complexos pelas dificuldades relacionadas com rupturas das barras em seções transversais contidas em planos que contém as seções das garras do corpo-de-prova. O ACl 4403R-04 traz os procedimentos deste ensaio, porém a resistência à tração das barras de FRP deve ser fornecida pela indústria responsável pelo produto a fim de evitar a necessidade de testes complexos a cada utilização. A indústria por sua deve ser fiscalizada a fim de que um responsável técnico assuma a veracidade das informações fornecidas do produto. 
Propriedades à compressão - Quando componentes de FRP são solicitados à compressão longitudinal, os modelos aplicáveis ao comportamento à tração não são mais válidos, pois a ruína na compressão é muitas vezes associada a microfissuração das fibras com restrição da matriz polimérica. É difícil prever o comportamento das barras à compressão, e, este depende muito do tipo de ensaio e da geometria da amostra. O que se pode observar é que a resistência à compressão para barras de FRP é imensamente menor que a de tração. O módulo de elasticidade à compressão para barras de FRP é em torno de 80\% menor que o módulo à tração (ACl 440R-96).

Propriedades de cisalhamento - Os fatores que dominam o comportamento das barras de FRP ao cisalhamento são as propriedades da matriz polimérica e a distribuição de tensões locais. A literatura especializada é dedicada especialmente para o cisalhamento no plano de estruturas laminares, mas as barras de FRP são sujeitas principalmente ao cisalhamento transversal (FIB TG 9.3-2003).

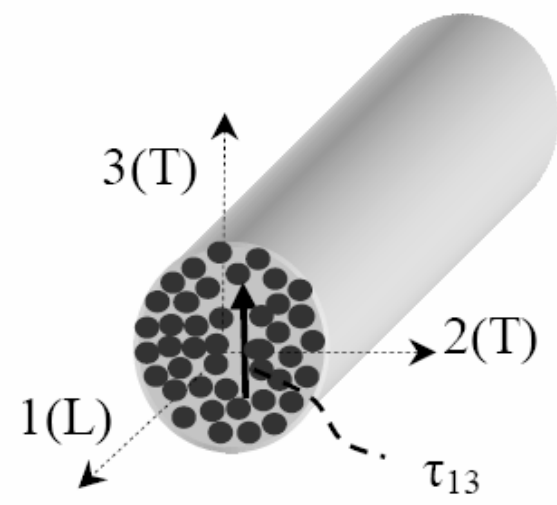

Figura 2.9 - Barra de FRP sujeita ao cisalhamento transversal - FIB TG 9.3-2003.

A Figura 2.9 mostra a solicitação ao cisalhamento transversal, com o vetor da tensão contida no plano da seção transversal.

A Tabela 2.7 resume as principais propriedades de um tipo de barra de GFRP, lembrando que a mudança da fibra ou da resina constituinte pode modificar as propriedades das barras. Essa variabilidade indica a necessidade de padronização dos processos produtivos e dos materiais utilizados. 
Tabela 2.7 Propriedades das barras de GFRP formadas de fibra de vidro-E - FIB TG 9.3-2003.

\begin{tabular}{|c|c|}
\hline Propriedade & Vidro - E/ Epóxi \\
\hline Fração do volume de fibras & 0,55 \\
\hline Densidade $\left(\mathrm{kg} / \mathrm{m}^{3}\right)$ & 2100 \\
\hline Módulo longitudinal $(\mathrm{GPa})$ & 39 \\
\hline Módulo transversal $(\mathrm{GPa})$ & 8,6 \\
\hline Módulo de cisalhamento no plano $(\mathrm{GPa})$ & 3,8 \\
\hline Coeficiente de Poisson maior & 0,28 \\
\hline Coeficiente de Poisson menor & 0,06 \\
\hline Resistência à tração longitudinal (MPa) & 1080 \\
\hline Resistência à tração transversal (MPa) & 39 \\
\hline Resistência ao cisalhamento no plano $(\mathrm{MPa})$ & 89 \\
\hline Deformação última à tração longitudinal $(\%)$ & 2,8 \\
\hline Deformação última à tração transversal $(\%)$ & 0,5 \\
\hline Resistência à compressão longitudinal $(\mathrm{MPa})$ & 620 \\
\hline Resistência à compressão transversal $(\mathrm{MPa})$ & 128 \\
\hline
\end{tabular}

\subsection{DURABILIDADE DAS BARRAS DE GFRP.}

As barras de GFRP têm se mostrado uma alternativa viável para armar estruturas em condições críticas de exposição. Porém, existe grande preocupação quanto à durabilidade das fibras de vidro no ambiente alcalino do concreto. $O$ ambiente interno do concreto possui alta alcalinidade e umidade com $\mathrm{pH}$ chegando até 13,5 (METHA E MONTEIRO 1994). A indústria está ainda desenvolvendo as barras de GFRP. Existe muita pesquisa envolvida para se chegar à fibra e à resina ideais à aplicação no concreto.

As fibras de vidro danificam-se por dois processos: ataque químico na fibra pela alcalinidade do cimento e concentração e crescimento dos produtos de hidratação entre filamentos individuais. A expressão química de Sen, Mariscal e Shahawy (1993), reproduz a reação álcali/vidro que ocorre nas fibras.

$-S_{i}-\mathrm{O}-\mathrm{S}_{i}-+\mathrm{OH}^{-} \rightarrow-S_{i}-\mathrm{OH}+\mathrm{S}_{i} \mathrm{O}^{-}$

Embora muitos estudos tenham sido realizados nesta área ainda é muito difícil prever o desempenho das GFRP no que concerne à durabilidade. São muitas as 
variáveis envolvidas: o mecanismo de degradação das GFRP com diferentes combinações dos materiais constituintes, num ambiente alcalino e submetidas a carregamentos sustentados, a sinergia dos efeitos de tensão, alcalinidade e umidade, o tipo de teste e o controle de qualidade das amostras (BENMOKRANE et al. 2002).

Sen, Mariscal e Shahaway (1993) investigaram a durabilidade de barras de GFRP compostas pela fibra de vidro S-2 e resina epóxi no concreto. Como a fibra de vidro é vulnerável ao ambiente alcalino do concreto, a pesquisa testava a hipótese de que a resina pudesse prover a proteção necessária às fibras. Os resultados mostraram que a resina de epóxi permite a difusão e, portanto, a reação álcali/vidro ocorre diminuindo em muito a capacidade resistente das amostras. Os maiores danos localizavam-se nas regiões submersas das amostras (presença de umidade) e nas regiões próximas à interface do concreto.

Para aumentar a durabilidade das GFRP no concreto algumas medidas foram sugeridas: não se pode confiar em apenas uma medida isolada de proteção das fibras; deve-se considerar a hipótese de outros materiais constituintes como a fibra de vidro álcali resistente e uma resina menos permeável; a utilização de outras medidas de proteção; a diminuição da permeabilidade do concreto.

Tannous e Saadatmanesh (1999) utilizaram a fibra de vidro álcali resistente, pois estudos anteriores com a fibra de vidro-E mostraram uma grande vulnerabilidade. A grande concentração de zirconia $\left(\mathrm{ZrO}_{2}\right)$ neste tipo de fibra supostamente melhoraria o seu desempenho num ambiente alcalino. As resinas utilizadas foram as de poliéster e vinil éster.

Os resultados mostraram que o módulo de elasticidade mudou muito pouco, indicando que o dano foi causado apenas às partes penetradas pela solução alcalina. A deformação última diminuiu, indicando um comportamento mais frágil das amostras. A Tabela 2.8 apresenta que o comportamento das amostras com resina de vinil éster foi melhor que o das barras com resina de poliéster, mas o ganho de durabilidade com a utilização de fibras de vidro álcali resistentes não foi observado. 
Tabela 2.8 Perdas de resistência das barras de GFRP para diferentes idades e ambientes agressivos - Tannous e

\begin{tabular}{|c|c|c|c|c|c|c|c|}
\hline \multicolumn{8}{|c|}{ Saadatmanesh (1999) } \\
\hline $\begin{array}{c}\text { Ambiente/ tipo de FRP } \\
\text { (1) }\end{array}$ & $\begin{array}{c}\mathrm{F}_{0} \\
\text { Inicial } \\
(\mathrm{kN}) \\
(2)\end{array}$ & $\begin{array}{c}\mathrm{F}_{\mathrm{r}} \\
\text { seis } \\
\text { meses } \\
(\mathrm{kN}) \\
(3)\end{array}$ & $\begin{array}{l}\text { Perda de } \\
\text { resistência } \\
(\%) \\
(4)\end{array}$ & $\begin{array}{c}\mathrm{F}_{\mathrm{r}} \\
\text { um } \\
\text { ano } \\
(\mathrm{kN}) \\
(5)\end{array}$ & $\begin{array}{l}\text { Perda de } \\
\text { resistência } \\
(\%) \\
(6)\end{array}$ & $\begin{array}{c}\mathrm{F}_{\mathrm{r}} \\
\text { dois } \\
\text { anos } \\
(\mathrm{kN}) \\
(7)\end{array}$ & $\begin{array}{l}\text { Perda de } \\
\text { resistência } \\
(\%) \\
(8)\end{array}$ \\
\hline \multicolumn{8}{|c|}{ (a) $10 \mathrm{~mm}$ f, vidro AR /poliéster } \\
\hline Vigas B-2 e B-3 & 60.0 & - & - & 47.1 & 21.5 & 42.3 & 29.5 \\
\hline $\begin{array}{c}\mathrm{NaCl} 1 \mathrm{CaCl} 2(2: 1), 7 \% \text { por } \\
\text { peso }\end{array}$ & 60.0 & 45.6 & 24.0 & - & - & - & - \\
\hline Vigas B-4 e B-5 & 60.0 & - & - & 44.5 & 25.8 & 39.5 & 34.2 \\
\hline $\begin{array}{c}\mathrm{NaCl} 1 \mathrm{MgCl} 2(2: 1), 7 \% \text { por } \\
\text { peso }\end{array}$ & 60.0 & 44.3 & 26.2 & - & - & - & - \\
\hline $\mathrm{Ca}(\mathrm{OH}) 2$ solução, $T=25^{\circ} \mathrm{C}$ & 61.3 & 53.5 & 12.8 & - & - & - & - \\
\hline Vigas B-7 e B-8 & 61.3 & - & - & 45.8 & 25.3 & 42.3 & 31.0 \\
\hline $\begin{array}{c}\mathrm{NaCl} 1 \mathrm{CaCl} 2(2: 1), 7 \% \text { por } \\
\text { peso }\end{array}$ & 61.3 & 47.4 & 22.7 & - & - & - & - \\
\hline Vigas B-9 e B-10 & 61.3 & - & - & 46.2 & 24.6 & 44.0 & 28.2 \\
\hline $\begin{array}{c}\mathrm{NaCl} 1 \mathrm{MgCl} 2(2: 1), 7 \% \text { por } \\
\text { peso }\end{array}$ & 61.3 & 45.9 & 25.1 & - & - & - & - \\
\hline
\end{tabular}

Kajorncheappunngam, Gupta e GangaRao (2002) conduziram um estudo utilizando barras de GFRP constituídas de fibras de vidro-E e resina epóxi. A maior perda de resistência se deu nas amostras submetidas à uma solução de 5 mols de $\mathrm{NaOH}$ durante 5 meses (tempo estimado utilizando-se aceleradores de tempo), para as amostras em temperatura ambiente a perda foi de $27,8 \%$ da resistência (Figura 2.10) e para as amostras submetidas à temperaturas de até $60^{\circ} \mathrm{C}$ a perda foi da ordem de $70 \%$ (Figura 2.11).

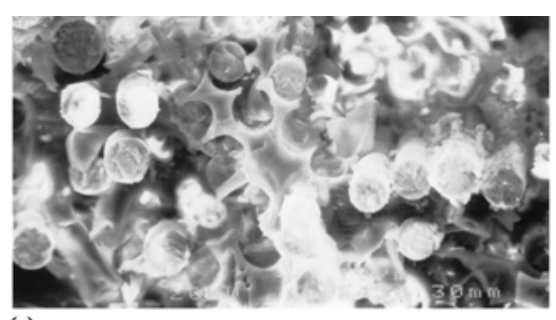

(a)

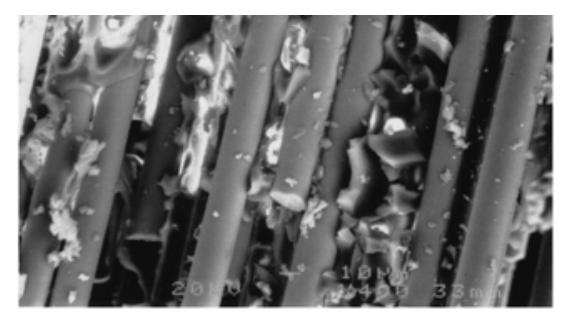

(b)

Figura 2.10 - Amostras submetidas à solução de 5 mols de $\mathrm{NaOH}$ em temperatura ambiente. a)seção transversal das fibras e b) seção longitudinal das fibras. 

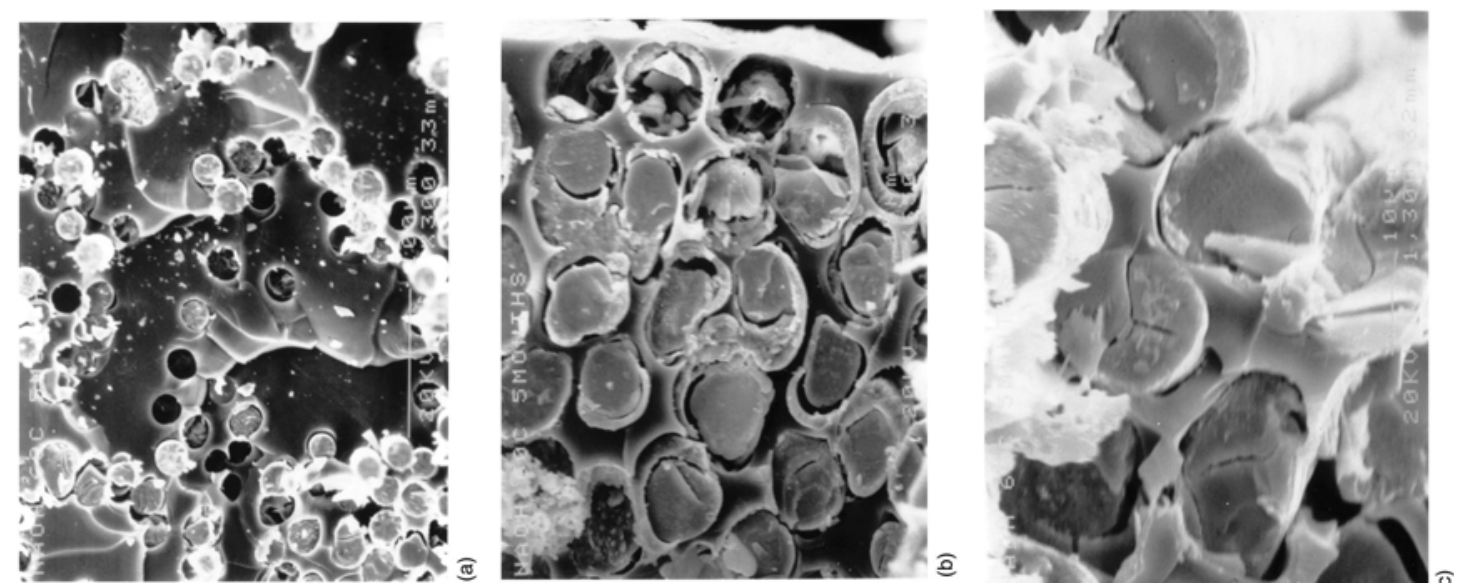

Figura 2.11 - Amostras submetidas à solução de 5 mols de $\mathrm{NaOH}$ em temperatura de $60^{\circ} \mathrm{C}$.

Os resultados mostraram que as resinas epóxi comercialmente utilizadas, são muito pouco duráveis o que demanda o desenvolvimento de produtos de melhor qualidade. A durabilidade das barras de GFRP mostrou-se intimamente relacionada com a resistência química e à umidade e da integridade da superfície de interface com o concreto.

Hullat, Hollaway e Thorne (2002) investigaram as barras de GFRP produzidas pela empresa Advanced Composites Group (ACG), foram testados dois arranjos de fibras, um com orientação ortogonal e outro com orientação de $45^{\circ}$. Na Figura 2.12 pode-se observar os resultados obtidos pelos autores, a Figura 2.12-a e Figura 2.12b apresentam a variação da tensão nas barras submetidas a temperaturas de 40 a $60^{\circ} \mathrm{C}$, soluções salinas e raios UV. Já a Figura 2.12-c compara a capacidade resistente das barras de GFRP com as duas orientações das fibras e barras de CFRP.

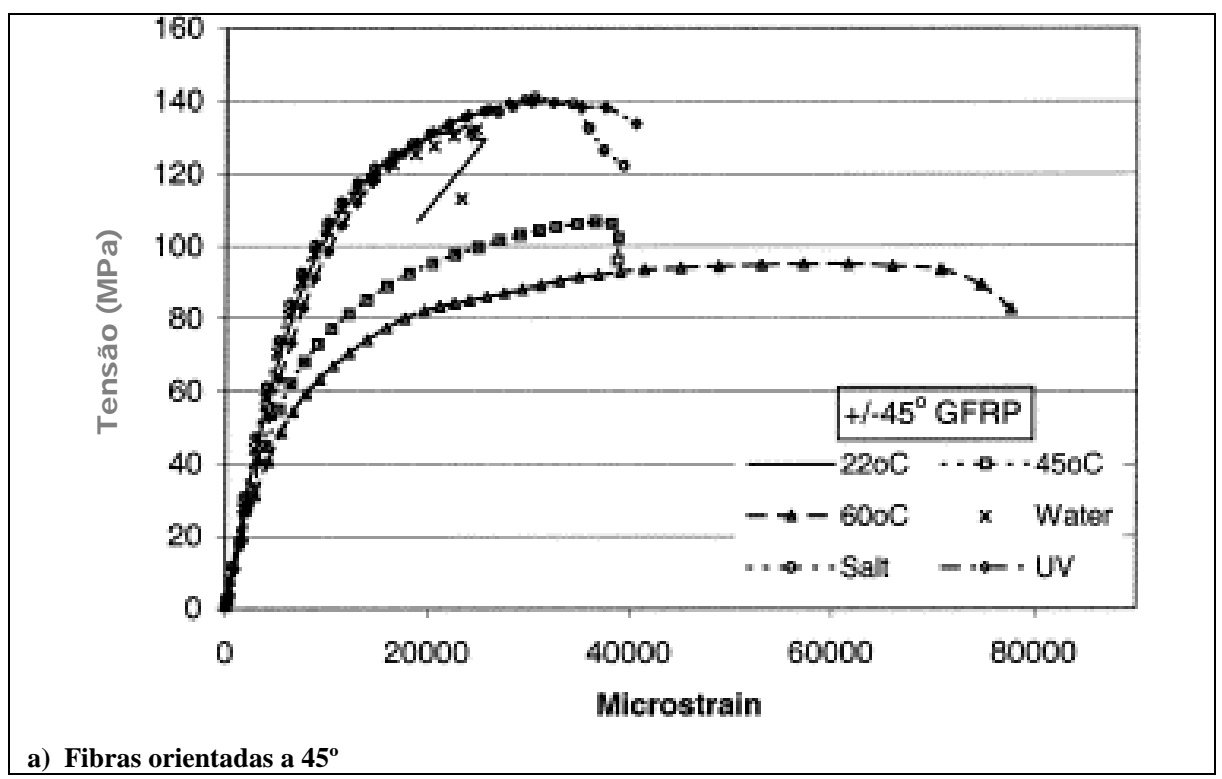




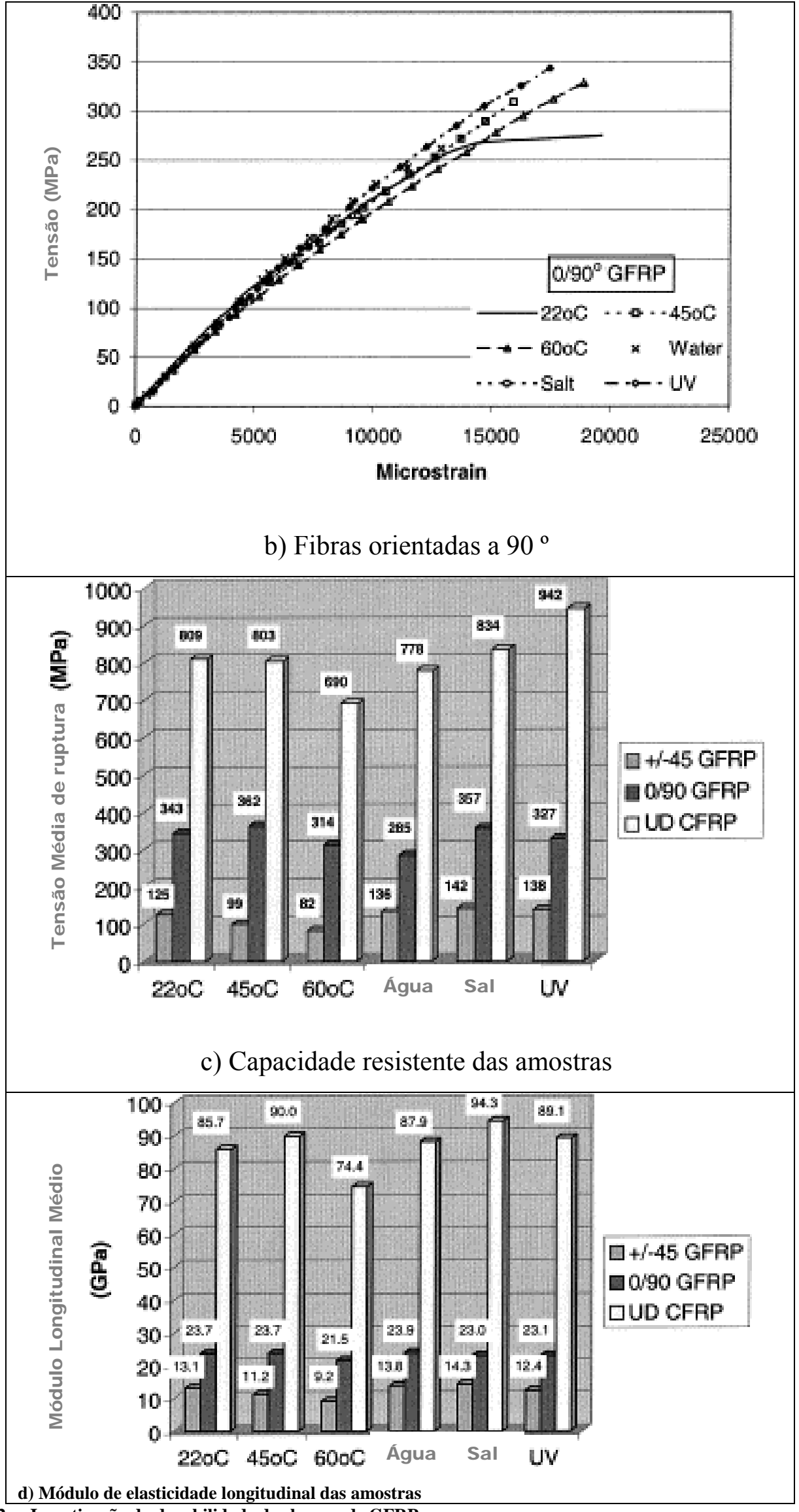

Figura 2.12 - Investigação da durabilidade das barras de GFRP 
Todas as amostras apresentaram grande perda de resistência ao se aproximarem da temperatura de cura da resina polimérica. Houve redução da resistência em todos os ambientes de exposição exceto na exposição a raios UV. Os resultados mostraram grande variabilidade entre as amostras. Uma minuciosa observação via microscópio seria de extrema ajuda na descrição fiel das causas de ruína. O módulo longitudinal apresentou pequena variação e foi pouco afetado pelas exposições.

Benmokrane et al. (2002) realizou mais de 400 testes com amostras de três diferentes indústrias, utilizando diferentes materiais e diferentes combinações de materiais. Foram avaliadas diversas variáveis, dentre elas o tipo de fibra, a matriz e as condições às quais as amostras foram submetidas. As fibras utilizadas foram a vidro-E e a álcali resistente (AR). A combinação $A R /$ vinil éster mostrou-se eficazmente durável quando submetida a uma tensão de $30 \%$ da última, já a vidro-E/ vinil éster mostrou uma perda de $16 \%$ da resistência inicial.

Tabela 2.9 Resistências residuais típicas de GFRP envelhecidas em diferentes ambientes alcalinos a $22^{\circ} \mathrm{C}$

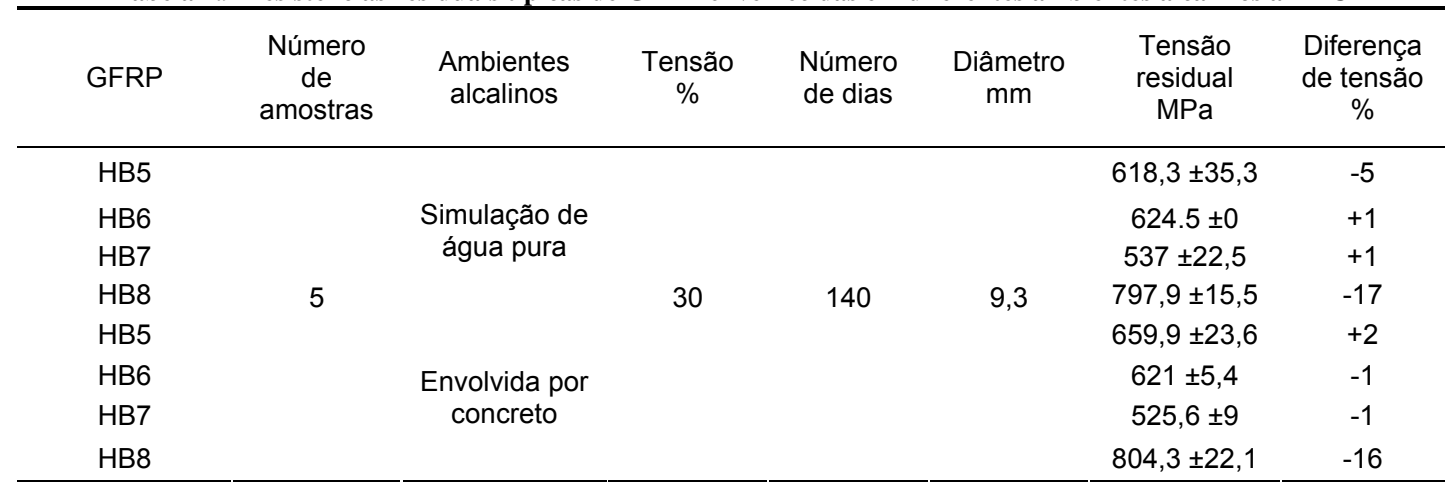

O trabalho apresenta dados suficientes para garantir que sob tensões menores que $25 \%$ da resistência última da barra, o comportamento das GFRP é bastante satisfatório no que se refere à durabilidade das fibras conforme apresentado na Tabela 2.9 .

Micelli e Nanni (2004) investigaram o comportamento de diversos tipos de FRP em ambientes diferentes de exposição, incluindo simulações do ambiente alcalino do concreto, solução pura, agentes ambientais incluindo gelo-degelo, umidade relativa alta, altas temperaturas e radiação UV. Os diferentes tipos de barras avaliados são mostrados na Figura 2.13. 


\begin{tabular}{|c|c|c|c|c|}
\hline BARRA & FIBRA & MATRIZ & DIÂMETRO & SUPERFÍCIE \\
\hline $\mathrm{C} 1$ & Carbono & Epóxi/viniléster & 8.26 & \\
\hline $\mathrm{C} 2$ & Carbono & Epóxi/ viniléster & 8.00 & \\
\hline C3 & Carbono & Epóxi & 7.94 & \\
\hline G1 (protótipo) & Vidro E & Termoplástica & 12.00 & 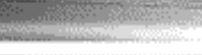 \\
\hline G2 & Vidro E & Poliéster & 6.35 & \\
\hline
\end{tabular}

Figura 2.13 - Barras de FRP submetidas aos ambientes

Os resultados mostraram que as propriedades das resinas são fatores de extrema importância para a durabilidade da FRP e as GFRP são susceptíveis ao ambiente alcalino quando a proteção que deveria prover da resina não é adequada. $O$ decréscimo da resistência para 21 dias e 42 dias, como mostra o gráfico da Figura 2.14 foi de $30 \%$ e $59 \%$ respectivamente para a amostra G2. Por isso o uso de resina poliéster para GFRP não é recomendado. Os resultados com resina termoplástica (G1) foram extremamente satisfatórios.

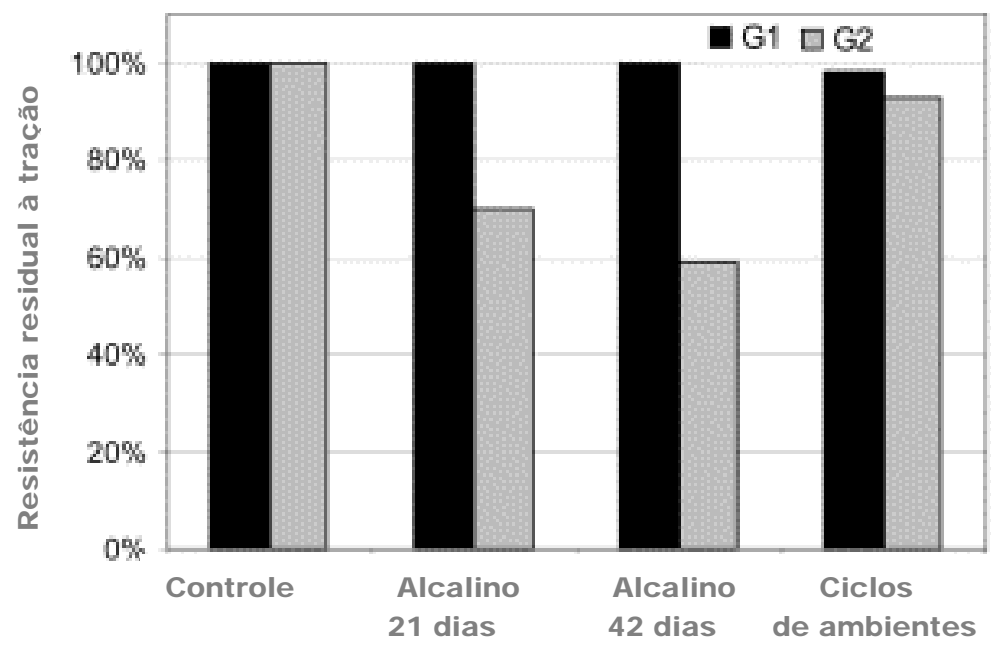

Idade/ ambiente

Figura 2.14 - Gráfico da perda de resistência para as diferentes idades e os diferentes ambientes nas barras G1 e G2.

A durabilidade das barras é a questão de maior inquietação dos estudiosos de FRP, embora sejam muitos os estudos, os comportamentos nem sempre são semelhantes e as barras encontram-se num processo industrial de aperfeiçoamento contínuo. A barra ótima para aplicação no concreto ainda não foi alcançada. Deve-se, 
portanto, considerar no dimensionamento de estruturas de FRP uma redução da capacidade resistente das barras de GFRP.

\subsection{DIMENSIONAMENTO DE VIGAS ARMADAS COM BARRAS DE FRP.}

O dimensionamento de elementos de concreto armado é feito com os procedimentos pré-definidos por meio de diversos estudos e conhecimentos práticos reunidos desde o início da sua utilização.

A mudança da armadura de aço para FRP acarreta comportamentos diferentes o que demanda procedimentos adaptados às propriedades da nova armadura. A utilização de barras de FRP possui uma história ainda muito recente e somente em obras com objetivo de pesquisa portanto, os procedimentos definidos serão ainda muito discutidos e modificados. O concreto armado com armadura convencional de aço possui normas de dimensionamento que são atualizadas com certa freqüência, normas para dimensionamento de estruturas com FRP foram desenvolvidas no Japão, EUA, Canadá e na Europa ainda estão em fase de desenvolvimento.

Pode-se notar um grande conservadorismo na determinação dos limites de utilização das barras de FRP, o que é natural para materiais em fase inicial de aplicação. Outros fatores são as várias divergências entre os procedimentos, lembrando que a maioria é baseada em alguma norma de concreto armado convencional e, como é de conhecimento geral, existem várias normas cada uma com um estilo próprio de proceder.

O ACl 440.1R-03 baseia-se no ACl 380-95. No Canadá as prescrições de estruturas armadas com FRP foram adicionadas ao Canadian Highway Bridge Design Code (CHBDC) em 1998. No Japão em 1997, depois de estudos com FRP iniciados em 1989, foi adicionado no JSCE 1997 as diretrizes referentes à estruturas de concreto armadas com FRP. Na Europa está ainda em andamento o desenvolvimento das diretrizes para o dimensionamento de estruturas com FRP, o grupo FIB 9.3 está na fase final do desenvolvimento de diretrizes baseadas no modelo do EUROCODE de 1990. 


\subsubsection{FILOSOFIA DE DIMENSIONAMENTO.}

Como para as estruturas de concreto armadas com barras de aço, os elementos são dimensionados para garantir a segurança com relação à ruína e a adequação da estrutura à sua utilização. Mesmo sendo as situações de serviço que normalmente se encontram os limites das estruturas de concreto armadas com GFRP, em conseqüência do baixo módulo de elasticidade das barras principalmente, o seu dimensionamento é baseado na capacidade última de resistência (ELU). Este dimensionamento é semelhante ao empregado para estruturas de concreto convencionais.

\subsubsection{ELU - ESTADO LIMITE ÚLTIMO.}

O critério de dimensionamento no ELU - Estado Limite Último se define pela expressão 2-2 que relaciona as resistências e as solicitações, ou seja, as resistências devem ser maiores ou iguais às solicitações.

$R_{d} \geq S_{d}$

As solicitações de cálculo $S_{d}$ são obtidas, majorando as ações com um fator de segurança e a partir delas calculados os esforços solicitantes.

Já a resistência de cálculo é obtida minorando a capacidade resistente de cada material dependendo das propriedades individuais de cada componente, do ambiente em que a estrutura será inserida e a função para a qual está sendo projetada. A resistência do concreto é minorada pelo mesmo coeficiente. Enquanto o coeficiente do aço é substituído por outro calculado a partir das propriedades da barra de FRP.

\subsubsection{Coeficiente de segurança da barra de FRP.}

Existe uma grande preocupação quanto à durabilidade de uma estrutura qualquer. Do ponto de vista da durabilidade as estruturas de concreto armadas com FRP devem ser tratadas de maneira diferente das estruturas com armadura convencional, pois fatores como a corrosão da armadura, não são mais relevantes, mas outros como a durabilidade da armadura e a proteção da fibra têm papel importante nas propriedades das barras de FRP e, portanto, na vida útil da estrutura como um todo. Cada norma possui sua maneira própria de tratar o coeficiente de segurança como apresentado na Tabela 2.10 . 
Tabela 2.10 Coeficientes de segurança de barras de FRP - Adapatado do FIB tg 9.3 - 2003

\begin{tabular}{|c|c|c|c|c|c|c|}
\hline Fator & $\mathrm{ACl}^{1}$ & NS3473 & CHBDC & JSCE & BISE & FIB 9.3 \\
\hline Deteriorização ambiental & $\begin{array}{l}\text { "coeficiente de redução } \\
\text { ambiental" } C_{E} \\
\text { GFRP: } 0,70-0,80 \\
\text { AFRP: } 0,80-0,90 \\
\text { CFRP: } 0,90-1,00\end{array}$ & $\begin{array}{c}\text { "fator de conversão" } \\
\eta_{\text {env }} \\
\text { GFRP: } 0,50 \\
\text { AFRP: } 0,90 \\
\text { CFRP: } 1,00\end{array}$ & $\begin{array}{c}\text { "fator de resistência" } \\
\phi_{F R P} \\
\text { GFRP: } 0,75 \\
\text { AFRP: } 0,85 \\
\text { CFRP: } 0,85\end{array}$ & $\begin{array}{c}\text { "fator do material" } \frac{1}{\gamma_{f m}} \\
\text { GFRP: } 0,77 \\
\text { AFRP: } 0,87 \\
\text { CFRP: } 0,87\end{array}$ & \multirow{2}{*}{$\begin{array}{c}\text { "fator do material" } \frac{1}{\gamma_{m}} \\
\text { GFRP: } 0,30 \\
\text { AFRP: } 0,50 \\
\text { CFRP: } 0,60\end{array}$} & \multirow{3}{*}{$\eta_{e n v}$} \\
\hline $\begin{array}{l}\text { Redução para cargas de } \\
\text { longa duraçao }\end{array}$ & Sem definição & $\begin{array}{c}\text { "fator de conversão" } \\
\eta_{L t} \\
\text { GFRP: } 0,8-1,0 \\
\text { AFRP: } 0,7-1,0 \\
\text { CFRP: } 0,9-1,0\end{array}$ & $\begin{array}{l}\text { fator } F \\
\text { GFRP: } 0,8-1,0 \\
\text { AFRP: } 0,5-1,0 \\
\text { CFRP: } 0,9-1,0\end{array}$ & & & \\
\hline Redução total & $\begin{array}{l}\text { GFRP: } 0,70-0,80 \\
\text { AFRP: } 0,80-0,90 \\
\text { CFRP: } 0,90-1,00\end{array}$ & $\begin{array}{l}\text { GFRP: } 0,40-0,50 \\
\text { AFRP: } 0,63-0,90 \\
\text { CFRP: } 0,90-1,00\end{array}$ & $\begin{array}{l}\text { GFRP: } 0,60-0,75 \\
\text { AFRP: } 0,42-0,85 \\
\text { CFRP: } 0,76-0,85\end{array}$ & $\begin{array}{l}\text { GFRP: } 0,77 \\
\text { AFRP: } 0,87 \\
\text { CFRP: } 0,87\end{array}$ & $\begin{array}{l}\text { GFRP: } 0,30 \\
\text { AFRP: } 0,50 \\
\text { CFRP: } 0,60\end{array}$ & \\
\hline $\begin{array}{l}\text { Limites de tensão para } \\
\text { cargas permanentes }\end{array}$ & $\begin{array}{l}\text { GFRP: } 0,14-0,16 \\
\text { AFRP: } 0,16-0,18 \\
\text { CFRP: } 0,44-0,50\end{array}$ & $\begin{array}{l}\text { Limite de tensão } \\
\text { ainda não } \\
\text { especificado }\end{array}$ & $\begin{array}{l}\text { GFRP: } 0,60-0,75 \\
\text { AFRP: } 0,42-0,85 \\
\text { CFRP: } 0,76-0,85\end{array}$ & $\begin{array}{c}0,8 \times \text { "resistência à } \\
\text { fluência } \\
\text { menor que } 0,7 \\
\text { GFRP: } \leq 0,7 \\
\text { AFRP: } \leq 0,7 \\
\text { CFRP: } \leq 0,7\end{array}$ & $\begin{array}{l}\text { Limite de tensão ainda } \\
\text { não especificado }\end{array}$ & $\begin{array}{l}\text { Limite de tensão ainda } \\
\text { não especificado }\end{array}$ \\
\hline
\end{tabular}

${ }^{1}$ (1) ACI - American Concrete Instutute; NS3473 - "Norma Norueguesa"; CHBDC - Canadian Highway Bridge Design Code; JSCE - Japan Society of Civil Engineers; BISE - "Norma Holandesa”; FIB - Federation Internacinal du Béton. 
No caso do coeficiente de redução das barras de FRP para a FIB 9.3, a determinação depende de outros fatores que vão além do tipo de fibra da barra como apresenta a equação 2-3.

$$
\begin{aligned}
& f_{f t d}=f_{f t c} \cdot \eta_{e n v} \\
& \eta_{e n v}=\left(1-\Delta f_{f t, e n v} \cdot \eta_{m o} \cdot \eta_{T} \cdot \eta_{S L}\right)
\end{aligned}
$$

$\Delta f_{f t, e n v}$ é o fator que trata da ação do ambiente nas fibras que é a parte do composto mais susceptível à ação de agentes externos. É um fator de segurança padrão para a capacidade resistente à tração de barras de uma estrutura de concreto armado com vida útil estimada de 100 anos, sob condição padrão de exposição (estrutura externa, sem contato permanente com água e temperatura anual média entre 5 e $15^{\circ} \mathrm{C}$ ), os valores estão apresentados na Tabela 2.11 .

\begin{tabular}{cc} 
Tabela 2.11 Coeficiente de redução por causa da ação do ambiente nas fibras \\
\multicolumn{1}{c}{$\Delta f_{f t, e n v}$} \\
\hline GFRP & 0,5 \\
AFRP & 0,4 \\
CFRP & 0,2
\end{tabular}

$\eta_{m o}$ é o fator que demonstra a preocupação quanto à fragilidade das fibras de vidro e aramida à exposição em ambientes de elevada umidade. Portanto, o parâmetro analisado é a umidade relativa do ambiente ao qual a estrutura estará exposta. Na Tabela 2.12 pode-se avaliar este coeficiente para cada situação de umidade.

Tabela 2.12 Coeficiente de correção para a umidade no concreto

\begin{tabular}{|c|c|c|}
\hline $\begin{array}{c}\text { Seco } \\
\text { (umidade relativa } \\
U \approx 50 \% \text { ) }\end{array}$ & $\begin{array}{c}\text { Úmido } \\
\text { (concreto sem contato } \\
\text { permanente com água, } \\
\text { umidade relativa } \\
\cup \approx 80 \% \text { ) }\end{array}$ & $\begin{array}{c}\text { Úmido Saturado } \\
\text { (concreto permanentemente } \\
\text { em contato com água, } \\
\text { umidade relativa } U \approx 100 \% \text { ) }\end{array}$ \\
\hline 0,65 & 1,0 & 1,5 \\
\hline
\end{tabular}

$$
\eta_{m o}
$$

$\eta_{T}$ é o fator que considera a variação das temperatura do ambiente de exposição da estrutura. $\mathrm{O}$ aumento da temperatura em $10^{\circ} \mathrm{C}$ duplica as reações químicas (Perez-Bendito e Silva 1998), por isso, é esperada uma relação linear de 
redução da capacidade resistente com o aumento ou diminuição da temperatura em $10^{\circ} \mathrm{C}$, conforme os valores na Tabela 2.13.

Tabela 2.13 Coeficiente de correção para a temperatura média anual

$\eta_{T}$

\begin{tabular}{ccc}
\hline $\mathrm{T}<5^{\circ} \mathrm{C}$ & $5^{\circ} \mathrm{C}<\mathrm{T}<15^{\circ} \mathrm{C}$ & $15^{\circ} \mathrm{C}<\mathrm{T}<25^{\circ} \mathrm{C}$ \\
\hline 0,85 & 1,0 & 1,15
\end{tabular}

$\eta_{S L}$ é o fator de segurança de vida útil da estrutura. A vida útil considerada padrão pela FIB é de 100 anos, mas para estruturas com uma vida útil menor deve-se reduzir o fator de segurança (Tabela 2.14).

Tabela 2.14 Coeficiente de correção vida útil

$\eta_{S L}$

\begin{tabular}{cc} 
Vida útil $=\mathbf{5 0}$ anos & Vida útil $=\mathbf{1 0 0}$ anos \\
\hline 0,85 & 1,0
\end{tabular}

\subsubsection{Tensões Normais - Dimensionamento à flexão.}

As estruturas convencionais de concreto armado com barras de aço são, na melhor situação, dimensionadas para que a barra de aço entre em escoamento. Para que isto seja possível, a capacidade resistente das barras é utilizada em sua totalidade, para garantir o escoamento e, portanto, a ductilidade da estrutura. $O$ elemento dimensionado utilizando-se a totalidade da sua capacidade resistente é dito sub armado. No caso de a tensão ser muito menor que a capacidade da armadura, o elemento é chamado de super armado, e a ruína da estrutura é dada pelo esmagamento do concreto comprimido.

As barras de FRP são desprovidas de escoamento, o seu comportamento é considerado elástico linear e frágil, na totalidade de sua capacidade resistente. Portanto, não se dimensiona um elemento armado com FRP considerando o escoamento das barras da armadura. A melhor situação de dimensionamento é quando a ruína ocorre por esmagamento do concreto na fibra mais comprimida.

A ruína balanceada, na qual ocorrem a deformação da armadura e o esmagamento do concreto simultaneamente, é a forma mais econômica de dimensionamento. As estruturas armadas com barras de aço, para o caso de ruína balanceada, apresentam a linha neutra localizada mais ou menos no meio da altura 
útil da seção transversal. Isto se deve ao fato de que a relação resistência/ rigidez de um elemento armado com barras metálicas é muito semelhante à relação para o concreto simples, fazendo com que a fibra neutra encontre-se no meio da seção transversal.

Para elementos armados com FRP, a ruína balanceada ocorre com a linha neutra localizada na parte superior da altura útil da seção transversal, perto da superfície comprimida. A relação resistência/ rigidez não se mantém semelhante à de elementos de concreto simples. Como mostra a Figura 2.15.

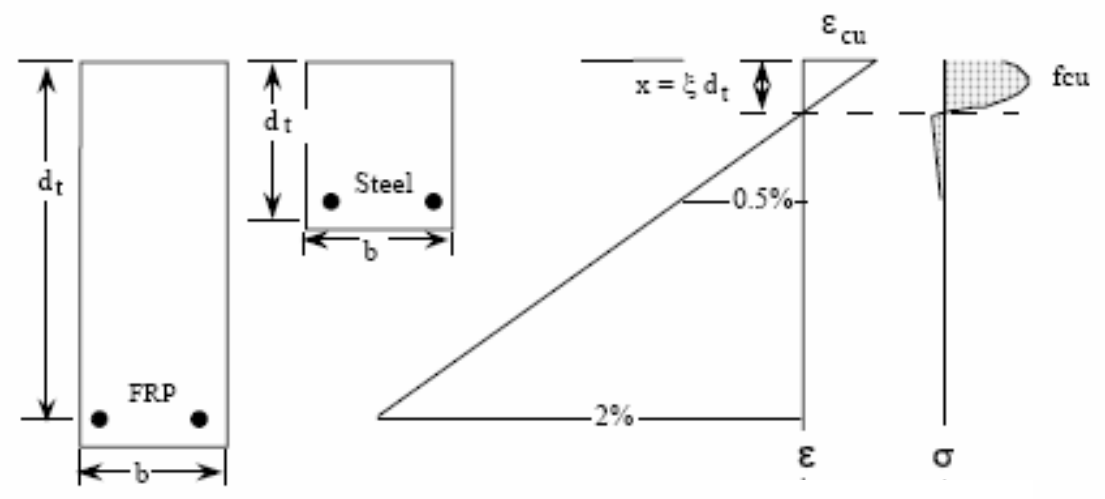

Figura 2.15 Distribuição das deformações para uma armadura de GFRP - Pilakoutas 2002

Em estruturas armadas com FRP são dois os tipos de ruína apresentados:

- Ruptura da barra de FRP;

- Esmagamento do concreto.

No caso de ruína por ruptura da barra de FRP, esta se apresenta de modo repentino e brusco, pois não existe escoamento das barras de FRP, sendo que elas possuem comportamento elástico linear e ruptura frágil. A ruína por esmagamento do concreto é mais recomendável, pois existe uma certa ductilidade neste tipo de ruína em conseqüência do desenvolvimento do comportamento plástico do concreto antes da ruína (ACI 440.1R-03, FIB 9.3 TG-2003, Bakht et al. 2000, Nanni 2005).

\subsubsection{Hipóteses de cálculo.}

Assim como no dimensionamento de elementos de concreto armados com barras de aço, algumas hipóteses são necessárias para simplificar o fenômeno real que ocorre nestes elementos. 
- As seções planas permanecem planas após a deformação do elemento (hipótese de Bernoulli);

- A deformação máxima do concreto antes da ruína é de 3\%;

- A capacidade resistente do concreto à tração não é considerada na resistência do elemento;

- O comportamento das barras de FRP é elástico linear (obedece a Lei de Hooke) até a ruptura e;

- Existe aderência perfeita entre o concreto e as barras de FRP.

\subsubsection{Resistência à flexão}

Discutem-se a seguir as rotinas de acordo com autores e códigos normativos internacionais.

a. ACI 440.1R-03, Nanni (2003), JSCE (1997)²

Apresentam-se as rotinas definidas pelo ACl 440.1-03, Nanni (2003) e a norma japonesa, JSCE (1997). Estas são muito semelhantes o que justifica a apresentação em conjunto, sendo as diferenças destacadas no decorrer do texto.

O dimensionamento de uma peça considerando a capacidade última de resistência consiste em majorar as ações às quais a peça está submetida e minorar a sua capacidade resistente de modo a assegurar com segurança que esta não é menor que a primeira, ou seja:

$\phi \cdot M_{n} \geq M_{u}$

$M_{u}$ é o momento calculado a partir das ações que o elemento é submetido, já multiplicadas pelos fatores de majoração probabilísticos definidos no ACl 318-95.

$M_{n}$ é o momento resistente do elemento calculado utilizando-se as equações de equilíbrio e a compatibilidade das deformações.

\footnotetext{
${ }^{2}$ As informações sobre as diretrizes de dimensionamento proposta pela JSCE (1997) são fornecidas no próprio ACI 440.1R -2003.
} 
$\phi$ é um coeficiente dependente do tipo de ruína que governa o comportamento da peça.

Os parâmetros para definir o tipo de ruína são a taxa de armadura de FRP da peça e a taxa de armadura balanceada (taxa de armadura para a qual ocorrem os dois tipos de ruínas simultaneamente).

A taxa de armadura de FRP é definida na expressão 2-5:

$\rho_{f}=\frac{A_{f}}{b \cdot d}$

A expressão 2-6 define taxa de armadura balanceada como sendo:

$\rho_{f b}=0,85 \cdot \beta_{1} \frac{f_{c}^{\prime}}{f_{f u}} \frac{E_{f} \cdot \varepsilon_{c u}}{E_{f} \cdot \varepsilon_{c u}+f_{f u}}$

Sendo:

$\rho_{f}<\rho_{f b}$ a ruína se inicia pela ruptura da barra;

$\rho_{f}>\rho_{f b}$ a ruína é iniciada pelo esmagamento do concreto

Ainda na expressão 2-4, o valor da resistência nominal à flexão $\left(M_{n}\right)$ é dependente do tipo de ruína que governa o comportamento do elemento, portanto são três os casos possíveis:

CASO A) Ruína governada pelo esmagamento do concreto:

$\rho_{f}>1,4 \rho_{f b}$

O diagrama de tensões no concreto pode ser aproximado para o retangular apresentado no $\mathrm{ACl}$ 318-95 (Figura 2.16).

Portanto das equações de equilíbrio, juntamente com a compatibilidade das deformações, pode ser calculada a capacidade resistente do elemento. 


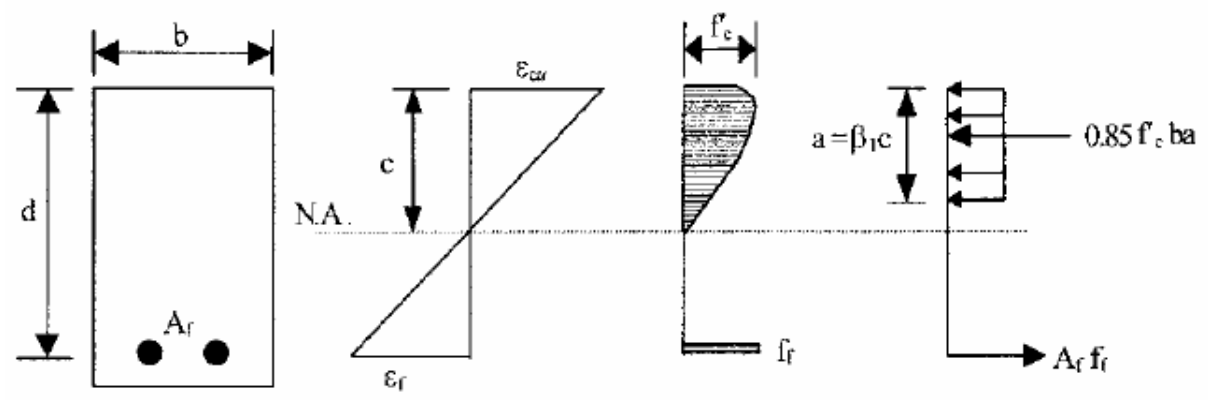

Figura 2.16 - Diagrama aproximado retangular - ACI 318-95.

Sendo que a força resultante na barra de FRP é descrita na equação 2-7 e o valor do braço da alavanca descrito na equação 2-8.

$R_{f}=A_{f} \cdot f_{f}$

$\left(d-\frac{a}{2}\right)$

A resistência nominal à flexão pode ser calculada através da multiplicação da força resultante na armadura e o braço de alavanca definido pelo binário de forças.

$M_{n}=A_{f} \cdot f_{f} \cdot\left(d-\frac{a}{2}\right)$

Do equilíbrio das forças pode-se dizer que:

$R_{f}=R_{c}$

Portanto:

$A_{f} \cdot f_{f}=0,85 \cdot f_{c}^{\prime} \cdot b \cdot a$

Da igualdade de forças, define-se o valor da altura do diagrama retangular equivalente (equação 2-11)

$a=\frac{A_{f} \cdot f_{f}}{0,85 \cdot f_{c}^{\prime} \cdot b}$

Como o diagrama tensão $x$ deformação das barras de FRP é elástico linear , pode-se afirmar que:

$f_{f}=E_{f} \cdot \varepsilon_{f}$ 
Utilizando a compatibilidade de deformações, define-se a equação 2-13

$\frac{\varepsilon_{f}}{(d-c)}=\frac{\varepsilon_{c u}}{c}$

Isolando o valor da deformação na armadura.

$$
\begin{aligned}
& \varepsilon_{f}=\varepsilon_{c u} \frac{(d-c)}{c} \\
& \varepsilon_{f}=\varepsilon_{c u} \frac{\left(d-\frac{a}{\beta_{1}}\right)}{\frac{a}{\beta_{1}}} \\
& \varepsilon_{f}=\varepsilon_{c u} \frac{\beta_{1} \cdot d-a}{a}
\end{aligned}
$$

Fica determinado o valor da tensão na armadura de GFRP em função de sua deformação e do diagrama equivalente de tensões.

$$
f_{f}=E_{f} \cdot \varepsilon_{c u} \frac{\beta_{1} \cdot d-a}{a}
$$

Substituindo a altura do diagrama equivalente e isolando a tensão na barra, a equação resulta em:

$f_{f}=\left(\sqrt{\frac{\left(E_{f} \cdot \varepsilon_{c u}\right)^{2}}{4}+\frac{0,85 \cdot \beta_{1} \cdot f_{c}^{\prime}}{\rho_{f}} \cdot E_{f} \cdot \varepsilon_{c u}}-0,5 \cdot E_{f} \cdot \varepsilon_{c u}\right) \leq f_{f u}$

Com a tensão na barra é possível calcular o momento resistente nominal.

Ou em termos das taxas de armadura e taxa balanceada de armadura:

$$
M_{n}=\rho_{f} \cdot f_{f} \cdot\left(1-0,59 \cdot \frac{\rho_{f} \cdot f_{f}}{f_{c}^{\prime}}\right) \cdot b \cdot d^{2}
$$

CASO B) Ruína governada pela ruptura da barra:

$\rho_{f}<\rho_{f b}$ 
- O diagrama de tensões no concreto não pode ser aproximado para o retangular apresentado no $\mathrm{ACl} 318-95$.

- Um diagrama equivalente deve ser calculado. As incógnitas deste diagrama são a deformação no concreto e a distância da fibra mais comprimida à linha neutra. Além disso os fatores que definem o diagrama retangular equivalente $\alpha_{1}$ e $\beta_{1}$ também são desconhecidos.

$$
\begin{aligned}
& \alpha_{1}=\frac{f_{c m}}{f_{c}^{\prime}} \\
& \beta_{1}=\frac{a}{c}
\end{aligned}
$$

A análise do diagrama envolvendo todas essas variáveis é muito complexa, portanto para efeito de simplificação a resistência nominal a flexão pode ser escrita da seguinte forma:

$$
M_{n}=A_{f} \cdot f_{f u} \cdot\left(d-\frac{\beta_{1} \cdot c}{2}\right)
$$

CASO C) Ruína governada pela ruptura da barra e esmagamento do concreto:

Esta é uma maneira conservativa de se encarar o CASO B, levando a linha neutra para um ponto tal que torne a ruína governada pelos dois fatores em conjunto. A resistência nominal à flexão pode ser calculada através da multiplicação da força resultante na armadura e o braço de alavanca também determinado por um binário de forças, mas sendo este determinado pela capacidade resistente do concreto.

$$
M_{n}=A_{f} \cdot f_{f u} \cdot\left(d-\frac{\beta_{1} \cdot c_{b}}{2}\right)
$$

Para levar a altura do diagrama de tensões à um valor tal que a capacidade resistente do concreto é atingida (equação 2-21), no diagrama de deformações definise como deformação no concreto a sua deformação última.

$$
c_{b}=\left(\frac{\varepsilon_{c u}}{\varepsilon_{c u}+\varepsilon_{f u}}\right) \cdot d
$$

Finalmente definindo o último parâmetro da equação 2-4, a reserva de resistência $\phi$ é definida de forma diferente em cada uma das seguintes diretrizes: 
- $\quad$ No Japão (JSCE 1997) $\phi=\frac{1}{1,3}$

- Brenmokrane (2002) baseado na teoria da probabilidade propôs $\phi=0,75$

- No ACl 318-95 na ruína por esmagamento do concreto $\phi=0,7$

- $\mathrm{ACl} 440.1 \mathrm{R}-03$ propõe:

$\phi=0,7$ para ruína governada pelo esmagamento do concreto;

$\phi=0,5$ para ruína governada pela ruptura da barra;

ou seja:

$\phi=\left\{\begin{array}{l}0,50 \rightarrow\left(\rho_{f} \leq \rho_{f b}\right) \\ \frac{\rho_{f}}{2 \cdot \rho_{f b}} \rightarrow\left(\rho_{f b}<\rho_{f}<\rho_{f b}\right) \\ 0,70 \rightarrow\left(\rho_{f} \geq 1,4 \rho_{f b}\right)\end{array}\right.$

Além dos fatores descritos anteriormente, as diretrizes ainda definem algumas considerações especiais para o dimensionamento dos elementos com barras de FRP.

- Armadura Mínima

O limite mínimo de armadura só faz sentido quando o elemento é dimensionado para que sua ruína seja governada pela ruptura da barra de FRP $\left(\rho_{f}<\rho_{f b}\right)$.

Ou seja:

$\phi \cdot M_{n} \geq M_{c r}$

$\phi=0,5$ e não $\phi=0,9$ como determinado pelo $\mathrm{ACl}$ 318-95. Por isso a expressão para cálculo da armadura mínima é modificada pela multiplicação de um fator de valor $1,8(0,9 / 0,5)$

$A_{f_{\text {min }}}=\frac{5,4 \sqrt{f_{c}^{\prime}}}{f_{f u}} \cdot b_{w} \cdot d \geq \frac{360}{f_{f u}} \cdot b_{w} \cdot d$

- Camadas Múltiplas de barras e diferentes tipos de FRP 
A tensão nas barras de FRP varia em função da sua distância da linha neutra. O fato de se utilizar tipos de FRP diferentes também influenciam para que a tensão nestas barras seja diferente. Estas situações exigem que a tensão nas barras seja determinada pela compatibilidade das deformações e se houver falta de informação sobre as diferentes distâncias, a barra a ser considerada é a mais distante da linha neutra e não mais a distância a partir do centro de gravidade das barras (ACI 318-95). Ou seja, a fibra mais distante da linha neutra é que controla a ruína de todas as camadas.

- Redistribuição de momentos fletores.

O comportamento dos elementos armados com FRP é diferente dos armados com barras de aço pelo fato de não existir plastificação, fato que torna impossível a redistribuição dos momentos fletores.

- Armadura de compressão

As barras de FRP possuem baixa resistência à compressão e sujeitas a grande variação quando comparada à sua resistência à tração. Para o dimensionamento usual esta resistência deve ser ignorada não sendo recomendada a utilização destas barras para armar pilares comprimidos. Além disso a armadura de compressão de vigas deve ser evitada, mas existem situações nas quais é impossível evitar $A_{f}^{\prime}$, por exemplo, barras guia para estribos e apoio de vigas contínuas. Para estes casos a solução para a variabilidade da resistência à compressão da barra é o seu confinamento.

$b$.

FIB 9.3 task group - 2003.

O dimensionamento de uma peça para sua capacidade última de resistência consiste em majorar as ações às quais a peça está submetida e minorar a sua capacidade resistente de modo a assegurar com segurança que esta não é menor que a primeira. O dimensionamento proposto pelo FIB TG 9.3-2003 é baseado no Eurocode 2. O dimensionamento de elementos armados com FRP leva à seções superarmadas, nas quais a capacidade resistente das barras não é totalmente utilizada. Essa mudança de filosofia leva à mudança do tipo de ruptura que antes era dúctil e agora é frágil. Para adaptar esta diferença, o dimensionamento é baseado no controle das deformações das barras de FRP. 


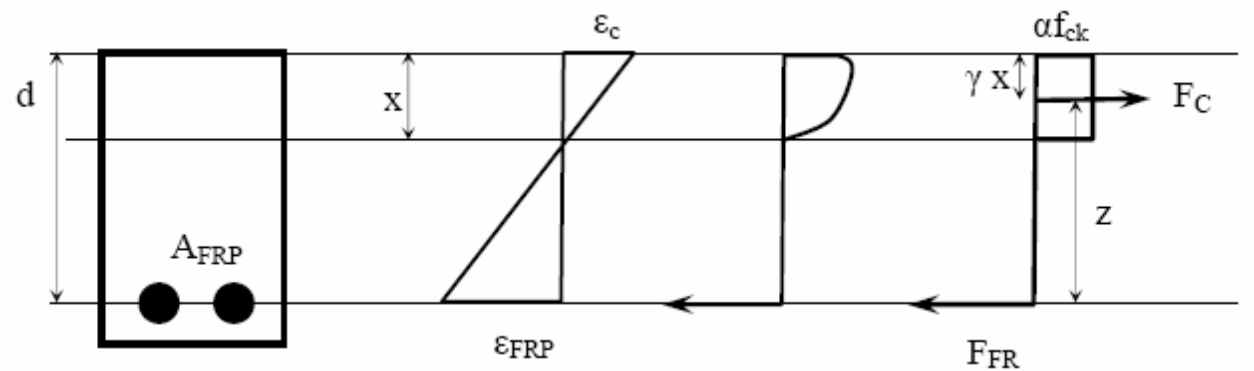

Figura 2.17 Diagrama de tensão do concreto armado com FRP - FIB 9.3 TG-2003.

Primeiramente calcula-se a altura útil do elemento a partir de um diâmetro prédefinido de barra. O dimensionamento é feito considerando que a ruína será por esmagamento do concreto a uma deformação de $3,5 \%$.

A equação 2-25 define a força última resultante no concreto.

$F_{C d=} \frac{\alpha \cdot f_{c k} \cdot x \cdot b}{\gamma_{c}}$

Sendo: $\alpha=-68711 \cdot \varepsilon_{c}^{2}+464,79 \cdot \varepsilon_{c}+0,01$

O coeficiente de simplificação do diagrama párábola retângulo para o retangular $(\alpha)$ e o de definição da aplicação da força resultante no concreto $(\gamma)$ foram fornecidos por Neocleos (2005).

Como a ruína é por esmagamento do concreto, a tensão na armadura não atinge a sua capacidade resistente e pode ser determinada por:

$f_{F R P}=\varepsilon_{F R P} \cdot E_{F R P}$

Para verificação, se a capacidade resistente da armadura foi atingida, o seu valor, definido pela equação 2-28, não pode ultrapassar a tensão anteriormente calculada em 2-27.

$f_{F R P d}=\frac{f_{F R P}}{\gamma_{F R P}}$

A força última na armadura é facilmente encontrada através da equação 2-29.

$F_{F R P d}=A_{F R P} \cdot f_{F R P}=A_{F R P} \cdot \varepsilon_{F R P} \cdot E_{F R P}$

Considerando o equilíbrio de forças, pode-se escrever:

$F_{C d}=F_{F R P}$ 
Substituindo na igualdade, as equações 2-27 e 2-25, com o valor da altura do diagrama equivalente em função das deformações, têm-se:

$\frac{\alpha \cdot f_{c k}\left(\frac{\varepsilon_{c} \cdot d}{\varepsilon_{F R P}+\varepsilon_{c}}\right) \cdot b}{\gamma_{c}}=A_{F R P} \cdot \varepsilon_{F R P} \cdot E_{F R P}$

Resolvendo para a deformação na armadura:

$\varepsilon_{F R P}^{2}+\varepsilon_{c} \cdot \varepsilon_{F R P}-\frac{\alpha \cdot f_{c k} \cdot b \cdot d \cdot \varepsilon_{c}}{\gamma_{c} \cdot A_{F R P} \cdot E_{F R P}}=0$

Antes de calcular o braço de alavanca do momento formado pelas forças, deve-se garantir que a tensão na armadura não atingiu a tensão de cálculo.

$\varepsilon_{F R P d}=\frac{f_{F R P}}{E_{F R P}}$

Se a deformação ultrapassar a deformação de cálculo da armadura de FRP, a ruína será governada pela ruptura da barra e a posição da linha neutra e a força na armadura é calculada como segue:

A força e a deformação na armadura são definidos como seus valores últimos e o cálculo da altura da linha neutra fica determinado por:

$F_{F R P d}=A_{F R P} \cdot f_{F R P d}$

$x=\frac{\varepsilon_{c} \cdot d}{\varepsilon_{F R P d}+\varepsilon_{c}}$

A força última no concreto fica definida por:

$F_{C d}=\frac{\alpha \cdot f_{c k}\left(\frac{\varepsilon_{c} \cdot d}{\varepsilon_{F R P d}+\varepsilon_{c}}\right) \cdot b}{\gamma_{c}}$

Se a deformação for menor que o limite de cálculo, a posição da resultante das tensões na área de concreto comprimido pode ser calculada e conseqüentemente o braço de alavanca é determinado por:

$\gamma=1962,6 \cdot \varepsilon_{c}^{2}+17,89 \cdot \varepsilon_{c}+0,33$

$z=d-\gamma \cdot x$ 
Finalmente o momento resistente pode ser calculado, para os dois tipos de ruína.

$M_{u}=F_{C d} \cdot z$

$M_{u}=F_{F R P d} \cdot z$

\subsection{ELS - ESTADO LIMITE DE SERVIÇO.}

Diferentemente do aço as barras de FRP, principalmente as barras de GFRP, apresentam pequena rigidez, e em conjunto com o concreto, o elemento armado com barras de GFRP apresenta uma rigidez muito pequena após a fissuração, aumentando as deformações.

As situações de serviço definidas para estruturas armadas com FRP são:

- Fissuração;

- Deformação.

A verificação para os limites de serviço não pode ser a mesma para elementos armados em aço e FRP. A diferença de rigidez entre esses materiais torna o comportamento em serviço diferente. Para elementos de concreto armados com a mesma área de armadura de aço e FRP, após o carregamento o elemento armado com barras de FRP apresentará uma maior deformação e maior abertura de fissuras (Gao, Benmokrane e Masmoudi 1998a e Theriault, Benmokrane e Gao 1998).

\subsubsection{Fissuração.}

As barras de FRP são mais resistentes à corrosão que as barras de aço, por isso limitações de fissuras com o objetivo de proteger as barras são desnecessárias. Pelo fato de possuir rigidez menor, as estruturas armadas com GFRP apresentam maiores aberturas nas fissuras.

As normas internacionais determinam limites para a abertura das fissuras por outros aspectos, como a estética da estrutura.

- Japão

Na norma japonesa (JSCE 1997) é estabelecido um limite para a abertura das fissuras, sendo a estética o único aspecto considerado, indicando: 
$0,5 \mathrm{~mm}$ para elementos no exterior da estrutura;

0,7 mm para elementos no interior da estrutura.

- Canadá

A norma canadense CHBDC (1998) estabelece a possibilidade de não se considerar as aberturas de fissuras para estruturas cuja vida útil é pequena (estruturas temporárias) e não existem restrições estéticas. O ACl 440.1R-03 defende esta posição, se respeitadas as condições acima determinadas.

As fissuras de estruturas armadas com FRP são maiores que as de estruturas com barras de aço. Estudos realizados comprovam a possibilidade de adaptação da equação de Gegely - Lutz (1973) (ACl 440.1R-03):

$w=0,76 \cdot \beta \cdot\left(E_{s} \cdot \varepsilon_{s}\right) \cdot \sqrt[3]{d_{c} \cdot A}$

Sendo que a abertura das fissuras é proporcional à deformação e não à tensão.

Adaptando para as barras de FRP, para barras de FRP com tensão de aderência equivalente à de barras de aço:

$w=0,76 \cdot \beta \cdot \frac{E_{s}}{E_{f}} \cdot f_{f} \cdot \sqrt[3]{d_{c} \cdot A}$ (unidades americanas)

Considerando a capacidade aderente das barras de FRP e transformando a equação para as unidades do SI:

$$
\begin{gathered}
w=\frac{2,2}{E_{f}} \cdot \beta \cdot k_{b} \cdot f_{f} \cdot \sqrt[3]{d_{c} \cdot A} \text { (MPa e mm) } \\
k_{b} \rightarrow \text { aderência } \\
k_{b}=1,0 \text { (aço barras corrugadas) } \\
k_{b}<1,0 \text { (aderência maior que a de barras de aço) } \\
k_{b}>1,0 \text { (aderência menor que a de barras de aço) } \\
k_{b}=1.2 \text { (quando o valor de } k_{b} \text { for desconhecido. }
\end{gathered}
$$




\subsubsection{Deformação.}

Após a deformação o elemento de concreto armado muda a sua rigidez e a inércia da seção fissurada é definida por:

$$
I_{c r}=\frac{b \cdot d^{3}}{3} \cdot k^{3}+n_{f} \cdot A_{f} \cdot d^{2} \cdot(1-k)^{2}
$$

Sendo:

$k=\sqrt{2 \cdot \rho_{f} \cdot n_{f}+\left(\rho_{f} \cdot n_{f}\right)^{2}}-\rho_{f} \cdot n_{f}$

Em 1977, segundo o $\mathrm{ACl}$ 440.1R, Branson determinou uma maneira de se aproximar a rigidez de um elemento de concreto armado considerando que existem regiões fissuradas e regiões íntegras:

$I_{e}=\left(\frac{M_{c r}}{M_{a}}\right)^{3} \cdot I_{g}+\left[1-\left(\frac{M_{c r}}{M_{a}}\right)^{3}\right] \cdot I_{c r} I_{g}$

$\mathrm{O}$ ACl 440.1R-03 propõe a adaptação da fórmula de Branson para estruturas de concreto armadas com FRP, no que se refere à diferença de rigidez das barras de FRP quando comparadas ao aço.

$$
\begin{aligned}
& I_{e}=\left(\frac{M_{c r}}{M_{a}}\right)^{3} \cdot I_{g} \cdot \beta_{d}+\left[1-\left(\frac{M_{c r}}{M_{a}}\right)^{3}\right] \cdot I_{c r \leq} I_{g} \\
& \beta_{d}=\alpha_{b} \cdot\left[\frac{E_{f}}{E_{s}}+1\right]
\end{aligned}
$$

Sendo $\alpha_{b}=0.5$ quando não se conhece o valor real do parâmetro de aderência.

As deformações são divididas em:

- Deformação imediata $\left(I_{e}\right)$

- Deformação lenta (cálculo semelhante à fluência de estruturas armadas com barras de aço 


\section{DIMENSIONAMENTO À FLEXÃO DE ELEMENTOS ARMADOS COM FRP}

\subsection{ELU}

Os momentos fletores atuantes nas seções transversais geram internamente, para o seu equilíbrio, tensões normais. Para o dimensionamento de elementos lineares sujeitos a tais tensões são utilizadas as hipóteses do ELU - Estado Limite Último e verificadas as condições do ELS - Estado Limite de Serviço.

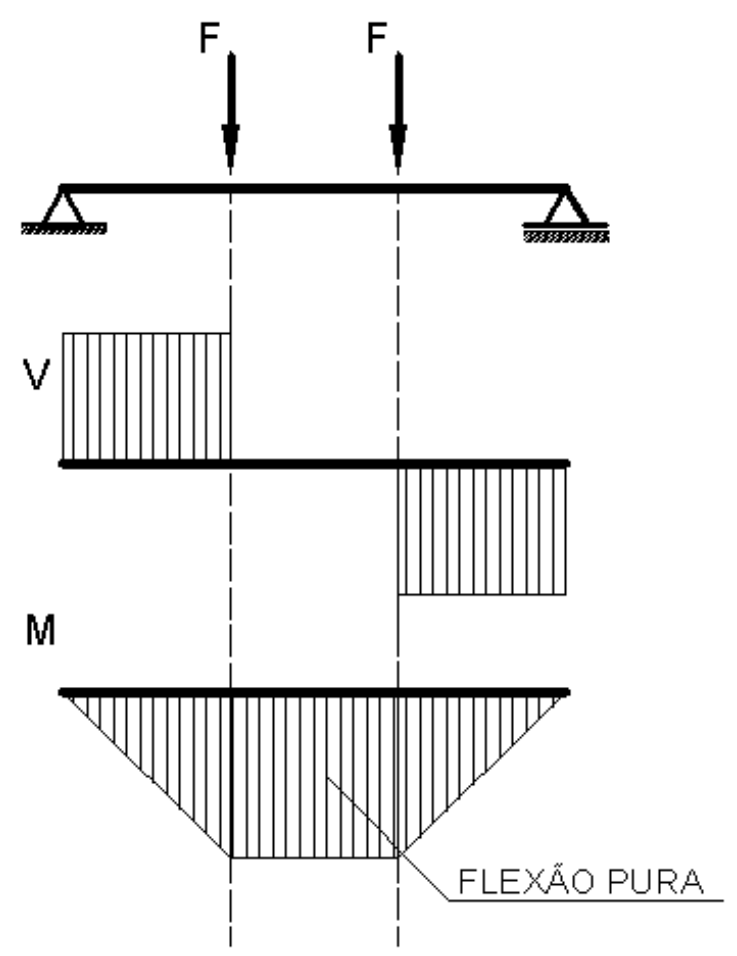

Figura 3.1 - Diagramas de Esforço Cortante e Momento Fletor de uma viga. 
As hipóteses do Estado Limite Último trata das condições estruturais para evitar a ruína da estrutura. Para atender às condições impostas, os esforços solicitantes, como os exemplificados na Figura 3.1, são majorados e a capacidade resistente dos materiais que compõem o elemento estrutural é minorada, e a inequação 2-2 entre resistência e solicitação precisa ser satisfeita.

$R_{d} \geq S_{d}$

As solicitações de cálculo $S_{d}$ são obtidas, majorando as ações com um fator de segurança denominado $\gamma_{f}$ e a partir delas calculados os esforços solicitantes de cálculo.

Já a resistência de cálculo é obtida pela minoração da capacidade resistente de cada material dependendo das propriedades individuais de cada componente, do ambiente em que a estrutura será inserida e a função para a qual está sendo projetada. O concreto, assim como na NBR 6118:2003, é minorado pelo mesmo coeficiente $\gamma_{c}$. Já o coeficiente $\gamma_{s}$ do aço é substituído por outro calculado a partir das propriedades da barra de FRP.

\subsubsection{Coeficiente de segurança da barra de FRP $\left(\gamma_{F R P}\right)$}

Existe preocupação quanto à durabilidade de uma estrutura qualquer e na norma atual de concreto armado isto é evidente.

A durabilidade de estruturas de concreto armadas com FRP depende de fatores diferentes, ou de tratamento diferenciado aos mesmos fatores das estruturas armadas com armadura metálica. Fatores como a corrosão da armadura não são mais relevantes, mas outros como a durabilidade e a proteção da fibra têm papel importante na manutenção das propriedades das barras de FRP e, portanto, na vida útil da estrutura como um todo. A abordagem da FIB TG 9.3-2003 parece ser a mais completa no que diz respeito aos fatores relacionados neste coeficiente. A tensão de cálculo da armadura é determinada multiplicando um fator menor que 1 com o valor de resistência característica à tração.

É importante salientar que sendo uma tecnologia ainda nova, os fatores de segurança são ainda muito altos o que indica a necessidade de pesquisas na área. 


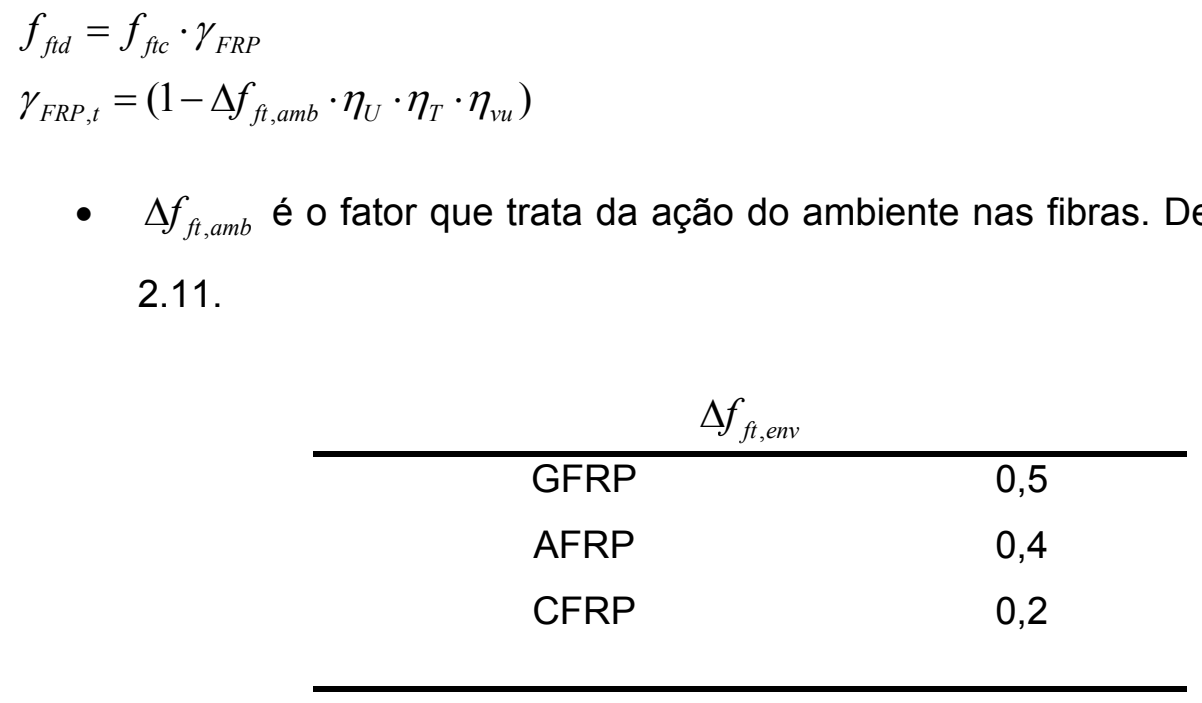

- $\eta_{U}$ é o fator que demonstra a preocupação quanto à fragilidade das fibras de vidro e aramida à exposição em ambientes de elevada umidade. Definido na Tabela 2.12.

\begin{tabular}{ccc}
\multicolumn{3}{c}{$\eta_{m o}$} \\
\hline $\begin{array}{c}\text { Seco } \\
\text { (umidade relativa } \\
U \approx 50 \%)\end{array}$ & $\begin{array}{c}\text { Úmido } \\
\text { permanente com água, } \\
\text { umidade relativa } \\
U \approx 80 \%)\end{array}$ & $\begin{array}{c}\text { Úmido Saturado } \\
\text { (concreto permanentemente } \\
\text { umidade relativa } U \approx 100 \%)\end{array}$ \\
\hline 0,65 & 1,0 & 1,5
\end{tabular}

- $\eta_{T}$ é o fator que considera a variação das temperatura do ambiente de exposição da estrutura. Definido na Tabela 2.13.

\begin{tabular}{ccc}
\multicolumn{3}{c}{$\eta_{T}$} \\
\hline $\mathrm{T}<5^{\circ} \mathrm{C}$ & $5^{\circ} \mathrm{C}<\mathrm{T}<15^{\circ} \mathrm{C}$ & $15^{\circ} \mathrm{C}<\mathrm{T}<25^{\circ} \mathrm{C}$ \\
\hline 0,85 & 1,0 & 1,15
\end{tabular}

As temperaturas anuais na Europa vão até os $25^{\circ} \mathrm{C}$, o que para a América Latina inclusive o Brasil é uma temperatura mínima para algumas regiões, principalmente as regiões Norte e Nordeste. Para corrigir esta situação é necessária 
uma adaptação deste coeficiente de correção pela utilização da relação linear existente entre o aumento da temperatura e o fator de correção.

Tabela 3.1 Coeficiente de correção para a temperatura média anual adaptado

$\eta_{T}$

\begin{tabular}{cccc}
\hline $\mathrm{T}<5^{\circ} \mathrm{C}$ & $5^{\circ} \mathrm{C}<\mathrm{T}<15^{\circ} \mathrm{C}$ & $15^{\circ} \mathrm{C}<\mathrm{T}<25^{\circ} \mathrm{C}$ & $25^{\circ} \mathrm{C}<\mathrm{T}<35^{\circ} \mathrm{C}$ \\
\hline 0,85 & 1,0 & 1,15 & 1,30
\end{tabular}

É claro que uma mudança como esta, deve ser seguida de estudos que comprovem a veracidade da relação linear entre resistência e temperatura para temperaturas médias anuais maiores que $25^{\circ} \mathrm{C}$.

- $\quad \eta_{v u}$ é o fator de segurança de vida útil da estrutura. Definido na Tabela 2.14.

Erro! Não é possível criar objetos a partir de códigos de campo de edição.

$\begin{array}{cc}\text { Vida útil }=50 \text { anos } & \text { Vida útil }=100 \text { anos } \\ 0,85 & 1,0\end{array}$

\subsubsection{Filosofia de dimensionamento}

As estruturas convencionais de concreto armado com barras de aço são dimensionadas segundo a NBR 6118:2003 para que a barra de aço entre em escoamento. Como já foi dito, no capítulo 2, as barras de FRP são desprovidas de escoamento.

\subsubsection{Tipos de ruina}

Em estruturas armadas com FRP são dois os tipos de ruína apresentados:

- Ruptura da barra de FRP;

- Esmagamento do concreto.

A grande variação de rigidez na zona de concreto comprimido, torna a diferença de rigidez entre as seções fissuradas e não-fissuradas muito grande. As tensões de uma seção a outra variam substancialmente, o que demanda muito da capacidade aderente entre o concreto e a barra de FRP. Esta demanda pode levar 0 
elemento à ruína a uma tensão muito menor que a resistência. Uma ruína de esgotamento de aderência.

A ruína balanceada, que inclui os dois tipos é a mais econômica, mas garantir a sua ocorrência é difícil, pois trabalhar com concreto armado é saber diferenciar a teoria e a prática no que se refere ao seu comportamento. Além disso, uma deformação muito alta na armadura tracionada resultaria no colapso do concreto nesta parte do elemento. Portanto, a melhor situação de dimensionamento é a qual a ruína ocorre por esmagamento do concreto na fibra mais comprimida, pois a ruína governada pela ruptura da barra de FRP é extremamente frágil, brusca e repentina.

Como a ruína mais viável e provável no dimensionamento de elementos armados com um tipo de FRP é o esmagamento do concreto, o coeficiente de segurança para minoração da capacidade resistente das barras de $\operatorname{FRP}\left(\gamma_{F R P}\right)$ pode ser dispensável. Uma vez que sua utilização não muda em nada a deformação de um elemento dimensionado dessa forma, podendo até levar o elemento à ruína por outro fenômeno que não a flexão. (FIB TG 9.3-2003).

\subsubsection{Dimensionamento à flexão}

A Figura 3.2 esquematiza o comportamento da seção tranversal. Este trabalho trata apenas de seções transversais retangulares.

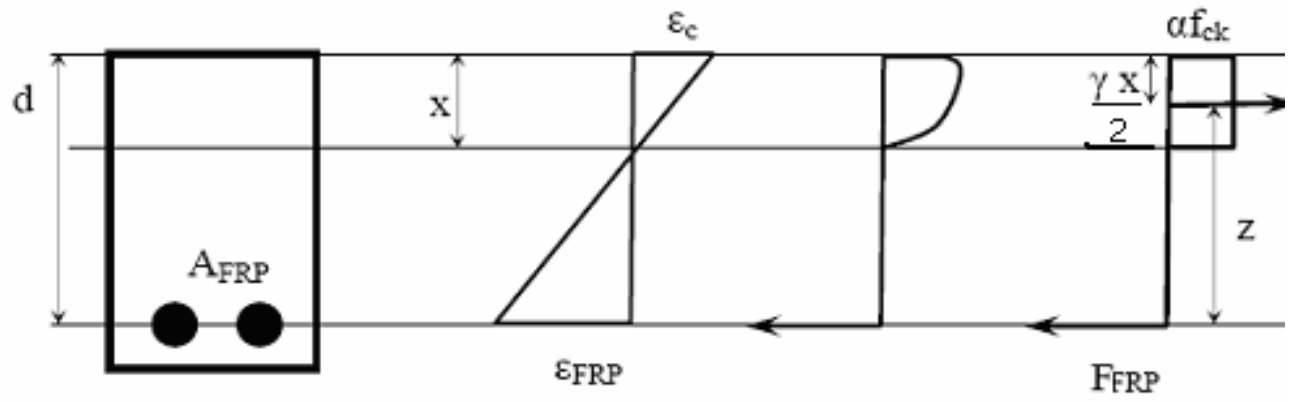

Figura 3.2 - Diagrama de tensão do concreto armado com FRP - Adaptado daFIB 9.3 TG-2003.

Para definir a capacidade resistente do elemento, avalia-se a altura útil do elemento a partir de um cobrimento necessário e do diâmetro das barras. $\mathrm{O}$ dimensionamento é feito considerando que a ruína será ocorrerá por esmagamento do concreto com uma deformação de 3,5\%o, utilizando o máximo possível da capacidade 
resistente de cálculo da barra de FRP, o coeficiente de segurança $\gamma_{F R P}$ é utilizado, sendo necessárias pesquisas afim de confirmar ou não essa utilização.

Seguindo e adaptando o modelo da NBR 6118:2003, vêm:

$$
\begin{aligned}
& y=\gamma \cdot x \\
& \sigma_{c d}=\alpha \cdot f_{c d} \\
& f_{c d=}=\frac{f_{c k}}{\gamma_{c}} \\
& \alpha=-68711 \cdot \varepsilon_{c}^{2}+464,79 \cdot \varepsilon_{c}+0,01 \\
& \gamma=2 \cdot\left(1962,6 \cdot \varepsilon_{c}^{2}+17,89 \cdot \varepsilon_{c}+0,33\right)
\end{aligned}
$$

As equações para cálculo dos parâmetros $\alpha$ e $\gamma$ são propostas por Neocleous (2005), por não se poder comprovar a validade da simplificação proposta pela NBR 6118:2003 e pelo Eurocode 2 do diagrama retangular de tensões na região da seção de concreto comprimido.

\subsubsection{Equação de equilíbrio:}

O equilíbrio das forças horizontais deve ser garantido.

$\sum F_{h}=0$

$R_{c c}=R_{F R P}$

Esse binário de forças gera um momento fletor resistente:

$$
M_{d}=R_{c c} \cdot\left[d-\frac{y}{2}\right]
$$

Sendo:

$R_{c c}=A_{c c} \cdot \sigma_{c d}$

$A_{c c}=b_{w} \cdot y$

$$
R_{c c}=b_{w} \cdot(\gamma \cdot x) \cdot\left(\alpha \cdot \sigma_{c d}\right)
$$

\subsubsection{Equação de compatibilidade das deformações:}

$\frac{\varepsilon_{c c}}{x}=\frac{\varepsilon_{F R P}}{d-x}$

\subsubsection{Cálculo da Posição da linha neutra:}

$$
x=\frac{\varepsilon_{c} \cdot d}{\varepsilon_{F R P}+\varepsilon_{c}}
$$


Considerando a deformação última do concreto 3,5\%:

$x=\frac{3,5 \cdot d}{\varepsilon_{F R P}+3,5}$

\subsubsection{Cálculo da deformação na armadura de FRP:}

Considerando o equilíbrio de forças, substituindo o valor da linha neutra e o valor da força na barra de FRP:

$R_{c c}=R_{F R P}$

$R_{F R P}=\sigma_{F R P} \cdot E_{F R P}$

$R_{F R P}=A_{F R P} \cdot \varepsilon_{F R P} \cdot E_{F R P}$

$\frac{\alpha \cdot f_{c k}\left(\frac{\varepsilon_{c} \cdot d}{\varepsilon_{F R P}+\varepsilon_{c}}\right) \cdot b_{w}}{\gamma_{c}}=A_{F R P} \cdot \varepsilon_{F R P} \cdot E_{F R P}$

Resolvendo para a deformação na armadura:

$\varepsilon_{F R P}^{2}+\varepsilon_{c} \cdot \varepsilon_{F R P}-\frac{\alpha \cdot f_{c k} \cdot b \cdot d \cdot \varepsilon_{c}}{\gamma_{c} \cdot A_{F R P} \cdot E_{F R P}}=0$

Como a ruína é relativa ao esmagamento do concreto, a tensão nas barras da armadura não atinge a capacidade resistente e pode ser determinada por:

$\sigma_{F R P}=\varepsilon_{F R P} \cdot E_{F R P}$

Capacidade resistente da armadura.

$\begin{aligned} f_{F R P d} & =\frac{f_{F R P}}{\gamma_{F R P}} \\ R_{F R P d} & =A_{F R P} \cdot f_{F R P}=A_{F R P} \cdot \varepsilon_{F R P} \cdot E_{F R P}\end{aligned}$

Antes de calcular o braço de alavanca do momento formado pelas forças, é preciso garantir que a tensão na armadura não atingiu a tensão de cálculo.

$\varepsilon_{F R P d}=\frac{f_{F R P}}{E_{F R P}}$

Se a deformação ultrapassar a deformação de cálculo da armadura de FRP, a ruína será governada pela ruptura da barra e a posição da linha neutra e a força na armadura é calculada como segue: 
A força resultante na armadura, é definida com a última.

$R_{F R P d}=A_{F R P} \cdot f_{F R P d}$

As deformações do concreto e da armadura são definidas como as últimas.

$x=\frac{\varepsilon_{c u} \cdot d}{\varepsilon_{F R P d}+\varepsilon_{c u}}$

$x=\frac{3,5 \cdot d}{\varepsilon_{F R P d}+3,5}$

A força resultante no concreto resulta em:

$R_{c c}=\frac{\alpha \cdot f_{c k}\left(\frac{3,5 \cdot d}{\varepsilon_{F R P d}+3,5}\right) \cdot b_{w}}{\gamma_{c}}$

\subsubsection{Cálculo do braço de alavanca e do momento resistente.}

Se a deformação for menor que o limite de cálculo, a posição da resultante das tensões na área de concreto comprimido pode ser calculada e, conseqüentemente, o braço de alavanca é determinado.

$z=d-\frac{y}{2}$

Finalmente o momento resistente pode ser calculado, para os dois tipos de ruína.

$M_{u}=R_{c c} \cdot z$

$M_{u}=R_{F R P d} \cdot z$

3.1.3.6 Análise dos diagramas de deformação para os casos propostos de dimensionamento.

Como se pode observar na Figura 3.3, existe grande semelhança no dimensionamento entre o proposto pela FIB TG 9.3-2003 e o proposto para estruturas de concreto armado convencionais pela NBR 6118:2003, podendo, portanto, ser adotado este procedimento adaptado a partir das duas. Existe ainda a necessidade de comprovação científica, pois, elementos armados com armaduras metálicas vêm sendo estudados a mais de um século, e ainda existem áreas nas quais o seu comportamento é uma incógnita, extrapolando para o comportamento de elementos armados com FRP que remontam a estudos de o mais tardar 10 anos, fica clara esta necessidade. 


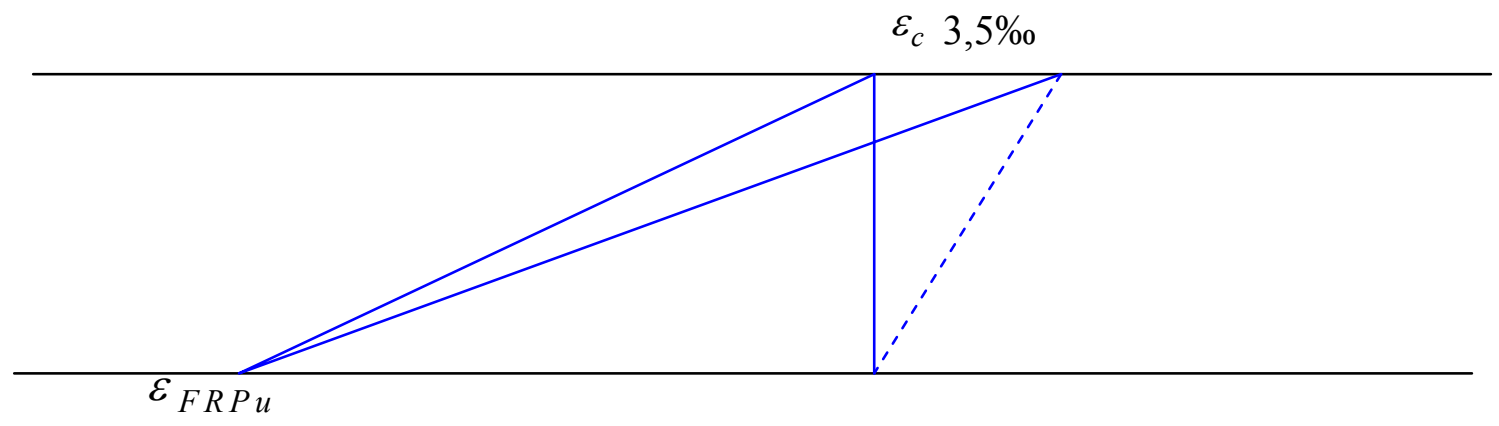

Figura 3.3 Diagrama de deformações

\subsection{ELS}

A verificação para os limites de serviço não pode ser a mesma para elementos armados em aço e FRP. A diferença de rigidez entre esses materiais torna o comportamento em serviço diferente. Para elementos de concreto iguais armados com a mesma área de armadura de aço e FRP, após o carregamento o elemento armado com barras de FRP apresentará uma maior deformação e maior abertura de fissuras (Gao, Benmokrane e Masmoudi 1998a e Theriault, Benmokrane e Gao 1998).

\subsubsection{Fissuração}

Adaptando a equação proposta pelo $\mathrm{ACl}$ 440.1R-03 que considera a capacidade aderente das barras de FRP.

$$
\begin{aligned}
& w=\frac{2,2}{E_{F R P}} \cdot \gamma \cdot k_{b} \cdot f_{F R P} \cdot \sqrt[3]{d^{\prime} \cdot A_{c c}} \text { (MPa e mm) } \\
& k_{b} \rightarrow \text { aderência } \\
& k_{b}=1,0 \text { (aço) } \\
& k_{b}<1,0 \text { (aderência maior que a de barras de aço) } \\
& k_{b}>1,0 \text { (aderência menor que a de barras de aço) } \\
& k_{b}=1,2 \text { (quando o valor de } k_{b} \text { for desconhecido). }
\end{aligned}
$$

\subsubsection{Deformação}

\subsubsection{Momento de inércia efetivo}

Após a deformação o elemento de concreto armado muda a sua rigidez: 


$$
\begin{aligned}
& I_{c r}=\frac{b_{w} \cdot d^{3}}{3} \cdot k^{3}+\alpha_{e} \cdot A_{F R P} \cdot d^{2} \cdot(1-k)^{2} \\
& k=\sqrt{2 \cdot \rho \cdot \alpha_{e}+\left(\rho \cdot \alpha_{e}\right)^{2}}-\rho \cdot \alpha_{e}
\end{aligned}
$$

$\mathrm{ACl} 440.1 \mathrm{R}-03$

O elemento é parcialmente fissurado, o seu comportamento muda ao longo do comprimento de acordo com a magnitude do esforço solicitante. A rigidez equivalente pode ser calculada pelas expressões adaptadas por Gao, Benmokrane e Masmoudi (1998) da fórmula de Branson utilizada para o concreto.

$$
\begin{aligned}
& I_{e}=\left(\frac{M_{c r}}{M_{a}}\right)^{3} \cdot I_{g} \cdot \beta_{d}+\left[1-\left(\frac{M_{c r}}{M_{a}}\right)^{3}\right] \cdot I_{c r} \leq I_{g} \\
& \beta_{d}=\alpha_{b} \cdot\left[\frac{E_{f}}{E_{s}}+1\right]
\end{aligned}
$$

sendo $\alpha_{b}=0.5$ quando não se conhece o valor real do parâmetro de aderência.

\subsubsection{Cálculo da deformação}

As deformações são divididas em:

- Deformação imediata $\left(\varepsilon_{i}\right)$

$\varepsilon_{i}=\frac{\sigma}{E}$

- Deformação de longo termo

$\varepsilon_{\left(c_{p}+s_{h}\right)}=0,6 \cdot\left(\varepsilon_{i}\right)$ é o valor recomendado pelo $\mathrm{ACI} 440.1 \mathrm{R}-03$. 


\section{INVESTIGAÇÃO}

\section{EXPERIMENTAL}

\subsection{DEFINIÇÃO DAS VARIÁVEIS}

A investigação experimental realizada neste trabalho foi viável, apesar do curto espaço de tempo do mestrado, em virtude do ensaio de flexão de quatro pontos tratarse de um ensaio frequentemente realizado no Laboratório de Estruturas - EESC USP.

O pórtico metálico de capacidade de $100 \mathrm{kN}$ em cada apoio, (Figura 4.1) já havia sido utilizado em outros ensaios de flexão de quatro pontos, sendo apenas necessária a sua correta fixação. 

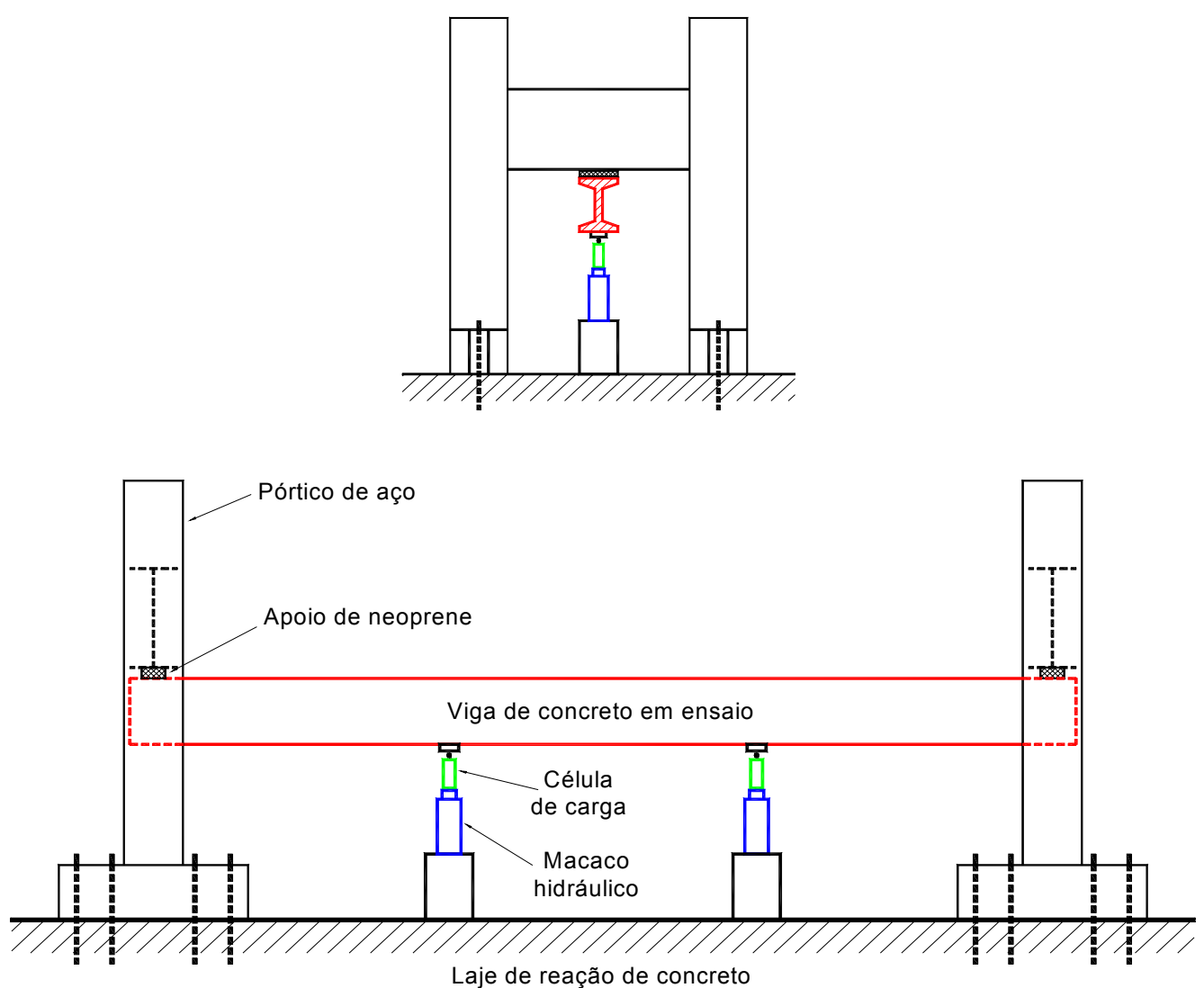

Figura 4.1 - Esquema do dispositivo de ensaio - Adaptado da apresentação do ensaio de vigas (Prof. Takeya).

Neste trabalho foram ensaiados seis modelos à flexão em quatro pontos, um armado com armadura metálica de aço CA-50, e os outros cinco com a barra de GFRP Aslam 100. Dois modelos de vigas armadas com GFRP (V-05 e V-06), tiveram suas barras detalhadas em ponta reta nas extremidades, sem gancho portanto, para efeito de comparação com as vigas armadas com a mesma quantidade de armadura (V-03 e V-04). As vigas de GFRP foram armadas igualando-se a capacidade resistente (V-02, V-03, V-05) e a deformação última (V-04 e V-06) da viga de concreto armada com aço (V-01). Dessa forma é analisado o comportamento das vigas armadas com GFRP sob o aspecto da deformação e da resistência.

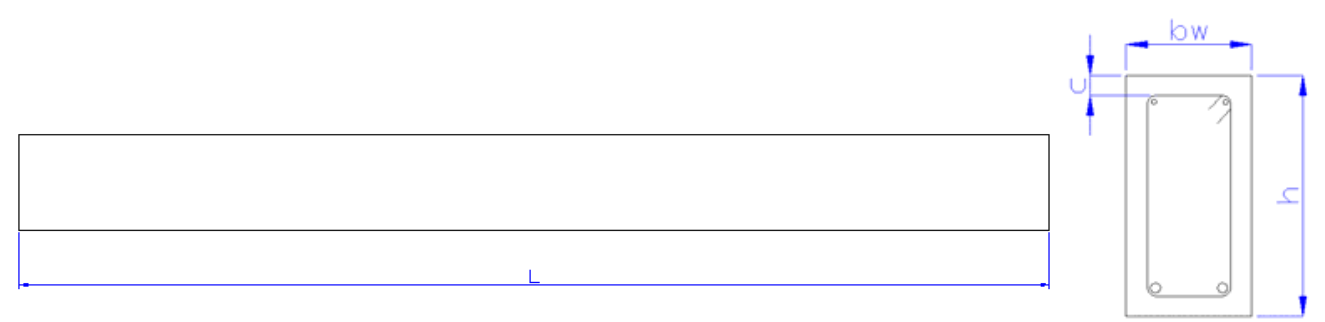

Figura 4.2 - Propriedades geométricas dos modelos e nomenclatura. 
Tabela 4.1 Propriedades geométricas dos modelos.

\begin{tabular}{|l|l|l|l|}
\hline $\mathbf{L}(\mathbf{c m})$ & $\mathbf{h}(\mathbf{c m})$ & $\mathbf{b}_{\mathrm{w}}(\mathbf{c m})$ & $\mathbf{c}(\mathbf{c m})$ \\
\hline 305 & 30 & 15 & 2,5 \\
\hline
\end{tabular}

Os modelos físicos construídos para esta pesquisa tiveram sua geometria definida como mostra a Tabela 4.1 e Figura 4.2, baseados em vigas comuns em edifícios de concreto armado. $O$ intuito de esta escolha partir de um elemento estrutural simples, avaliando todos os aspectos do comportamento das armaduras de GFRP e, em pesquisas posteriores, aumentar o grau de complexidade do elemento.

A viga de referência foi dimensionada adotando-se duas barras de $12,5 \mathrm{~mm}$ de diâmetro aço CA-50, definindo assim sua capacidade resistente. Os estribos foram adotados de maneira igual em todos os modelos: estribos de $8 \mathrm{~mm}$ de diâmetro a cada $13 \mathrm{~cm}$ ao longo de todas as vigas. A armadura de cisalhamento foi dimensionada para garantir que a ruptura do elemento seria em virtude das solicitações normais.

\subsection{DIMENSIONAMENTO E DETALHAMENTO DAS}

\section{ARMADURAS.}

\subsubsection{Dimensionamento}

O dimensionamento das armaduras longitudinais das vigas de concreto de GFRP foi determinado a partir das propriedades das barras da viga de concreto armada com aço CA-50.

A capacidade resistente desta viga foi determinada utilizando-se as equações de equilíbrio e de compatibilidade de deformações. A diferença de um dimensionamento comum foi o fato de a armadura ter sido adotada e partindo dela fora calculada a capacidade resistente, e não o processo inverso que é o usual.

As vigas dimensionadas para resistir ao mesmo momento fletor que a viga armada com barras de aço foram definidas partindo do momento último encontrado para a viga de referência utilizando-se as equação de equilíbrio e a compatibilidade de deformações enunciadas no capítulo III. Para avaliar melhor o comportamento das barras de GFRP foram definidos dois arranjos de armaduras, uma utilizando apenas a bitola de maior valor e a outra utilizando apenas a bitola de menor valor. 
Além de igualar as capacidades resistentes das vigas, para as vigas $\mathrm{V} 04$ e $\mathrm{V}$ 06 foi igualada a deformação última do aço: $10 \%$. O processo descrito no capítulo III foi então empregado, com a particularidade de se conhecer apenas a deformação requerida e não a capacidade resistente ou a distribuição da armadura. Nestas vigas foram utilizadas ambas as bitolas tendo-se assim todas as possibilidades de detalhamento com essas duas bitolas cobertas.

Quanto a ação de força cortante as vigas foram dimensionadas, adotando-se como armadura estribos de barras de aço CA-50 de $8 \mathrm{~mm}$ distribuídos a cada $13 \mathrm{~cm}$, para garantir a ruína por ação de momento fletor.

\subsubsection{Detalhamento}

A Figura 4.3 apresenta o detalhamento de cada um dos seis modelos, incluindo os tipos de armadura, dimensionamento e quantidade de armadura. 


\section{VIGA 01}

300

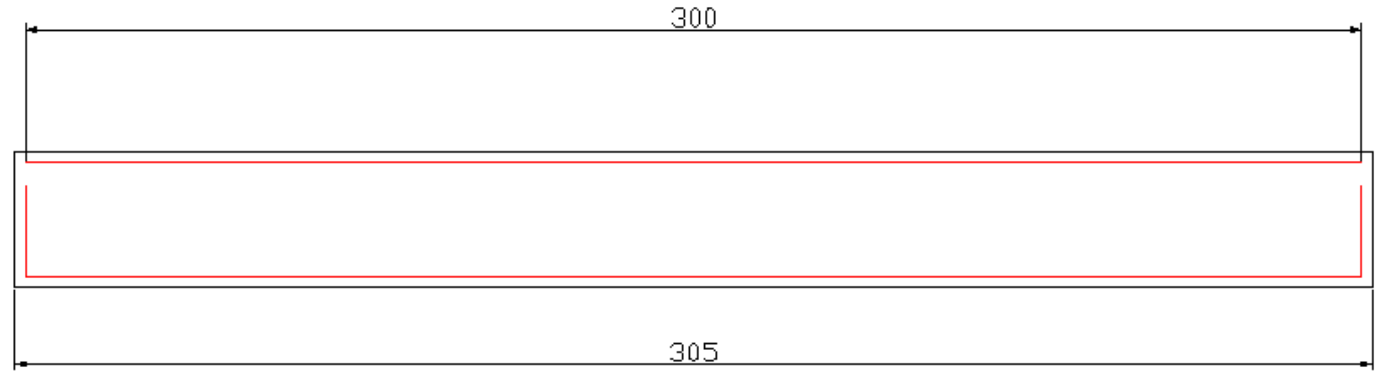

$\mathrm{N1} \varnothing 12,5 \mathrm{~mm}$ c/ $340 \mathrm{~cm}$

N2 $\varnothing 6,3 \mathrm{~mm}$ c/ $300 \mathrm{~cm}$

300
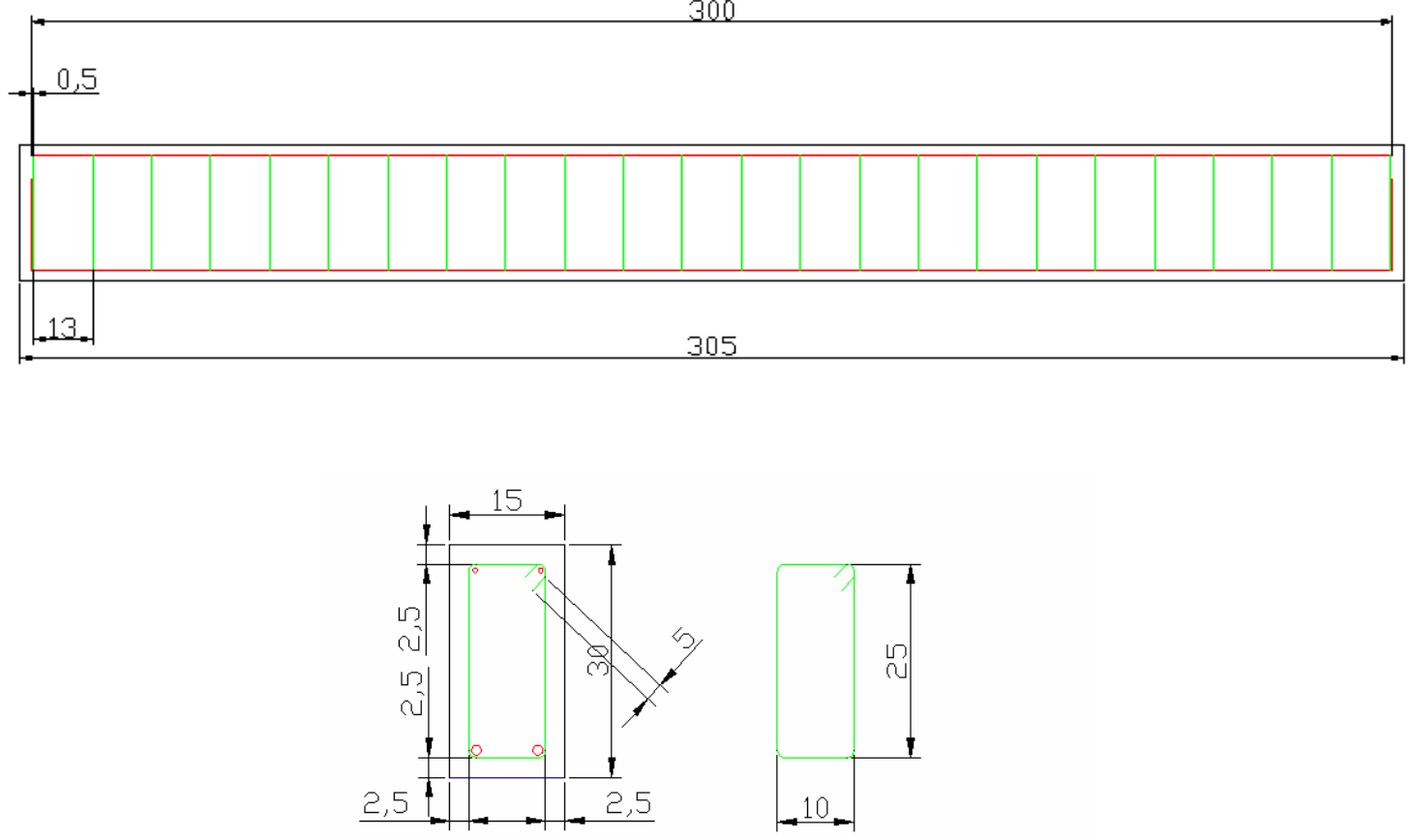

$N 3 \varnothing 8 \mathrm{~mm} c / 13 \mathrm{~cm} c=80 \mathrm{~cm}$

\begin{tabular}{|l|l|}
\hline Tipo de armadura & Aço CA-50 \\
\hline Tipo de dimensionamento & Viga de referência \\
\hline Quantidade de armadura longitudinal & $2 \Phi 12,5 \mathrm{~mm}$ \\
\hline
\end{tabular}




\section{VIGA 02}
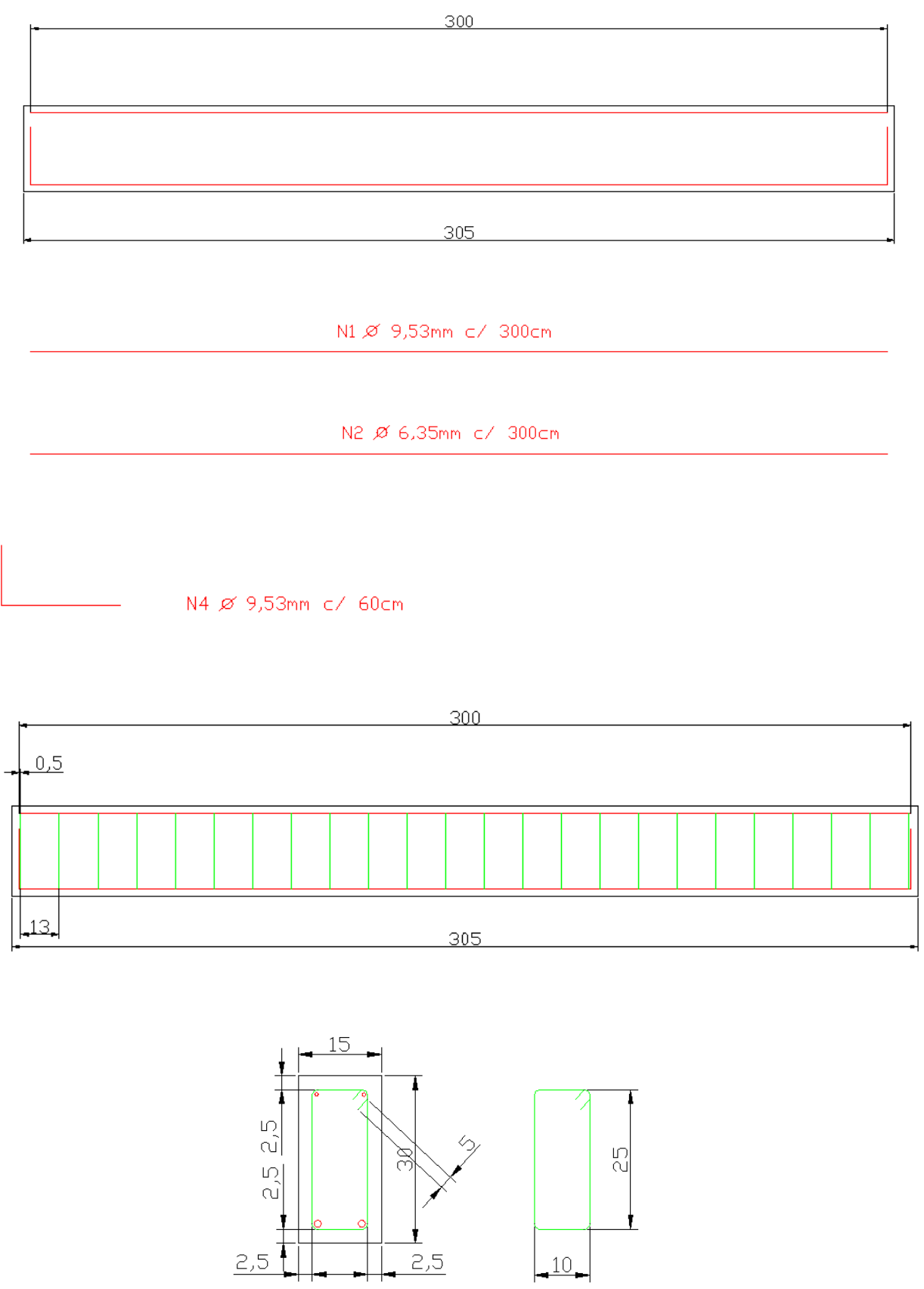

N3 $\varnothing 8 \mathrm{~mm} \subset / 13 c m \subset=80 c m$

\begin{tabular}{|l|l|}
\hline Tipo de armadura & GFRP- Aslam 100 \\
\hline Tipo de dimensionamento & Capacidade resistente \\
\hline Quantidade de armadura longitudinal & $2 \Phi 9,53 \mathrm{~mm}$ \\
\hline
\end{tabular}


VIGA 03

300

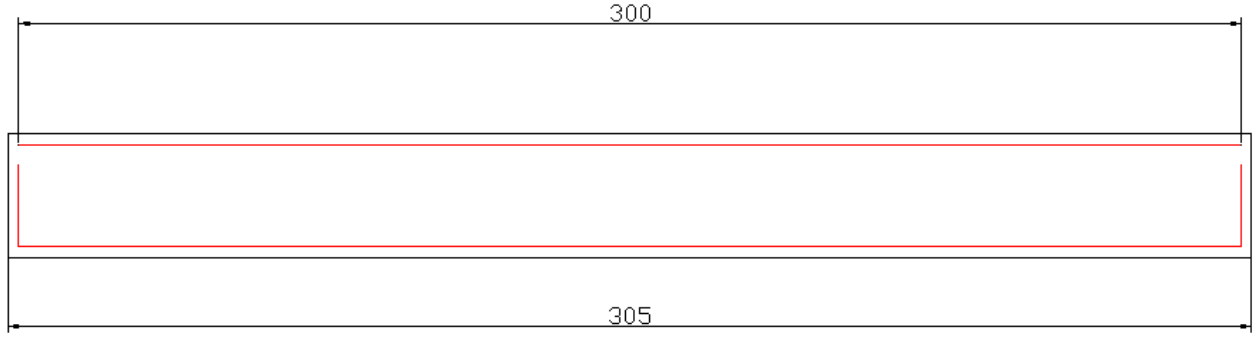

N1 $\varnothing 6,35 \mathrm{~mm} \mathrm{c/} 300 \mathrm{~cm}$
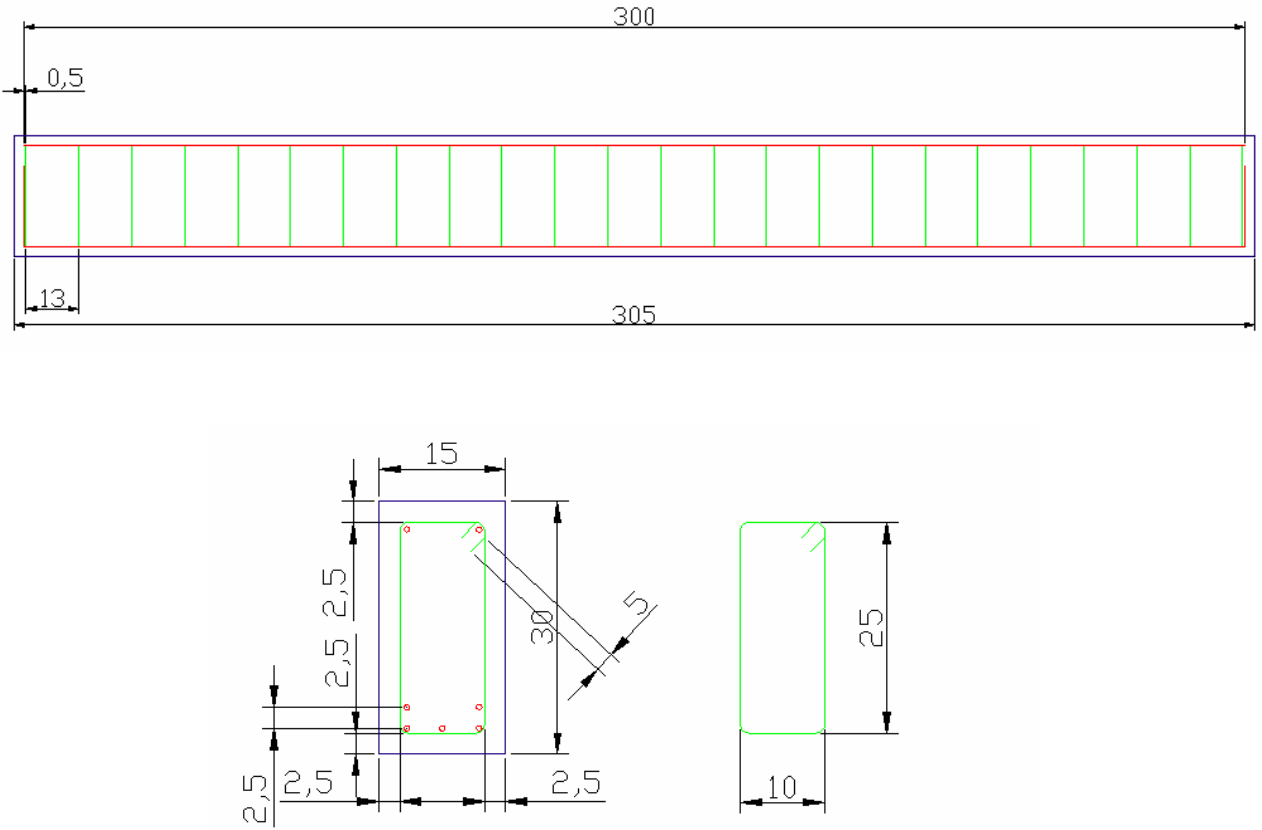

N3 $\varnothing 8 m m \subset / 13 \sqsubset m \quad c=80\llcorner m$

\begin{tabular}{|l|l|}
\hline Tipo de armadura & GFRP- Aslam 100 \\
\hline Tipo de dimensionamento & Capacidade resistente \\
\hline Quantidade de armadura longitudinal & $5 \Phi 6,35 \mathrm{~mm}$ \\
\hline
\end{tabular}




\section{VIGA 04}

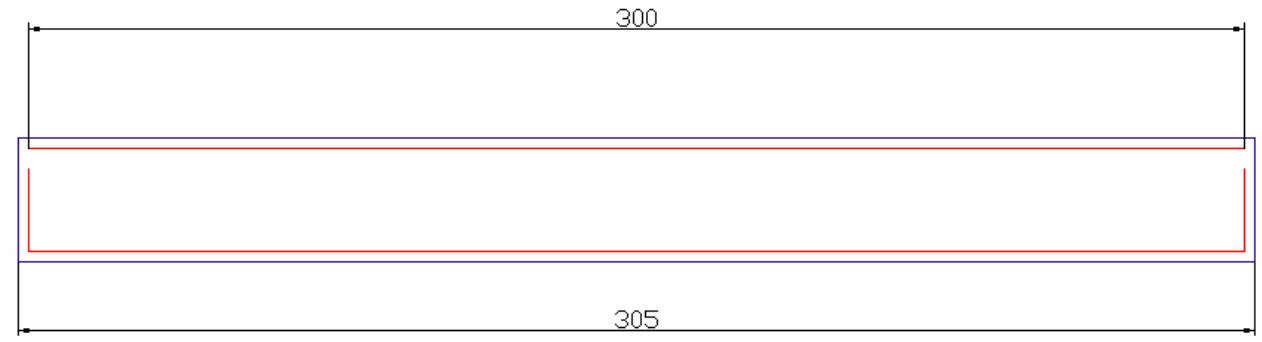

N1 $\varnothing 9,53 \mathrm{~mm} \subset / 300 c m$

Ne $\varnothing 6,35 \mathrm{~mm}$ c/ $300 \mathrm{~cm}$
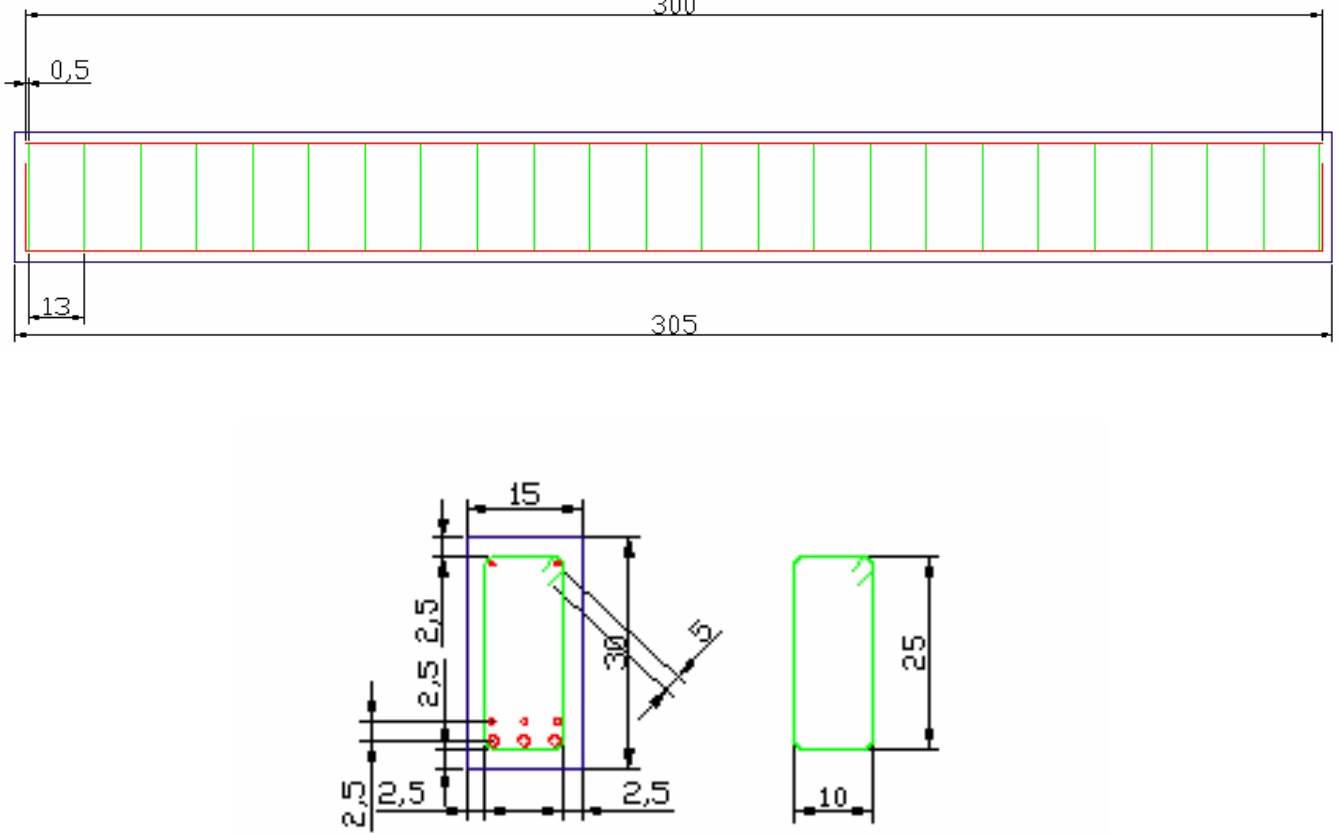

$$
\text { N4, } 8 \mathrm{~mm} \sqsubset / 13 \mathrm{~cm} c=80 \mathrm{~cm}
$$

\begin{tabular}{|l|l|}
\hline Tipo de armadura & GFRP- Aslam 100 \\
\hline Tipo de dimensionamento & Deformação específica \\
\hline Quantidade de armadura longitudinal & $3 \Phi 9,53 \mathrm{~mm}$ \\
& $3 \Phi 6,35 \mathrm{~mm}$ \\
\hline
\end{tabular}




\section{VIGA 05}
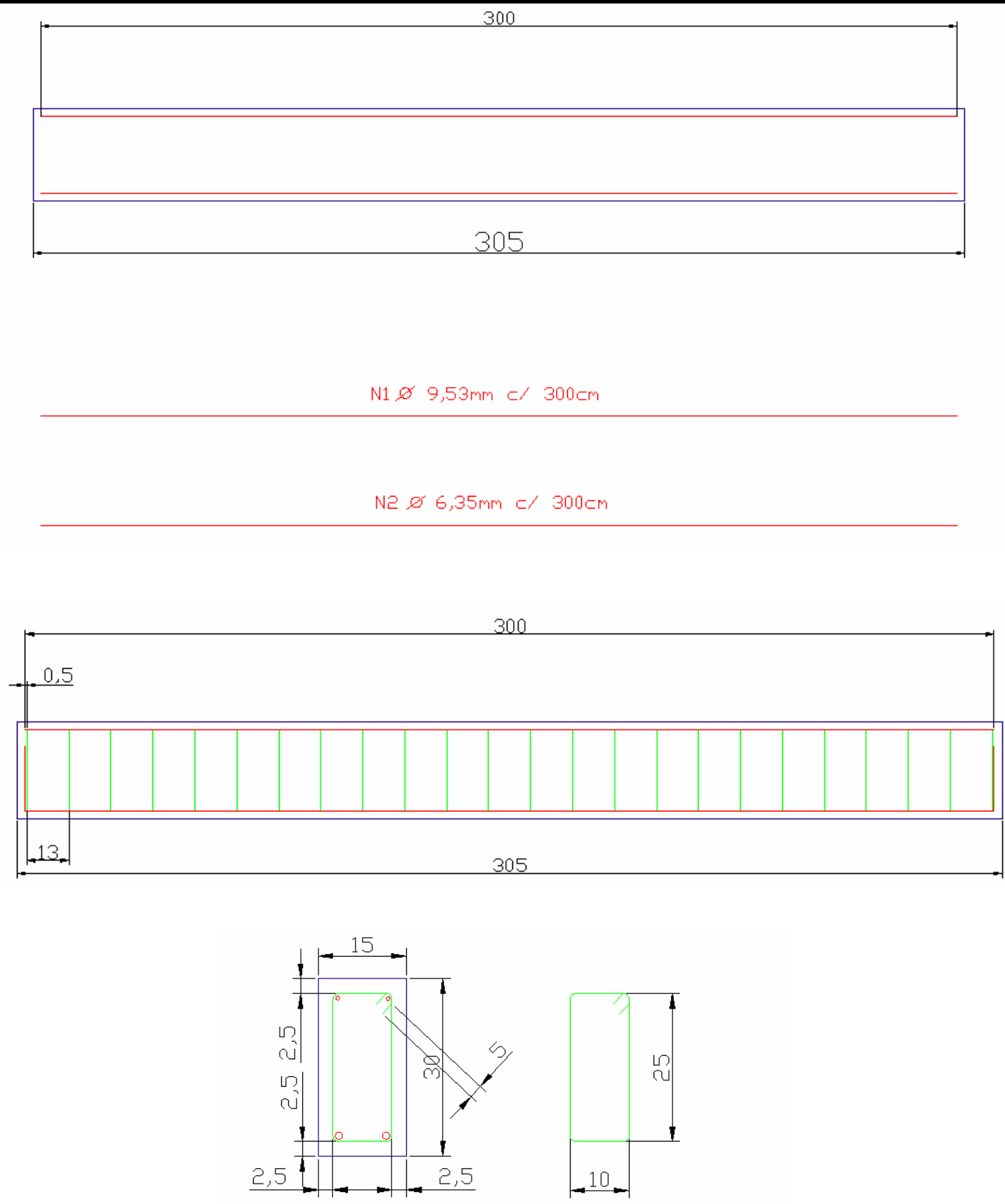

\section{N3ø 8mm ᄃ/ 13сm $ᄃ=80 \subset m$}

Tipo de armadura

Tipo de dimensionamento

Quantidade de armadura longitudinal
GFRP- Aslam 100

Capacidade resistente

$2 \Phi 9,53 \mathrm{~mm}$ 


\section{VIGA 06}

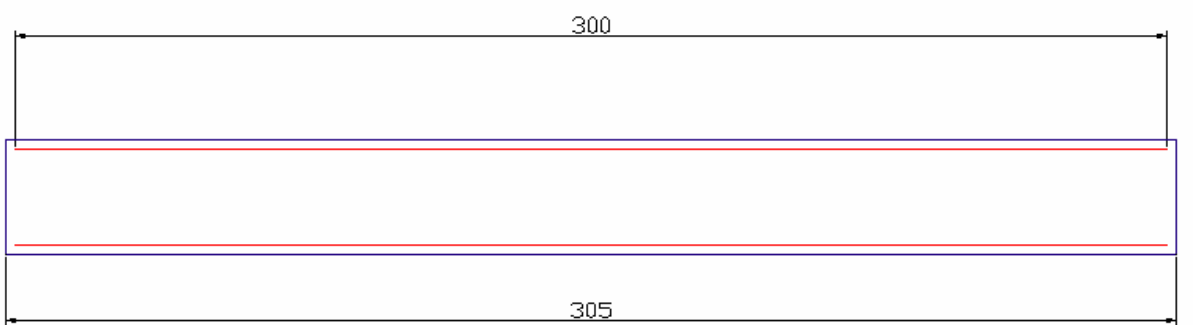

$\mathrm{N} 1 \not \varnothing \quad 9,53 \mathrm{~mm} \quad \mathrm{c} / 300 \mathrm{~cm}$

$\mathrm{N} 2 \not \varnothing 6,35 \mathrm{~mm}$ c/ $300 \mathrm{~cm}$
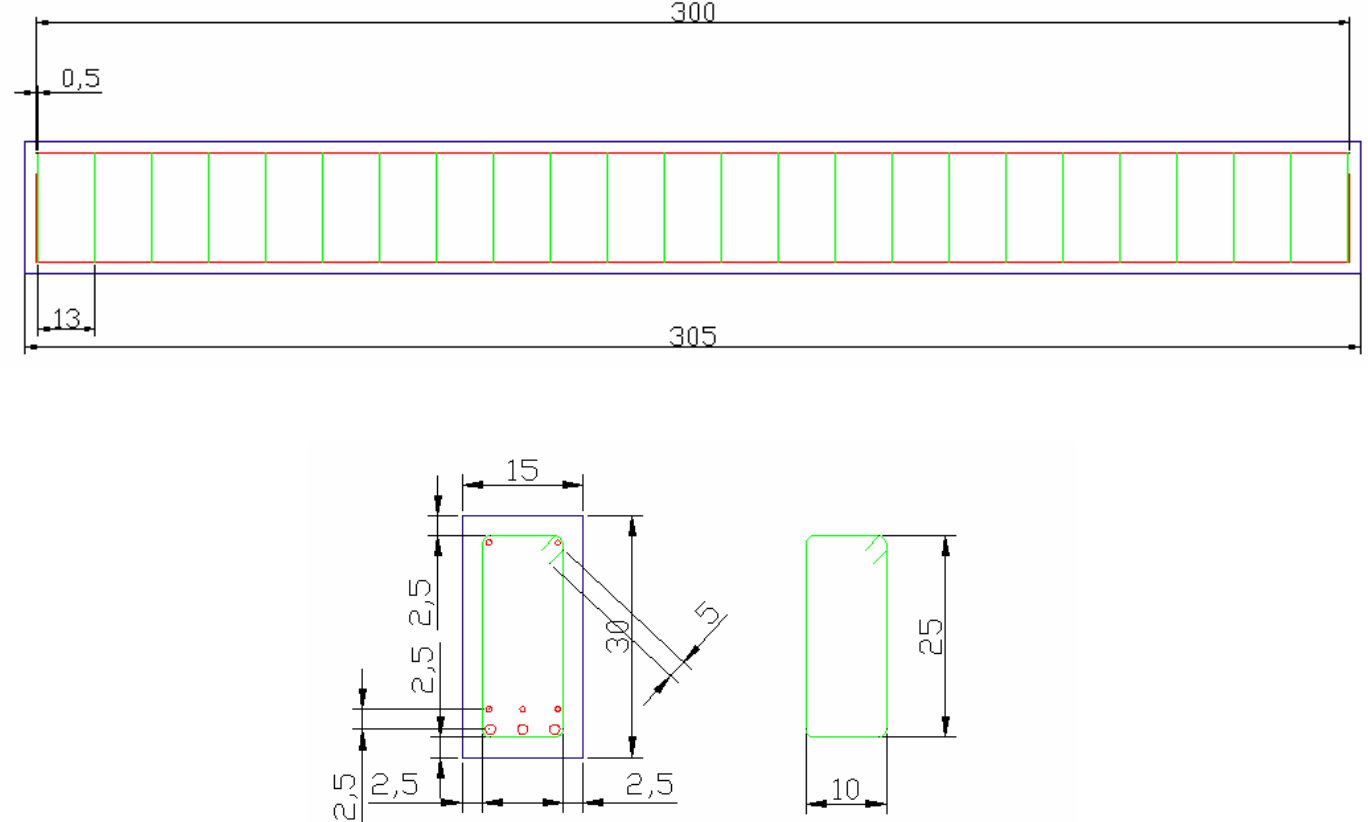

N4 $\varnothing 8 \mathrm{~mm} \subset c^{\prime} 13 \sqsubset \mathrm{cm} c=80 \mathrm{~cm}$

\begin{tabular}{|l|l|}
\hline Tipo de armadura & GFRP- Aslam 100 \\
\hline Tipo de dimensionamento & Viga de referência \\
\hline Quantidade de armadura longitudinal & $3 \Phi 9,53 \mathrm{~mm}$ \\
& $3 \Phi 6,35 \mathrm{~mm}$ \\
\hline
\end{tabular}

Figura 4.3 - Detalhamento dos modelos 


\subsection{PROGRAMA EXPERIMENTAL}

A seguir estão enumeradas as etapas da realização do programa experimental deste trabalho:

a) Montagem de duas fôrmas de madeira para as vigas;

b) Definição do traço do concreto por meio da realização de um estudo de traço;

c) Instrumentação das armaduras longitudinais das vigas e dos ganchos de GFRP e montagem da armaduras das vigas;

d) Moldagem das vigas;

e) Montagem do pórtico de reação;

f) Ensaio das seis vigas;

g) Ensaio dos corpos-de-prova do concreto das vigas;

h) Ensaio das barras de GFRP.

\subsubsection{Instrumentação}

Como o objetivo da pesquisa é analisar o comportamento de vigas armadas com GFRP, foram colocados extensômetros de modo a avaliar as deformações apenas nas barras longitudinais das vigas submetidas à tração. Para medir os deslocamentos dos modelos foram utilizados transdutores de deslocamento nas extremidades e no centro dos modelos. Na Figura 4.4 indica-se o posicionamento dos extensômetros e dos transdutores nos modelos. A Figura 4.5 mostra o significado da simbologia adotada. 


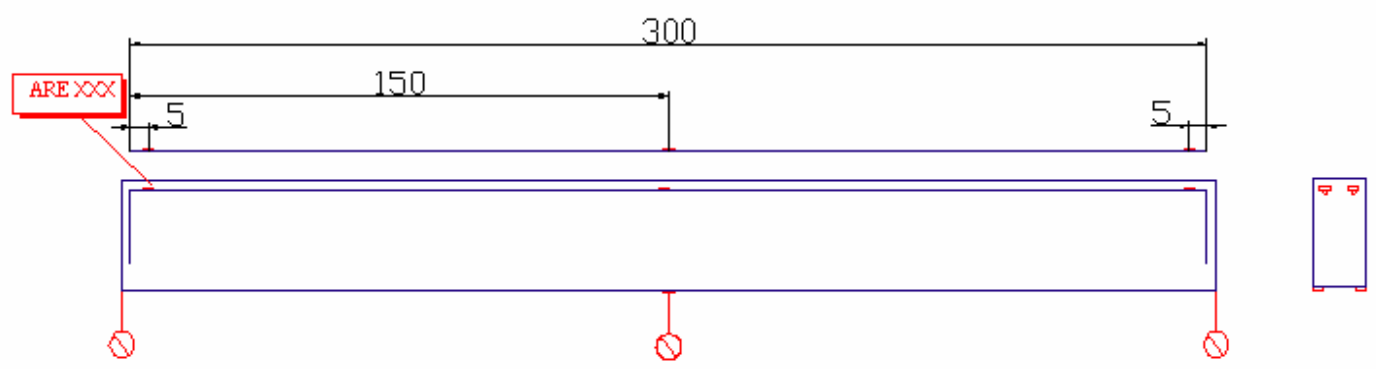

Figura 4.4 - Localização dos extensômetros e transdutores

\section{ARE123}

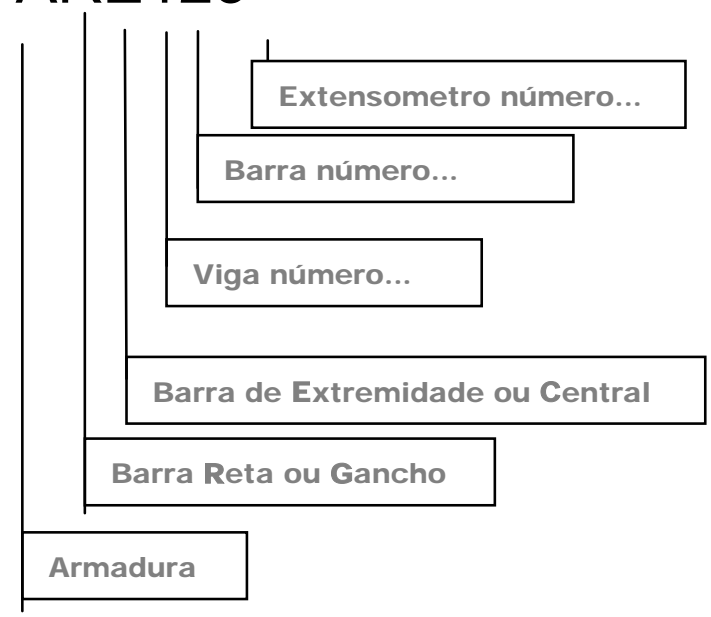

Figura 4.5 - Nomenclatura dos extensômetros

As barras longitudinais foram instrumentadas de modo a medir os deformações da região central e das extremidades das barras. No caso das vigas armadas com ganchos, estes também foram instrumentados como mostra a Figura 4.6.

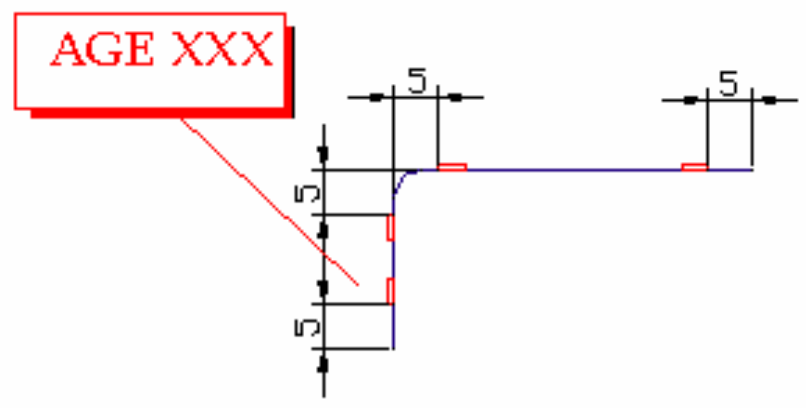

Figura 4.6 Localização dos extensômetros nos ganchos. 
A Tabela 4.2 especifica a quantidade de extensômetros e transdutores para cada modelo.

Tabela 4.2 - Quantidade de extensômetros dos modelos.

\begin{tabular}{l|lll}
\hline & Transdutores & $\begin{array}{l}\text { Extensômetros } \\
\text { Barras }\end{array}$ & $\begin{array}{l}\text { Extensômetros } \\
\text { Ganchos }\end{array}$ \\
\hline Viga 01 & 03 & 06 & - \\
Viga 02 & 03 & 03 & 04 \\
Viga 03 & 03 & 06 & 04 \\
Viga 04 & 03 & 09 & 04 \\
Viga 05 & 03 & 03 & - \\
Viga 06 & 03 & 09 & - \\
\hline
\end{tabular}

\subsubsection{Construção dos elementos e montagem dos protótipos}

A Figura 4.7 ilustra as principais etapas de construção dos seis modelos e a montagem dos protótipos.

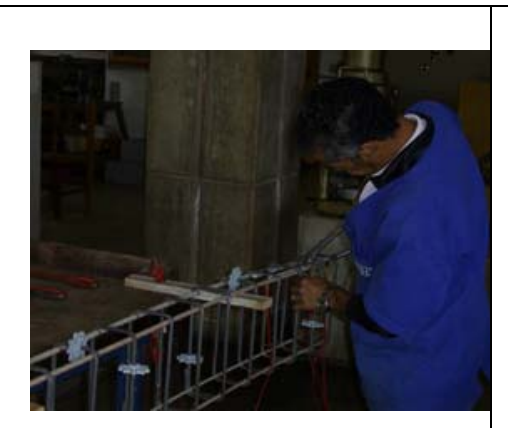

a) Montagem das armaduras

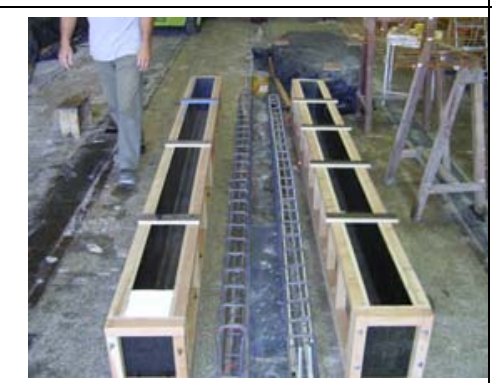

d) Fôrmas e vigas armadas

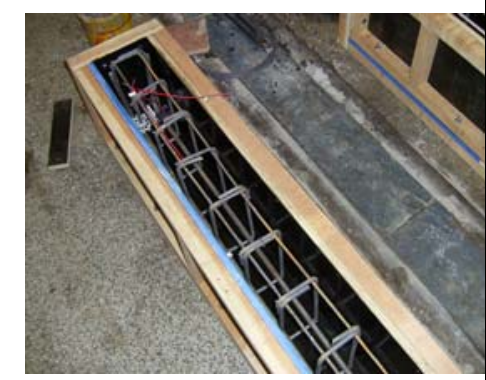

g) Inserção do modelo na fôrma

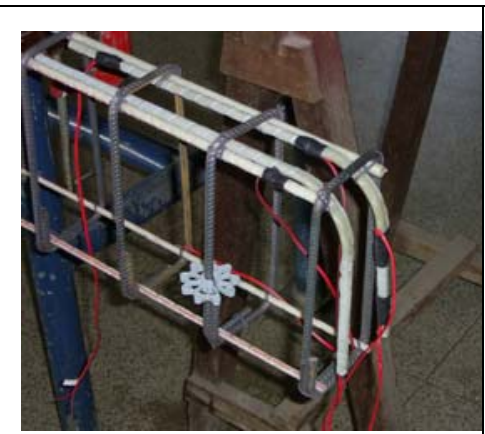

b) Colocação dos ganchos

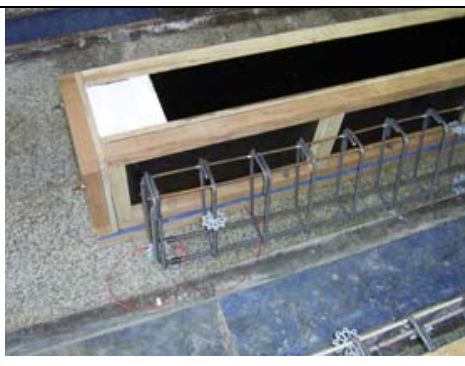

e) Colocação do polipropileno na extremidade da fôrma

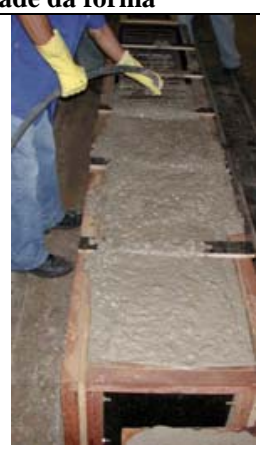

h) Concretagem da viga

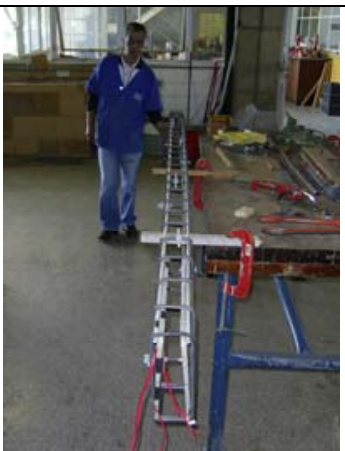

c) Vigas montadas

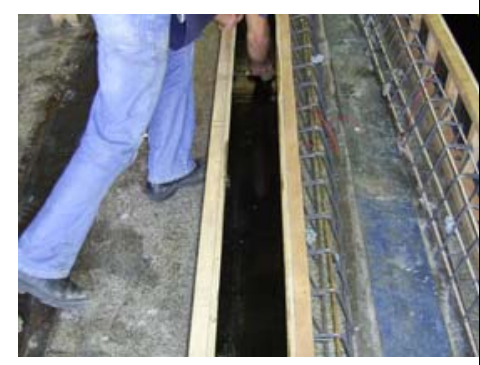

f) Aplicação do desmoldante

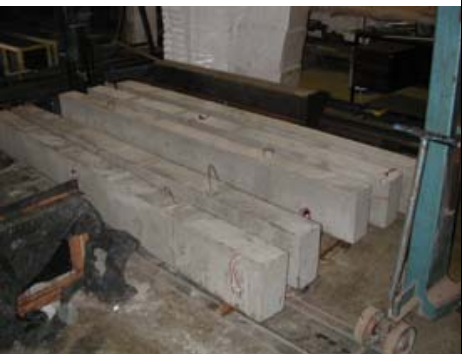

i)Armazenamento dos modelos 


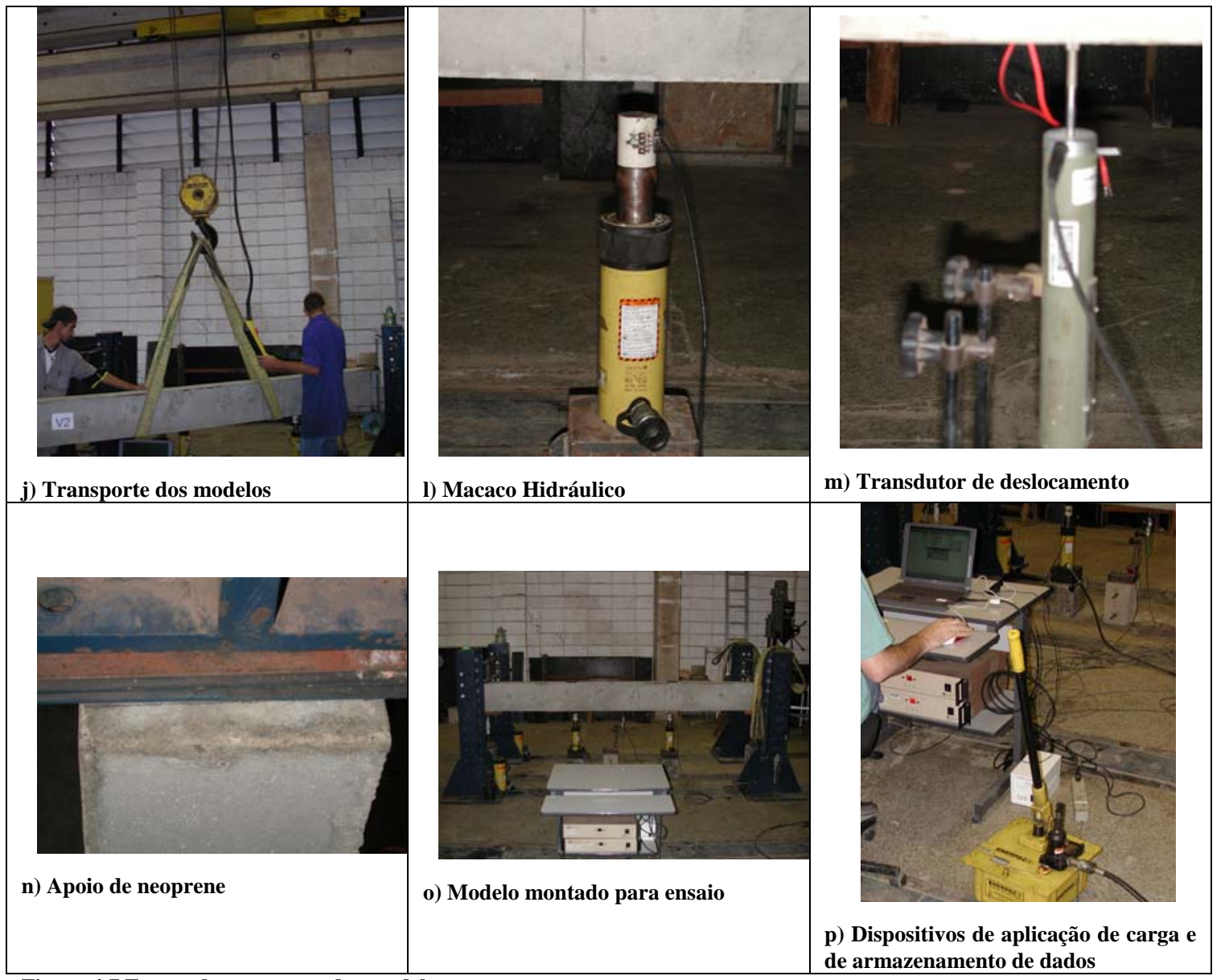

Figura 4.7 Etapas de montagem dos modelos de armazenamento de dados

As fôrmas foram executadas em madeira compensada de $18 \mathrm{~mm}$ de espessura montadas com caibros. As vigas foram concretadas na posição horizontal, e armazenadas apoiadas em três pontos.

Na Figura 4.8 pode-se observar o posicionamento dos pontos de aplicação das forças e a localização dos apoios nos modelos.

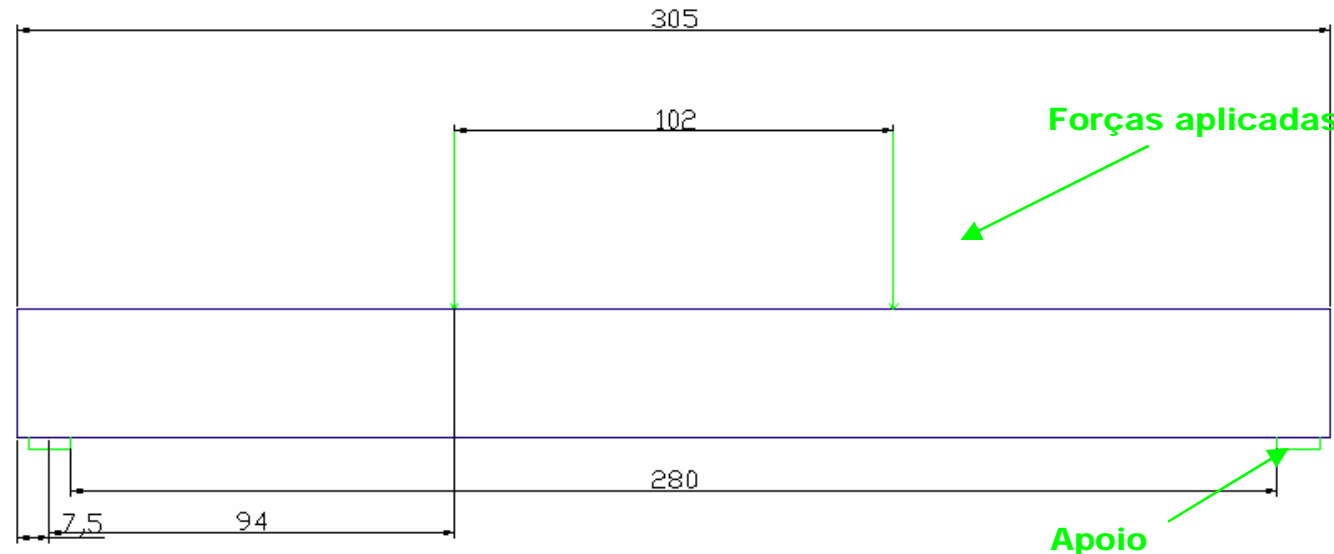

Figura 4.8 Localização dos pontos de apoio e de aplicação das forças nos modelos 


\subsubsection{Propriedades dos materiais}

\subsubsection{Concreto}

1) Estudo de traço

Para moldagem das vigas, foi adotado um concreto com resistência característica $f_{c j}=40 M P a$ e, portanto, foi realizado um estudo de traço com os materiais empregados. Este estudo foi realizado baseando-se nas diretrizes do livro Manual de dosagem e controle do concreto (HELENE e TERZIAN 1993). A Figura 4.9 mostra algumas das etapas para realização do estudo de traço do concreto para as vigas.

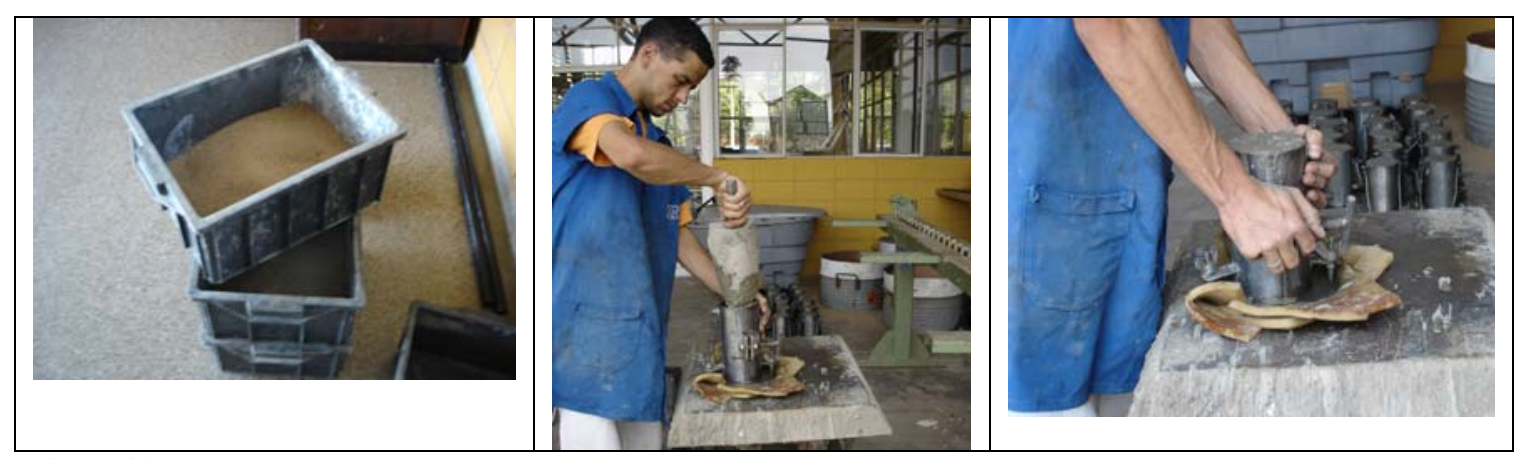

Figura 4.9 Moldagem dos corpos-de-prova

O teor de argamassa inicialmente adotado foi de 50\%, definindo dessa forma os traços normal, rico e pobre. Na Tabela 4.3 pode-se observar os traços adotados para realização do estudo.

Tabela 4.3 Traços adotados

\begin{tabular}{lc}
\hline Teor de argamassa & $50 \%$ \\
\hline traço 1:5,0 & $1: 2: 3$ \\
\hline traço 1:3,5 & $1: 1,26: 2,24$ \\
\hline traço $1: 6,5$ & $1: 2,76: 3,74$ \\
\hline
\end{tabular}

Foram ensaiados três corpos-de-prova para cada traço aos 3, 7, 14 e 28 dias. 


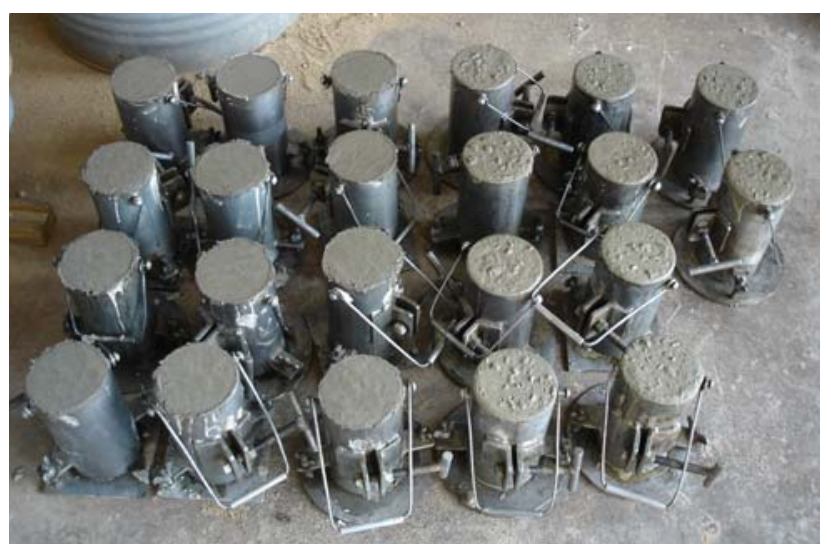

Figura 4.10 Corpos-de-prova de todos os traços

\section{2) Concreto das vigas}

Como se tratavam de duas fôrmas foram realizadas 3 séries de concretagem e para cada uma foram moldados seis corpos-de-prova, três para cada amassada na betoneira, para definição quanto à resistência à compressão, tração e o módulo de elasticidade. O ensaio de compressão, tração por compressão diametral e módulo de elasticidade foram realizados segundo diretrizes das normas NBR 5739:1994, NBR 7222: 1983 e NBR 8522: 1983 respectivamente. Na Figura 4.11 pode-se observar os corpos-de-prova prontos para a realização dos ensaios para definição do concreto das vigas.

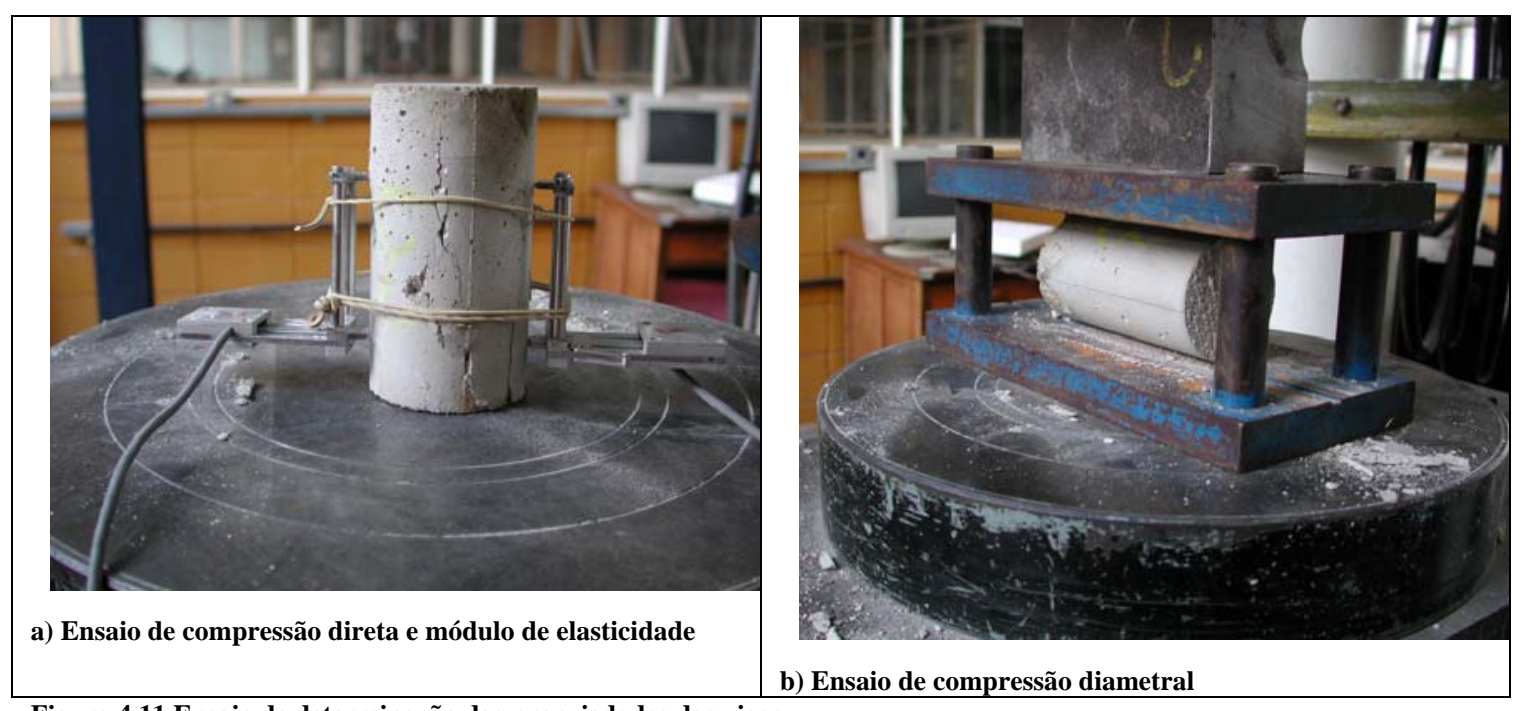

Figura 4.11 Ensaio de determinação das propriedades das vigas 


\subsubsection{Armaduras}

\section{1) Aço CA-50}

Como já foi mencionado, foram utilizadas barras de aço CA-50 de 12,5 mm, 6,3 $\mathrm{mm}$ e $8 \mathrm{~mm}$ e barras de GFRP de 9,53mm e $6,35 \mathrm{~mm}$.

As propriedades das barras de aço foram obtidas por meio de ensaio de tração direta. Para cada diâmetro de armadura, utilizaram-se três corpos-de-prova para análise das propriedades das barras. O ensaio foi realizado no equipamento INSTROM, seguindo a norma NBR 6349:1991. Na Figura 4.12 é possível observar os equipamentos utilizados na determinação das propriedades das barras de aço e a ruptura de um dos corpos-de-prova.

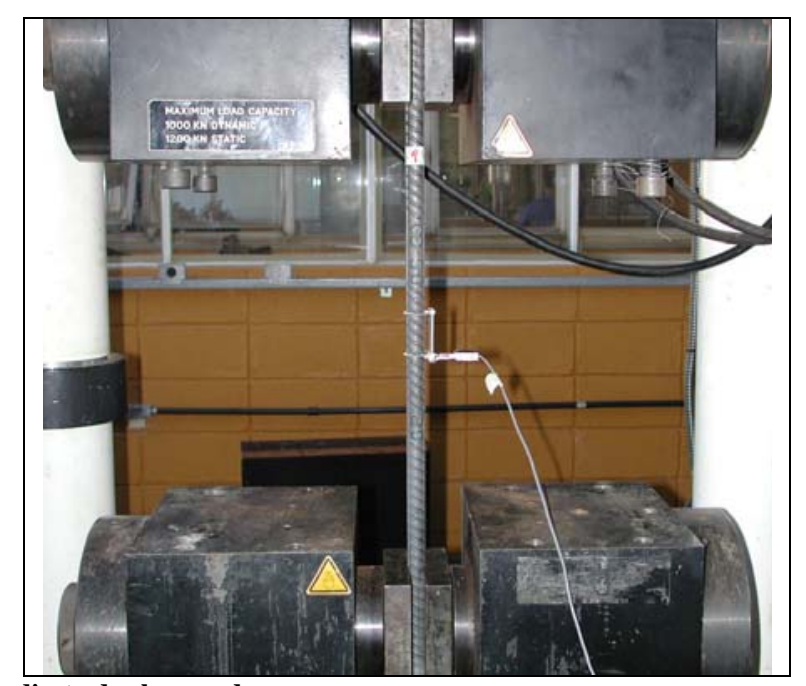

Figura 4.12 Ensaio de tração direta das barras de aço

2) GFRP - Aslam 100

As barras de GFRP foram fornecidas pela Hughes Brothers, sendo as propriedades mecânicas informadas pela empresa e apresentadas na Tabela 4.4. 
Tabela 4.4 Propriedades das barras de GFRP fornecidas pelo fabricante Huge Bro. Aslam 100.

\begin{tabular}{c|c|c|c|c}
$\begin{array}{c}\text { Diâmetro } \\
\text { da barra } \\
(\mathbf{m m})\end{array}$ & $\begin{array}{c}\text { Área } \\
\left(\mathbf{m m}_{\mathbf{2}}\right)\end{array}$ & $\begin{array}{c}\text { Diâmetro } \\
\text { Nominal } \\
\mathbf{( m m )}\end{array}$ & $\begin{array}{c}\text { Resistência à } \\
\text { tração garantida } \\
\mathbf{( M P a )}\end{array}$ & $\begin{array}{c}\text { Módulo de } \\
\text { ElasticidadeG } \\
\mathbf{P a}\end{array}$ \\
\hline 6 & 33,23 & 6,35 & 825 & 40,8 \\
\hline 9 & 84,32 & 9,53 & 760 & 40,8 \\
\hline 13 & 144,85 & 12,70 & 690 & 40,8 \\
\hline 16 & 217,56 & 15,88 & 655 & 40,8 \\
\hline 19 & 295,50 & 19,05 & 620 & 40,8 \\
\hline 22 & 382,73 & 22,23 & 586 & 40,8 \\
\hline 25 & 537,90 & 25,40 & 550 & 40,8 \\
\hline 29 & 645,00 & 28,65 & 517 & 40,8 \\
\hline 32 & 807,34 & 31,75 & 480 & 40,8
\end{tabular}

Para determinar as propriedades das barras empregadas foram realizados ensaios de tração direta segundo as diretrizes da norma ASTM D 3916 - 02. Conforme determinado nesta norma foram empregados dispositivos feitos de liga de alumínio fabricados apresentados na Figura 4.13. Este ensaio foi pioneiro no Laboratório de Estruturas - EESC - USP e a fabricação dos dispositivos se justifica pela fragilidade das barras de GFRP e por causa das tensões transversais. 


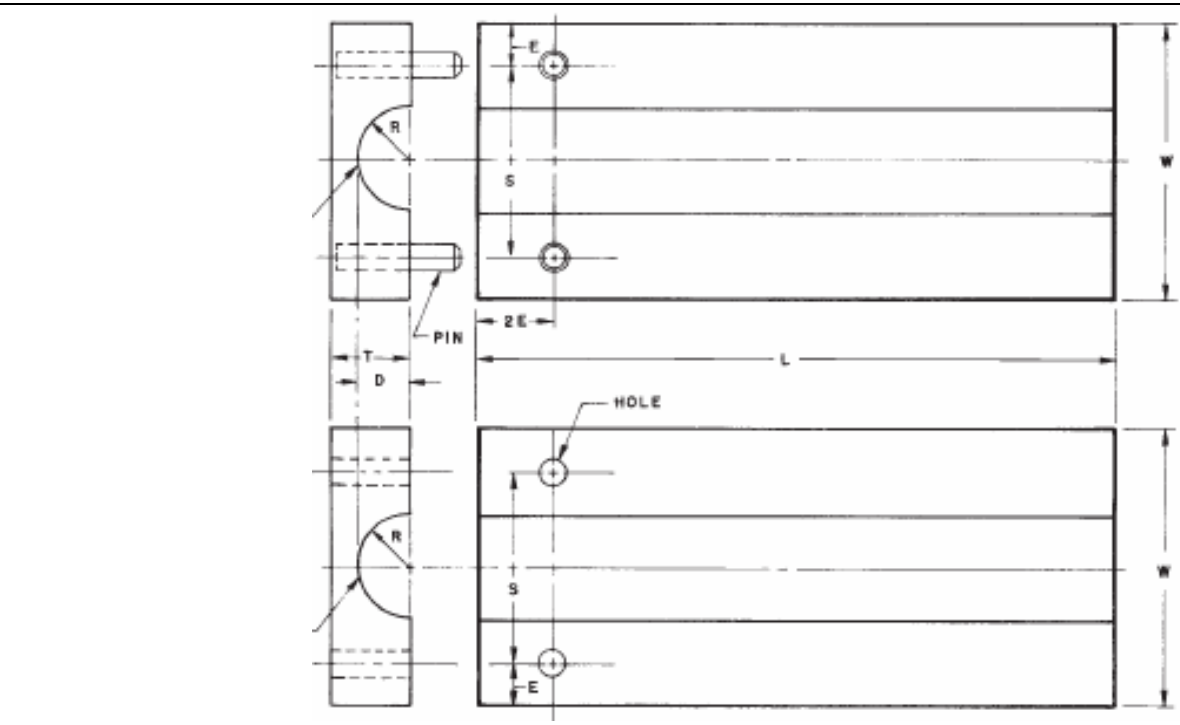

a) Projeto dos dispositivos de ensaio - ASTM D 3916-02.

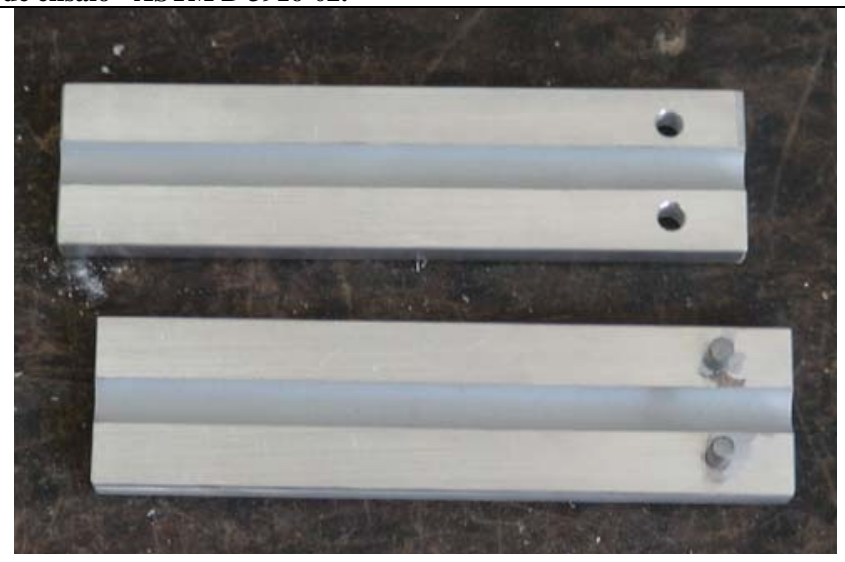

b) Dispositivos desenvolvidos para o ensaio das barras de GFRP.

Figura 4.13 Dispositivos para as garras do ensaio de tração direta das GFRP

Foram ensaiados 5 corpos-de-prova com diâmetro de 6,35mm e 6 corpos-deprova com diâmetro de 9,53mm. Mesmo seguindo as diretrizes da ASTM D $3916-02$ os exemplares romperam na garra dos corpos-de-prova, e mesmo os que apresentaram rompimento na seção livre da barra apresentaram algum tipo de dano na garra. O que demonstra ainda a necessidade de aprimoramento do ensaio. $O$ ensaio tratou-se de um ensaio comum de tração direta de barras com a diferença na fixação dos dispositivos de garra, foi realizado utilizando o equipamento INSTROM e extensômetros removíveis para determinação do módulo de elasticidade. Na Figura 4.14 é possível observar os equipamentos, o corpo-de-prova, a montagem do ensaio e a ruptura típica dos corpos-de-prova.

Em virtude dos problemas durante o ensaio, não se pode negar a ineficiência na determinação da capacidade última das barras de GFRP. Por outro lado, fica fácil observar a possibilidade do cálculo do módulo de elasticidade, já que o diagrama tensão $\mathrm{x}$ deformação apresenta o formato de reta. 


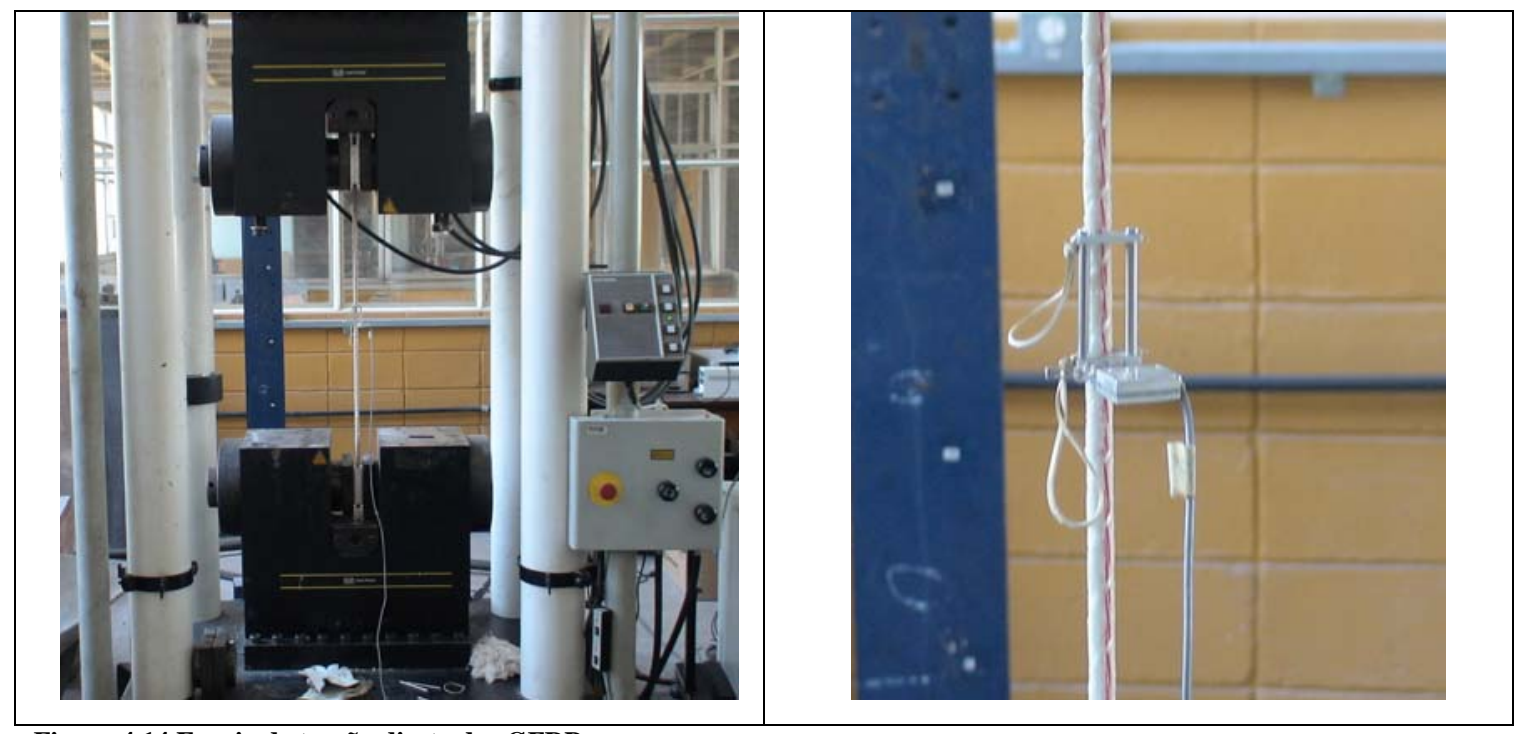

Figura 4.14 Ensaio de tração direta das GFRP

\subsubsection{Procedimento de ensaio das vigas}

Os modelos foram ensaiados segundo ordem de concretagem, sendo assim seguem a seguinte precedência nos ensaios: V01, V05, V02, V06, V04, V03. As ações foram aplicadas de baixo para cima utilizando macacos hidráulicos de capacidade de 250 kN munidos de células de carga de 100 kN,conforme esquema apresentado na Figura 4.15.

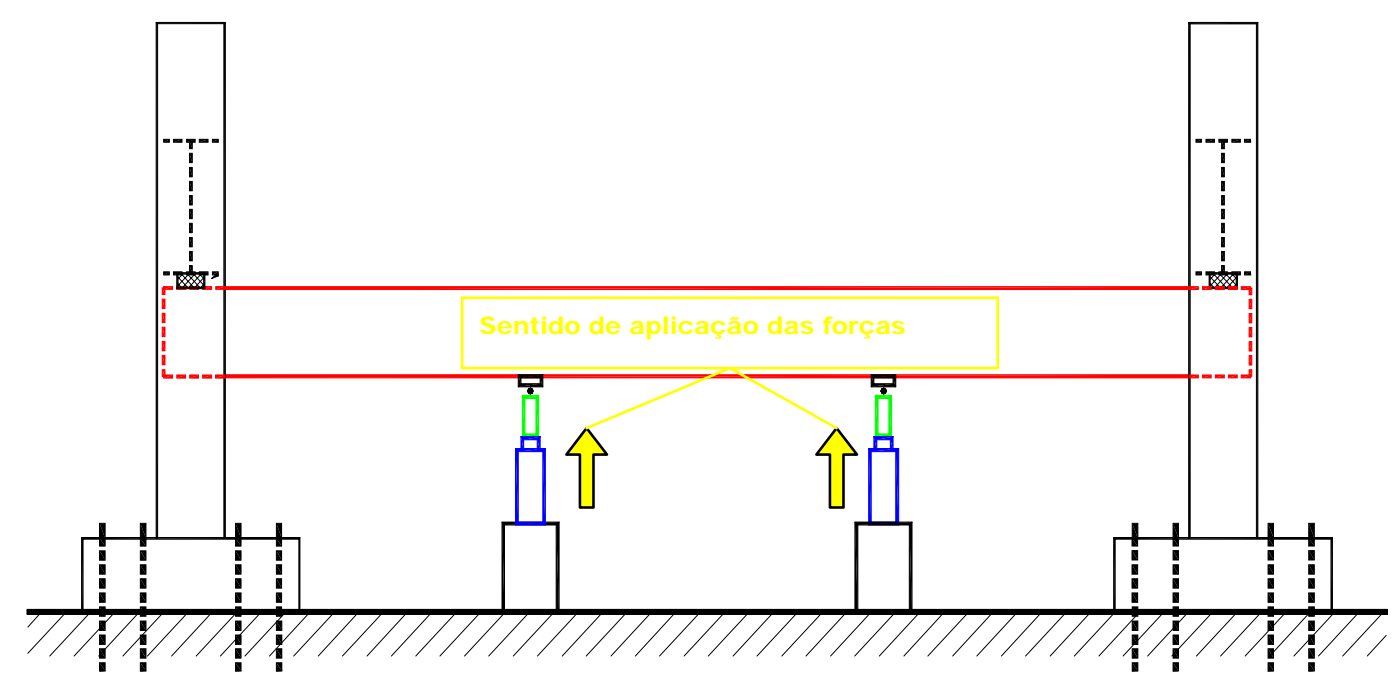

Figura 4.15 Esquema de realização do ensaio - Adaptado da apresentação do ensaio de vigas (Prof. Takeya).

Todos os modelos foram ensaiados até atingir a capacidade de deformação dos extensômetros (15\%) por medida de segurança, com exceção das vigas V04 e V03 que foram ensaiadas até a ruína. No ensaio da viga V03 foi ainda feito o 
acompanhamento da abertura das fissuras com incremento de $2 \mathrm{kN}$ nos macacos hidráulicos. 


\subsubsection{Dispositivos, Instrumentos e equipamentos utilizados nos ensaios.}

$\mathrm{Na}$ Tabela 4.5 estão descritos todos os equipamentos utilizados nos ensaios das vigas, concreto e materiais.

Tabela 4.5 Descrição dos equipamentos utilizados nos ensaios

\begin{tabular}{|c|c|c|c|c|c|}
\hline $\begin{array}{l}\text { Equipamento/ } \\
\text { Instrumento }\end{array}$ & Marca & Modelo & \multicolumn{2}{|c|}{ Características } & Finalidade \\
\hline $\begin{array}{c}\text { Sistema de } \\
\text { aquisição de dados } \\
\text { de extensometria }\end{array}$ & $\begin{array}{c}\text { Vishay } \\
\text { Measurements } \\
\text { Group, Inc. } \\
\end{array}$ & $\begin{array}{l}\text { SYSTEM } \\
5000\end{array}$ & \multicolumn{2}{|r|}{-} & $\begin{array}{c}\text { Aquisição } \\
\text { automática de } \\
\text { dados }\end{array}$ \\
\hline $\begin{array}{l}\text { Máquina de ensaio } \\
\text { servo-hidráulica }\end{array}$ & INSTRON & 8506 & \multicolumn{2}{|c|}{$\begin{array}{c}\text { Controle de } \\
\text { deslocamento do } \\
\text { pistão }\end{array}$} & $\begin{array}{c}\text { Definição das } \\
\text { propriedades } \\
\text { das armaduras e } \\
\text { do concreto }\end{array}$ \\
\hline $\begin{array}{l}\text { Máquina } \\
\text { hidráulica } \\
\text { automática }\end{array}$ & ELE & $\begin{array}{l}\text { Autotest } \\
2000\end{array}$ & \multicolumn{2}{|c|}{ Controle de força } & $\begin{array}{l}\text { Definiçãa das } \\
\text { propriedades do } \\
\text { concreto à } \\
\text { compressão e à } \\
\text { tração por } \\
\text { comp. } \\
\text { Diametral, no } \\
\text { estudo de traço }\end{array}$ \\
\hline $\begin{array}{l}\text { Extensômetros } \\
\text { elétricos de } \\
\text { resistência } \\
\end{array}$ & KYOWA & $\begin{array}{c}\text { KGF-5- } \\
120-C 1- \\
11 \\
\end{array}$ & \multicolumn{2}{|c|}{$\mathrm{GF}=2,12$} & $\begin{array}{c}\text { Medição das } \\
\text { deformações do } \\
\text { aço }\end{array}$ \\
\hline $\begin{array}{l}\text { Extensômetro } \\
\text { removível }\end{array}$ & MSI & - & \multicolumn{2}{|c|}{$\begin{array}{l}\text { Base de medida }= \\
10 \mathrm{~cm}\end{array}$} & $\begin{array}{c}\text { Medida de } \\
\text { deslocamento } \\
\text { no concreto para } \\
\text { determinar o } \\
\text { módulo Eci }\end{array}$ \\
\hline $\begin{array}{l}\text { Extensômetro } \\
\text { removível }\end{array}$ & MSI & - & \multicolumn{2}{|c|}{$\begin{array}{l}\text { Base de medida }= \\
10 \mathrm{~cm}, 5 \mathrm{~cm}\end{array}$} & $\begin{array}{c}\text { Medida de } \\
\text { deslocamento } \\
\text { nas barras de } \\
\text { GFRP para } \\
\text { determinação do } \\
\text { módulo de } \\
\text { elasticidade }\end{array}$ \\
\hline \multirow{2}{*}{$\begin{array}{l}\text { Transdutores de } \\
\text { deslocamento }\end{array}$} & \multirow[b]{2}{*}{ KYOWA } & Tipo & $\begin{array}{l}\text { Base } \\
(\mathrm{cm})\end{array}$ & $\begin{array}{c}\text { Resolução } \\
(\mathrm{mm})\end{array}$ & \multirow{2}{*}{$\begin{array}{l}\text { Medição de } \\
\text { deslocamentos } \\
\text { dos modelos }\end{array}$} \\
\hline & & DT-10D & 10 & 0,003 & \\
\hline
\end{tabular}




\section{APRESENTAÇÃO E ANÁLISE DOS RESULTADOS}

\subsection{CONCRETO}

\subsubsection{Estudo de Traço}

O estudo de traço foi uma etapa preliminar para definição do concreto utilizado na construção das vigas. Os agregados graúdo e miúdo utilizados neste estudo estão definidos a seguir:

\section{Agregado Miúdo}

Foi utilizado como agregado miúdo areia do tipo quartzosa proveniente do Rio Mogi-Guaçu. A caracterização deste material é apresentada na Tabela 5.1.

\section{Agregado Graúdo}

O agregado graúdo utilizado foi pedra britada de origem basáltica, oriunda da região de São Carlos. A caracterização deste material é apresentada na Tabela 5.1.

Tabela 5.1 Caracterização dos agregados.

\begin{tabular}{|c|c|c|c|}
\hline Material & $\begin{array}{c}\text { Massa Específica } \\
\left(\mathrm{g} / \mathrm{cm}^{3}\right)\end{array}$ & $\begin{array}{c}\text { Massa unitária } \\
\left(\mathrm{Kg} / \mathrm{dm}^{3)}\right.\end{array}$ & Graduação \\
\hline Agregado miúdo & 2,89 & 1,60 & Zona 3 (Média) \\
\hline Agregado graúdo & 2,61 & 1,60 & Brita 0 \\
\hline
\end{tabular}


Os resultados dos ensaios à compressão obtidos neste estudo estão dispostos na Figura 5.1, pode-se observar o ponto obtido para que a resistência do concreto nas vigas atingisse $40 \mathrm{MPa}$ aos 14 dias.

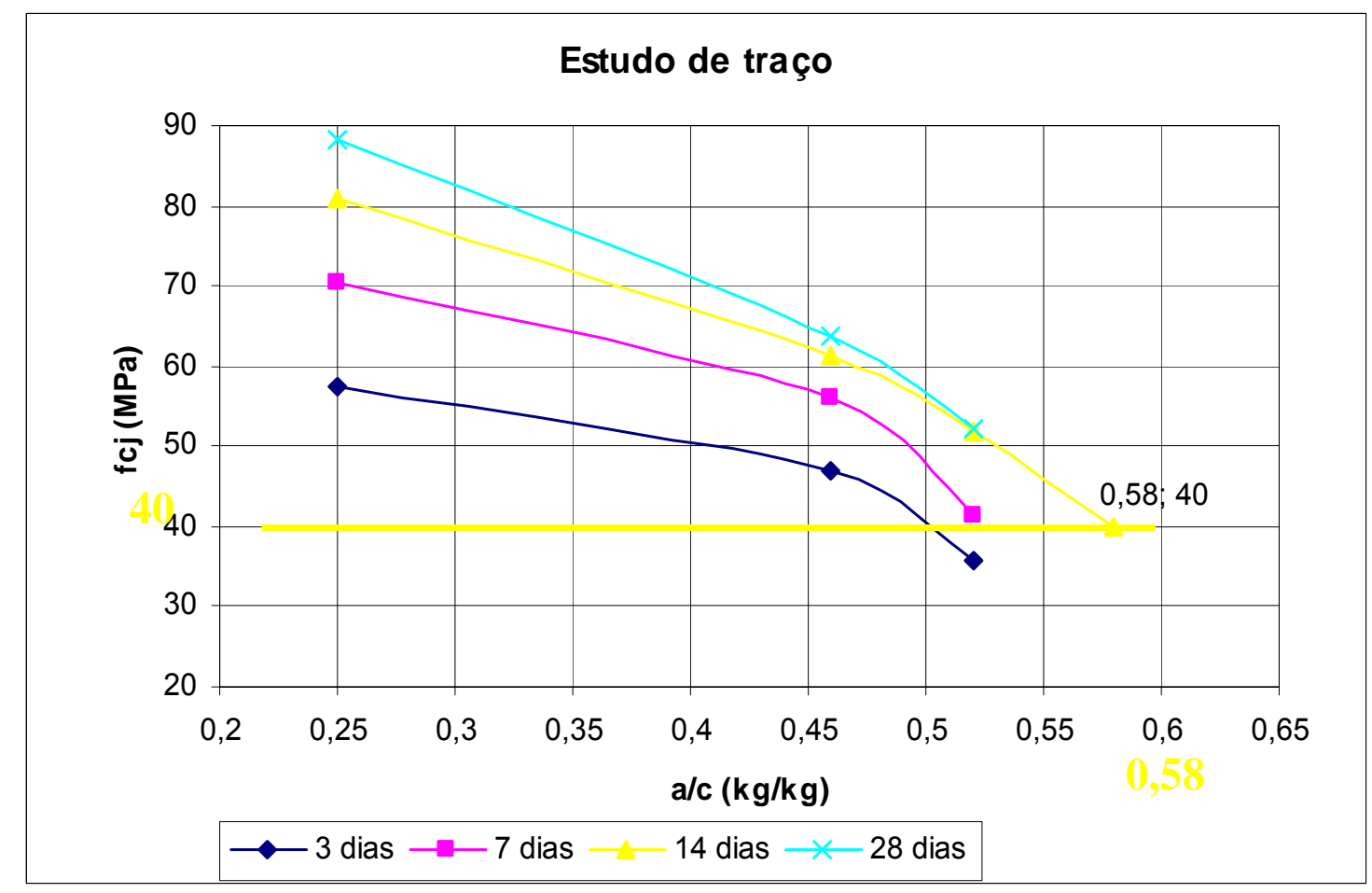

Figura 5.1 Diagrama de determinação do traço

Partindo dessa resistência e do fator água/ cimento definidos no gráfico anterior foi encontrado o traço definitivo que foi utilizado na concretagem das vigas.

Definidas as varáveis, o traço definitivo para uma resistência $f_{c_{j_{14}}}=40 \mathrm{MPa}$, foi 1: 2,8: 3,8, com um fator de água/ cimento de 0,58 e um consumo de cimento de 315 $\mathrm{kg} / \mathrm{m}^{3}$.

A Tabela 5.2 mostra as quantidades de cada material utilizado na concretagem das seis vigas: 
Tabela 5.2 Quantitativo de materiais

\begin{tabular}{|c|c|}
\cline { 2 - 2 } \multicolumn{1}{c|}{} & Massa \\
\hline cimento & $322,0 \mathrm{~kg}$ \\
\hline areia & $901,5 \mathrm{~kg}$ \\
\hline pedra britada & $1223,5 \mathrm{~kg}$ \\
\hline água & $186,7 \mathrm{~kg}$ \\
\hline
\end{tabular}

A Tabela 5.3 fornece os resultados dos Slump testes feitos durante cada concretagem.

Tabela 5.3 Resultado do Slump Test para cada concretagem
\begin{tabular}{|c|c|}
\hline Concretagem & Slump \\
\hline 01 & $58 \mathrm{~mm}$ \\
\hline 02 & $80 \mathrm{~mm}$ \\
\hline 03 & $55 \mathrm{~mm}$ \\
\hline
\end{tabular}

\subsubsection{Diagramas Tensão x Deformação}

Depois de concretadas, as vigas foram ensaiadas todas no mesmo dia, variando assim a idade do concreto nas vigas. A Tabela 5.4 e a Figura 5.2 fornecem os resultados obtidos para cada concretagem no dia em que as vigas foram ensaiadas. 

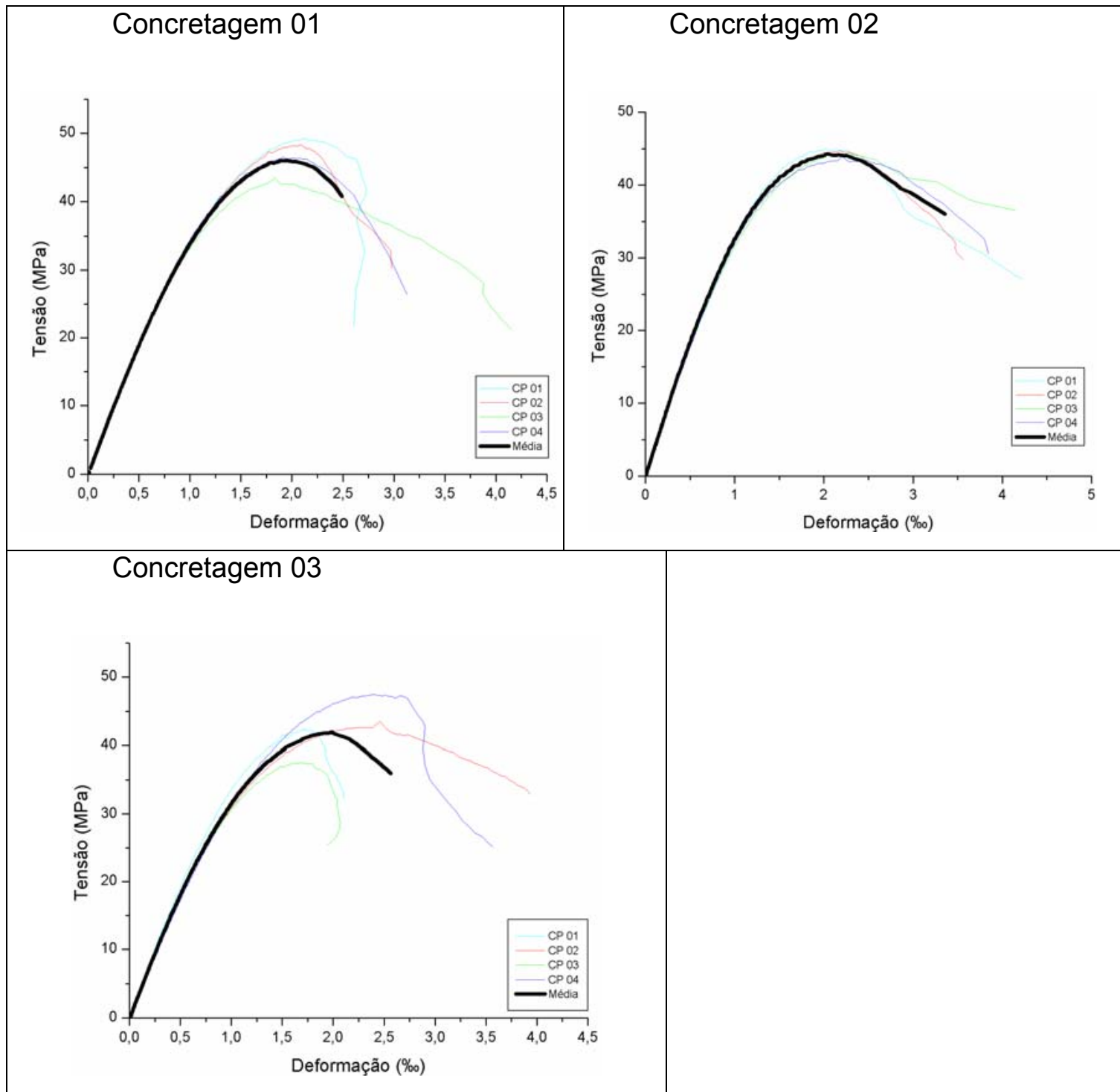

Figura 5.2 Diagramas Tensão X Deformação dos concretos

Tabela 5.4 Propriedades determinadas para cada concretagem

\begin{tabular}{c|ccc}
\cline { 2 - 4 } & Concretagem01 & Concretagem02 & Concretagem03 \\
\hline Resistência à compressão $(\mathrm{MPa})$ & 45,98 & 44,27 & 41,95 \\
Deformação Última $(\mathrm{mm} / \mathrm{m})$ & 1,96 & 2,03 & 1,99 \\
Resistência à tração $(\mathrm{MPa})$ & 3,12 & 3,30 & 3,11 \\
Módulo de Elast. Tang. Inicial & 38791,3 & 38193,7 & 37417,2 \\
$(\mathrm{MPa})$ & & & \\
Módulo de Elast. Secante $(\mathrm{MPa})$ & 23402,8 & 21728,3 & 21059,0 \\
\hline
\end{tabular}




\subsection{ARMADURAS}

\subsubsection{Aço CA-50}

Os resultados dos ensaios de tração direta das barras de aço realizados estão descritos na Figura 5.3 e Tabela 5.5.
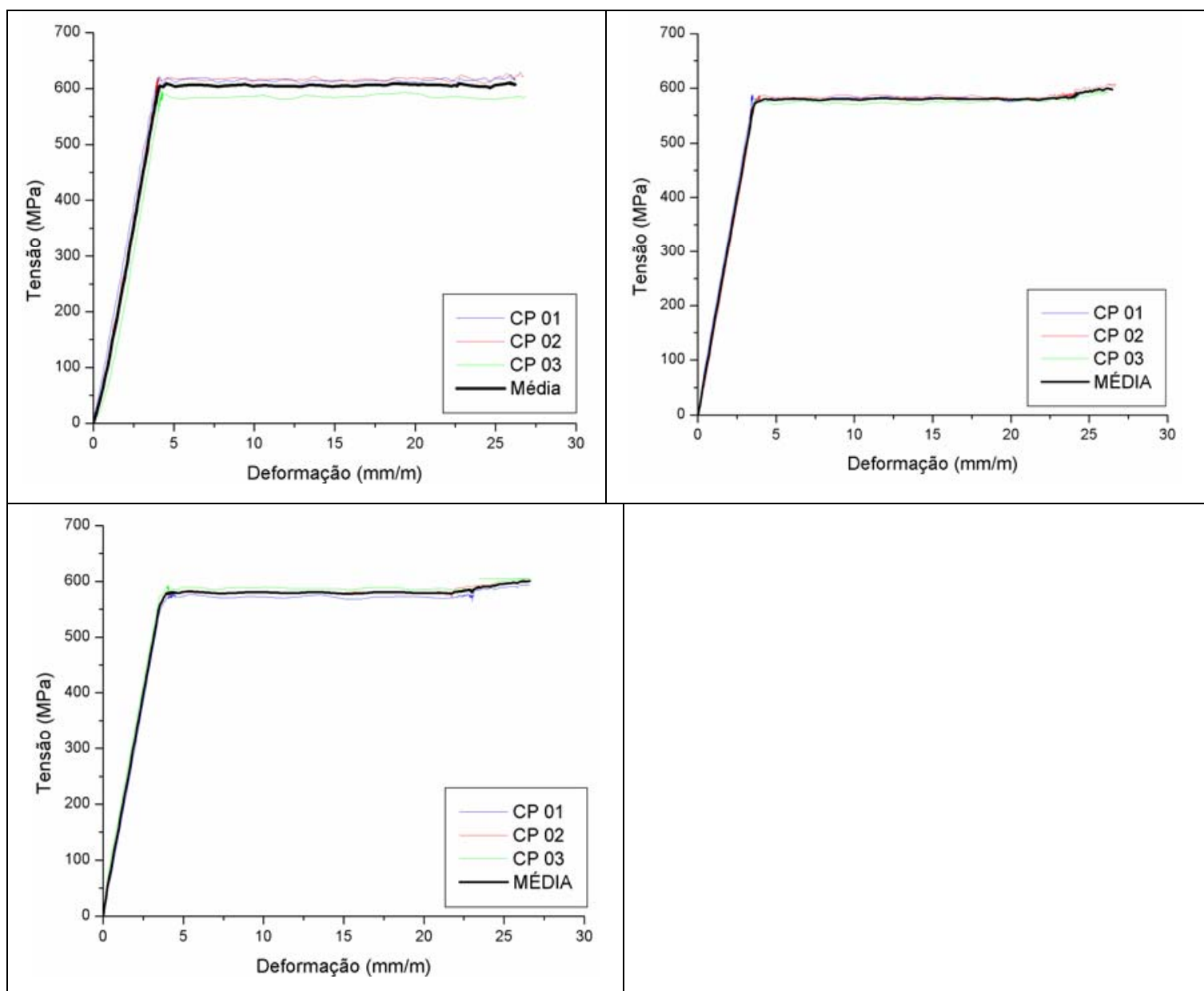

Figura 5.3 Diagramas Tensão X Deformação das barras de aço

Tabela 5.5 Propriedades determinadas para as barras de aço Resistência (MPa)

Deformação

$(\mathrm{mm} / \mathrm{m})$

\begin{tabular}{c|ccc}
\hline$\Phi=6,3 \mathrm{~mm}$ & Escoamento & 596,21 & 4,05 \\
& Última & 606,64 & 25,94 \\
\multirow{3}{*}{$\Phi=8 \mathrm{~mm}$} & Escoamento & 572,48 & 3,62 \\
& Última & 579,48 & 26,14 \\
\multirow{2}{*}{$\Phi=12,5 \mathrm{~mm}$} & Escoamento & 551,81 & 3,48 \\
& Última & 579,08 & 26,60 \\
\hline
\end{tabular}


$\mathrm{Na}$ Figura 5.4 pode-se verificar a ruptura típica dos corpos-de-prova submetidos ao ensaio de tração direta.

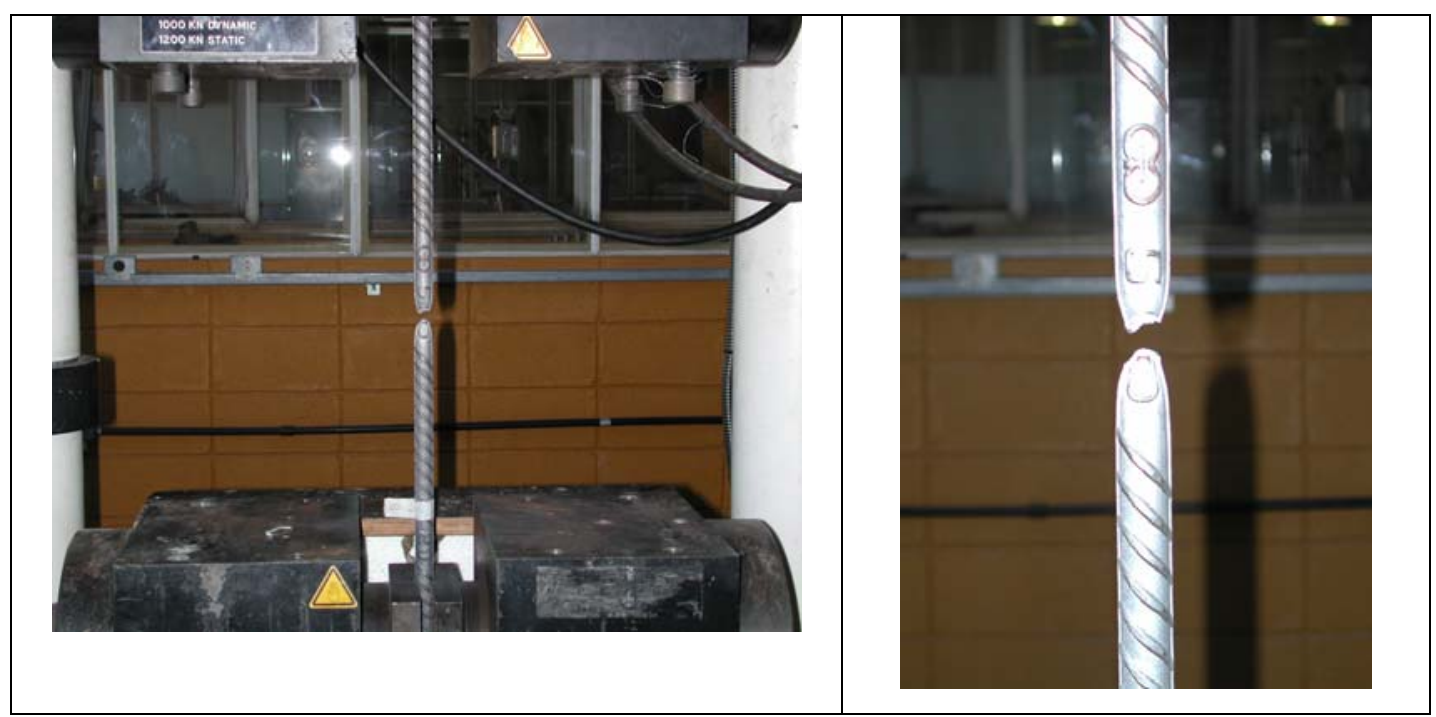

Figura 5.4 Exemplo de ruptura típica de ensaio de tração de barras de aço

\subsubsection{GFRP - Aslam 100}

As barras de GFRP ensaiadas à tração direta seguindo outra diretriz, ASTM D 3916 - 02 como explicitado anteriormente. Os resultados são mostrados na Figura 5.5 e

Tabela 5.6. Na Figura 5.6 pode-se observar a ruptura típica dos corpos-deprova ensaiados à tração direta no laboratório de estruturas. A influência da garra no rompimento do corpo-de-prova é inegável, uma vez que o dano nesta região é aparente.
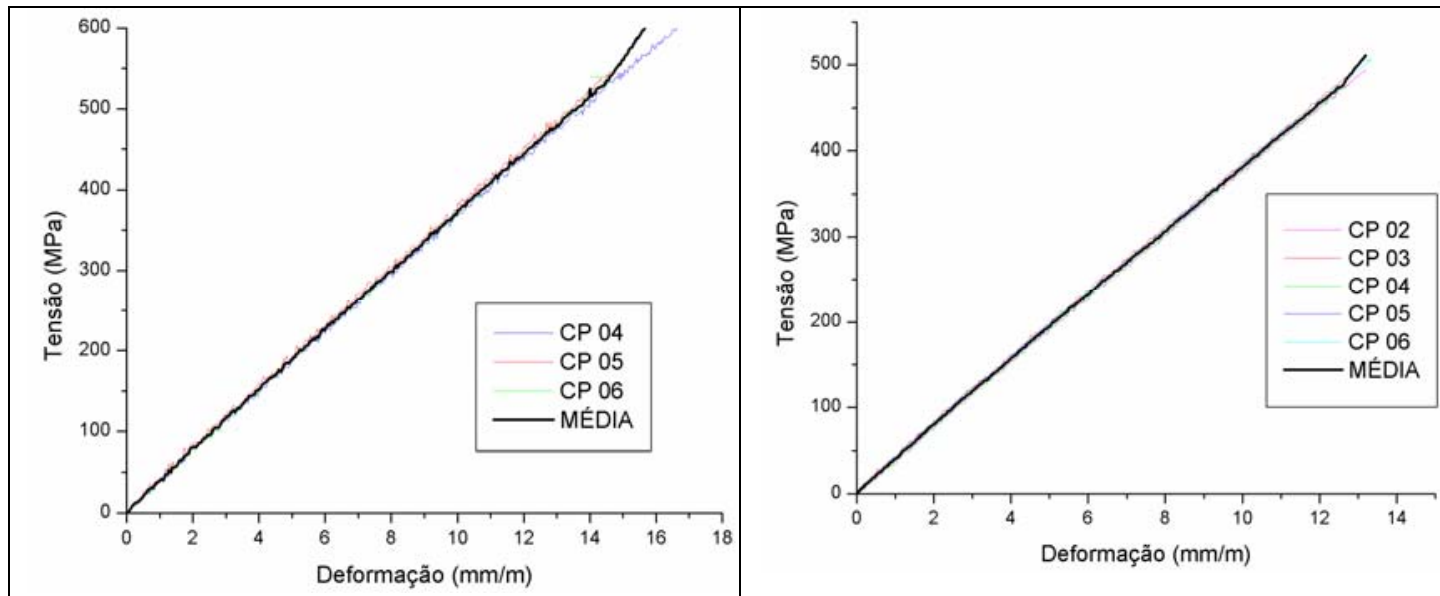

Figura 5.5 Diagramas Tensão X Deformação das barras de GFRP 
Tabela 5.6 Propriedades determinadas para as barras de GFRP

\begin{tabular}{l|ll}
\hline & $\Phi 6,35 \mathrm{~mm}$ & $\Phi 9,53 \mathrm{~mm}$ \\
\hline Diâmetro mínimo medido $(\mathrm{mm})$ & 6,8 & 10 \\
Módulo de Elasticidade $(\mathrm{GPa})$ & 37,17 & 38,16 \\
Resistência Última $(\mathrm{MPa})$ & 598,04 & 510,72 \\
Deformação Última $(\mathrm{mm} / \mathrm{m})$ & 17,08 & 13,19 \\
\hline
\end{tabular}

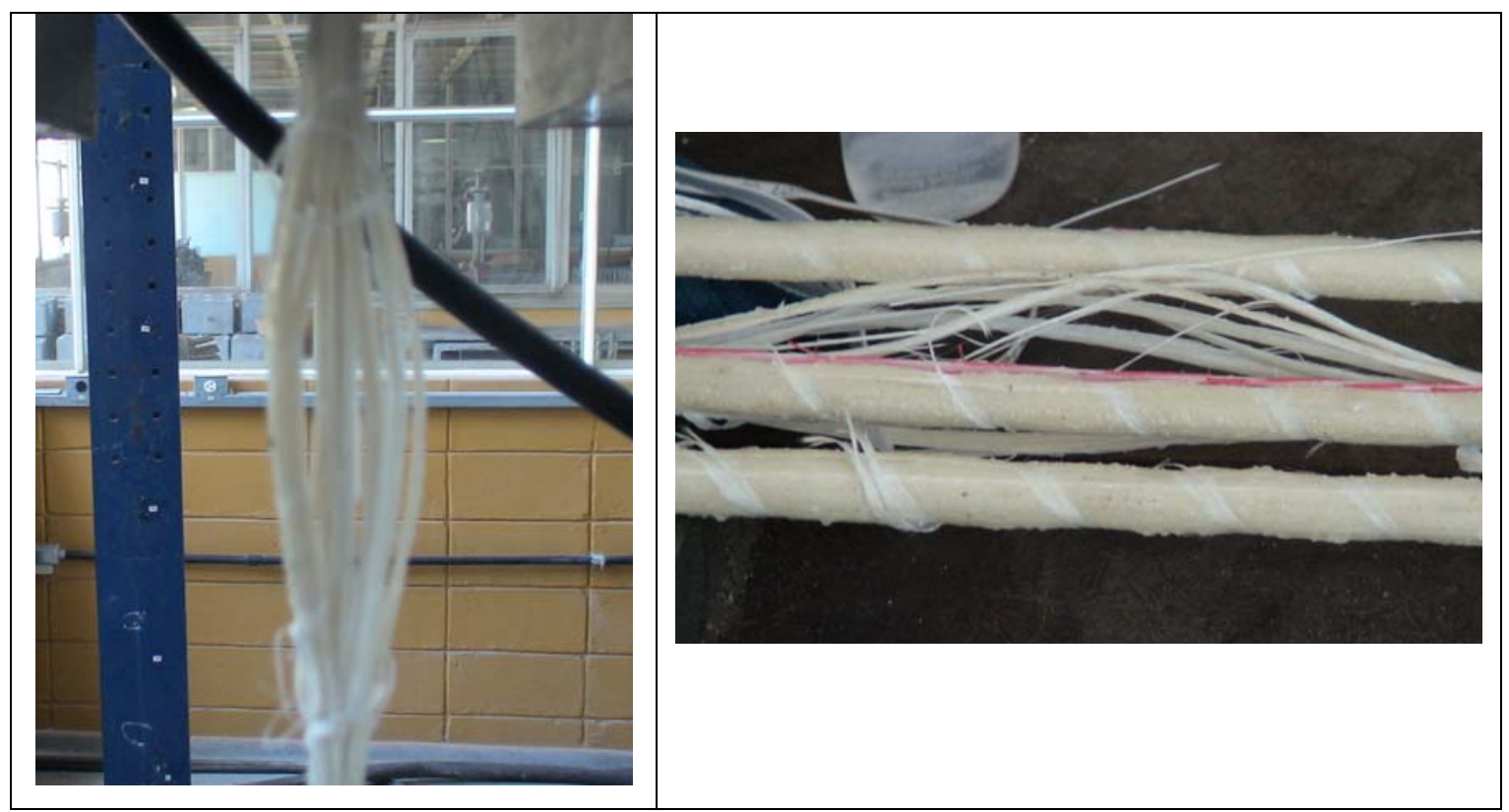

Figura 5.6 Ruptura típica dos corpos-de-prova de GFRP ensaiados à tração

\subsection{RESULTADOS E ANÁLISES DOS MODELOS}

\subsubsection{Deformação na armadura de tração.}

A diferença da deformação entre as barras de aço e as barras de GFRP é significativa e pode ser explicada em virtude do baixo módulo de elasticidade das barras de GFRP. Como não existe patamar de escoamento no comportamento destas barras submetidas à tração, conforme mostrou o ensaio de determinação das propriedades, o limite de deformação foi fixado em $10 \mathrm{~mm} / \mathrm{m}$. Este valor foi adotado em virtude da capacidade de deformação do concreto na seção tracionada para que o elemento não entre em colapso. 
A Figura 5.7 mostra para cada modelo quais as barras foram instrumentadas.

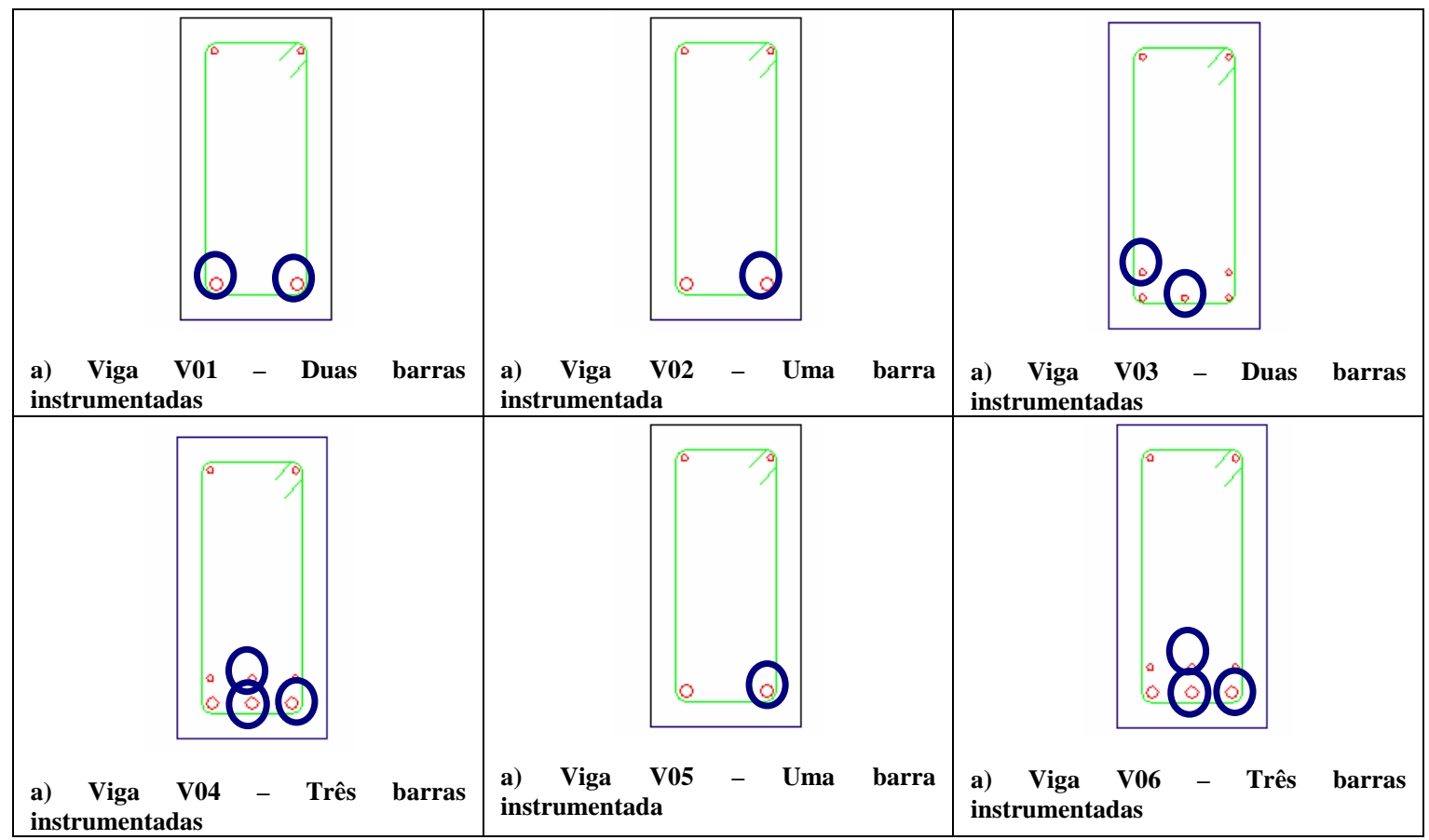

Figura 5.7 Localização das barras instrumentadas

\subsubsection{Viga com barras de aço}

A Figura 5.8 mostra o comportamento das duas barras de aço da viga piloto armado com aço, pode-se observar nitidamente os três estádios de deformação da viga. Logo após os $20 \mathrm{kN}$ pode-se observar a diferença de comportamento da viga fissurada e em torno dos $80 \mathrm{kN}$ pode-se observar a mudança de inclinação no diagrama definindo a passagem para o estádio III de deformação.
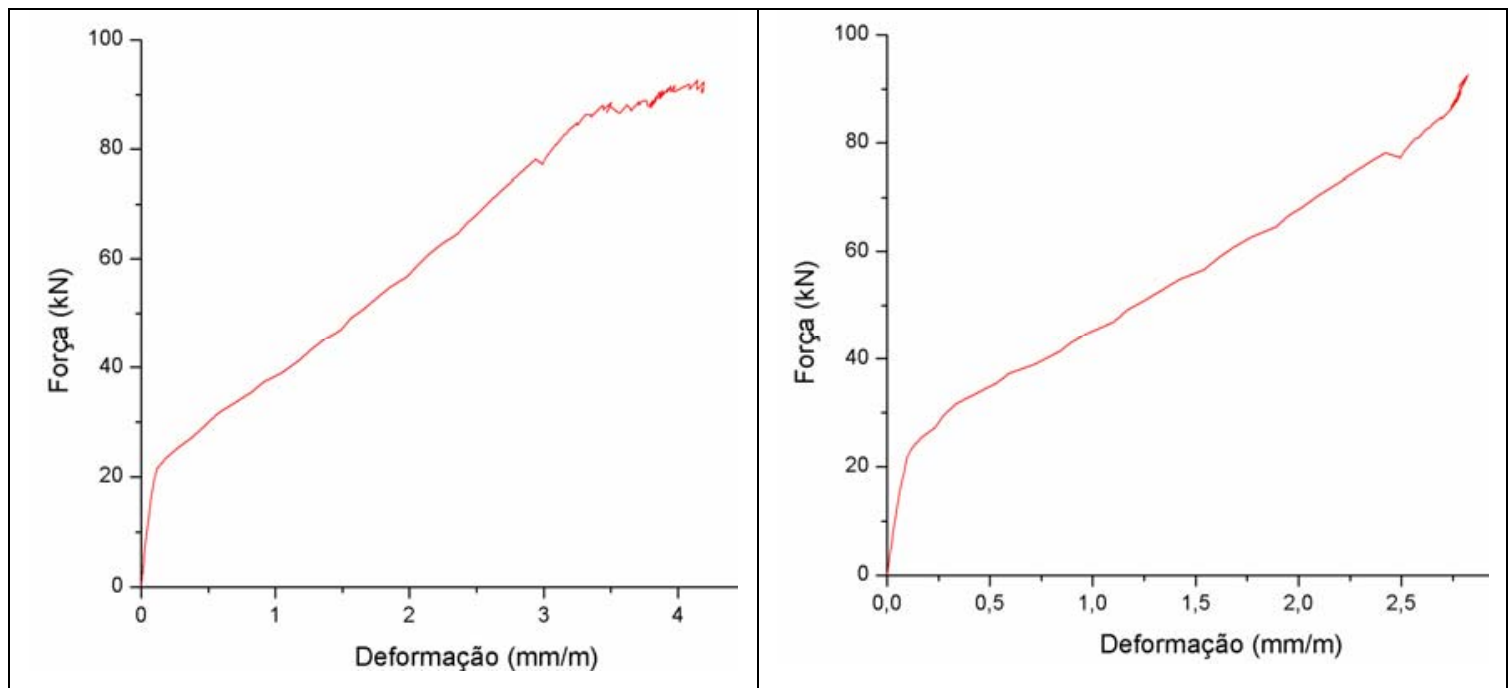

Figura 5.8 Diagramas Força X Deformação das barras do modelo 01 


\subsubsection{Vigas com equivalência de resistência}

$\mathrm{Na}$ Figura 5.9 são apresentados os três modelos com barras de GFRP dimensionados a partir da capacidade resistente do modelo armado com barras de aço.

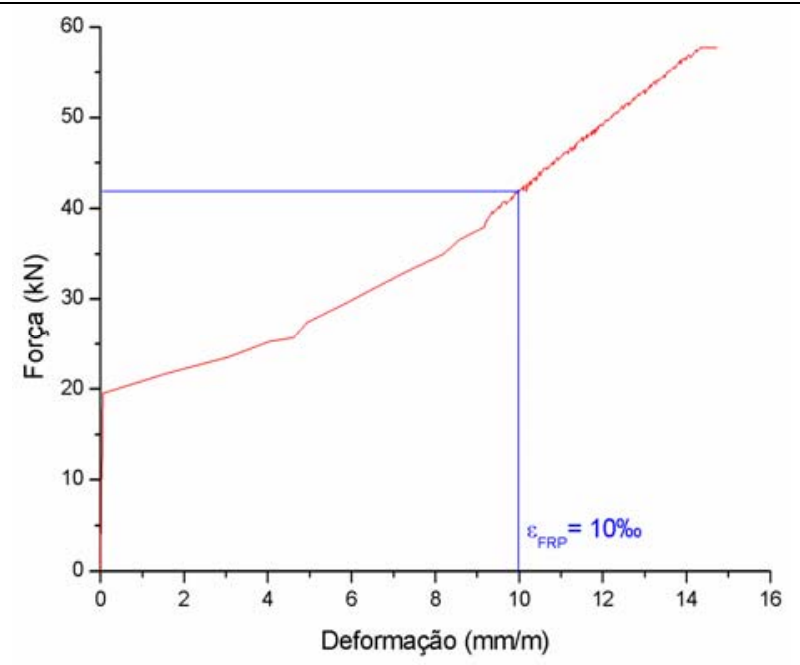

a) Viga 02 


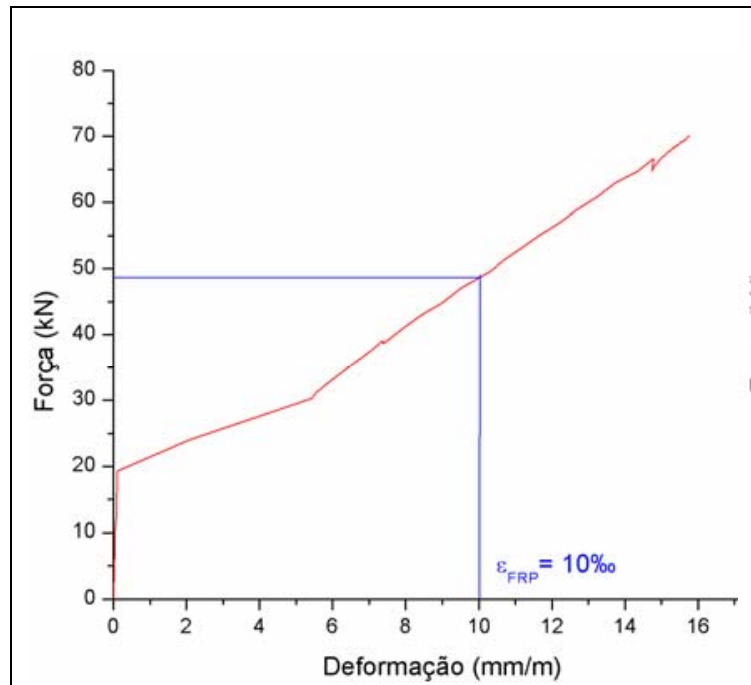

Barra da primeira camada

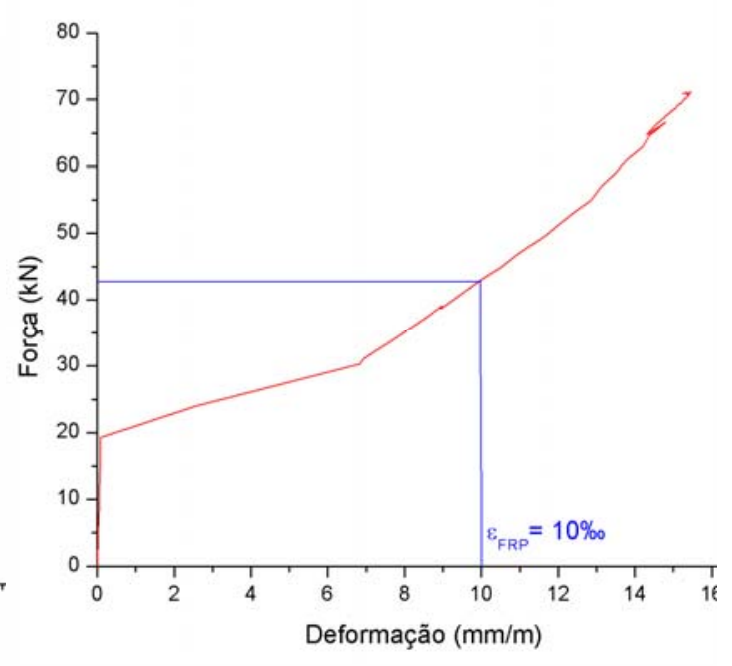

Barra da segunda camada

b) Viga 03

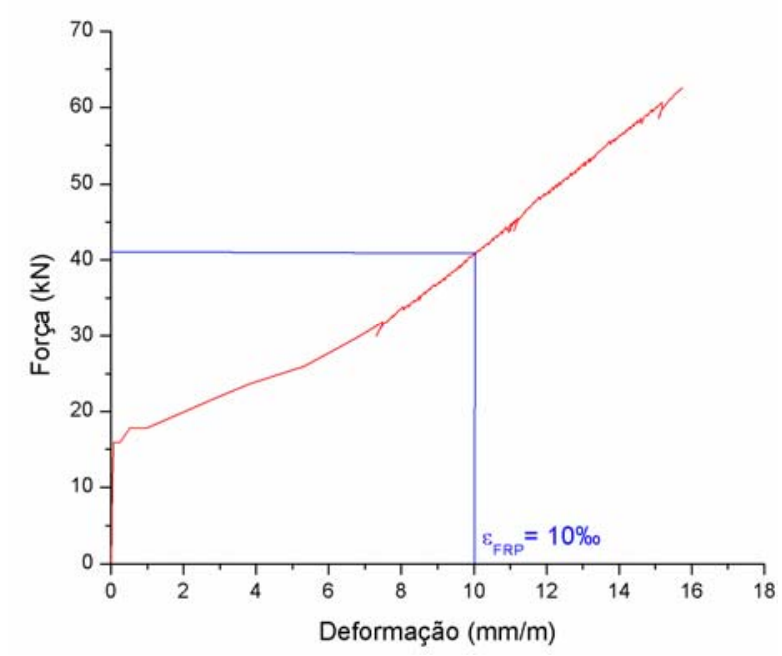

c) Viga 05

Figura 5.9 Diagramas Força X Deformação das barras dos modelos 02, 03 e 05

Pode-se observar claramente que para todas as vigas armadas com o critério de capacidade resistente logo após o carregamento de $40 \mathrm{kN}$, as barras de GFRP apresentaram deformação de $10 \mathrm{~mm} / \mathrm{m}$, um carregamento muito abaixo dos $80 \mathrm{kN}$ que determinaram à mudança do estádio de deformação da viga com barras de aço.

Como a única diferença entre as vigas 02 e 05 é a presença de ganchos nas extremidades das barras da viga 02, pode-se afirmar que para o critério de deformação da barra submetida à tração, a presença ou não de ganchos não se mostrou uma variável capaz de diferir o comportamento dos modelos. Na viga 03 
pode-se perceber que a barra da segunda camada representada pelo segundo diagrama atingiu a deformação limite aos $50 \mathrm{kN}$ de carregamento, isso se deve ao fato de seu centro de inércia estar mais próximo da linha neutra da viga.

Vigas com equivalência de deformação

Os modelos dimensionados segundo o critério da deformação limite de $10 \mathrm{~mm} / \mathrm{m}$ são apresentados sob o critério de deformação da armadura de GFRP submetida à tração na Figura 5.10 .

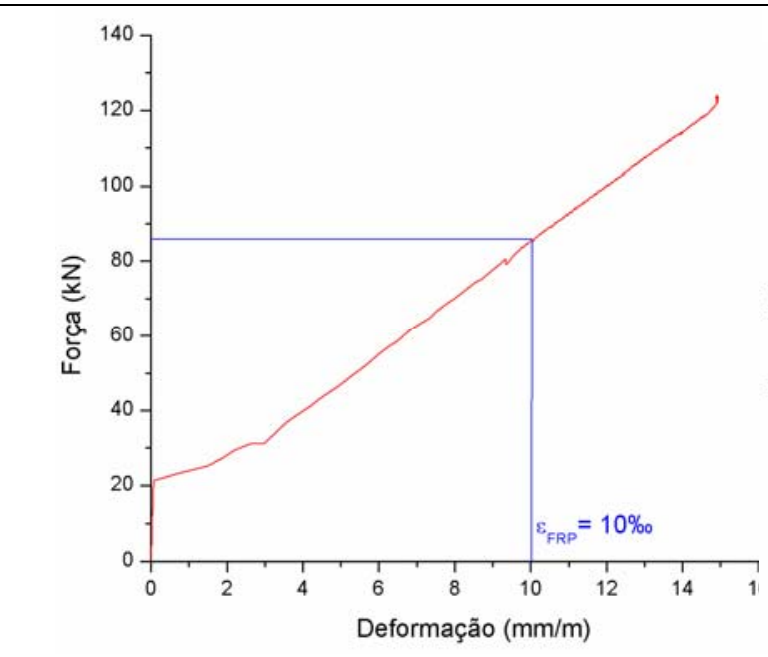

Barra central da primeira camada

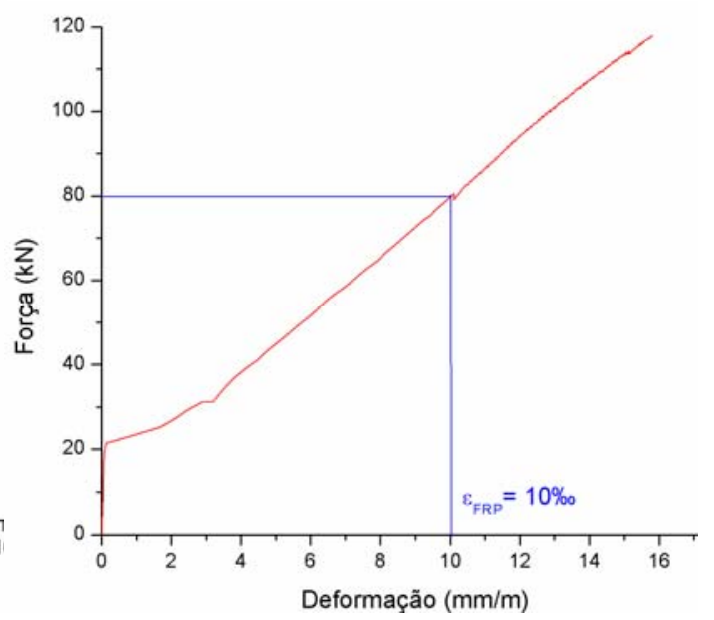

Barra de extremidade da primeira camada

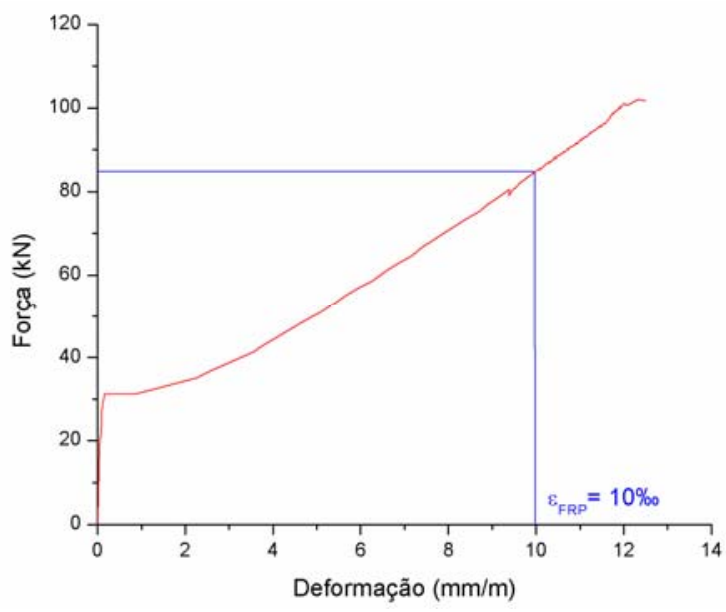

Barra da segunda camada 


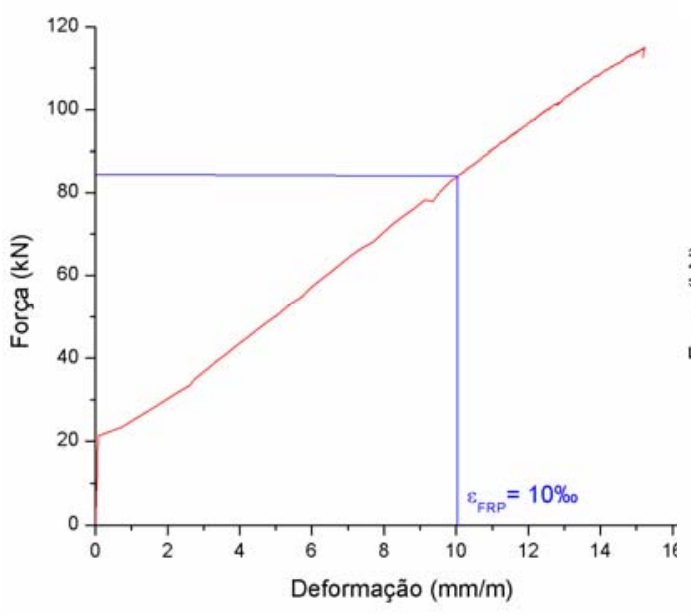

Barra central da primeira camada

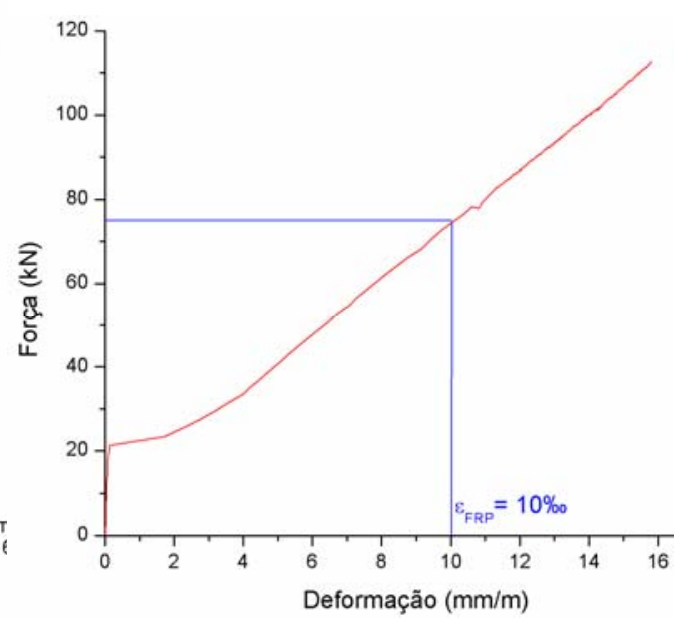

Barra de extremidade da segunda camada

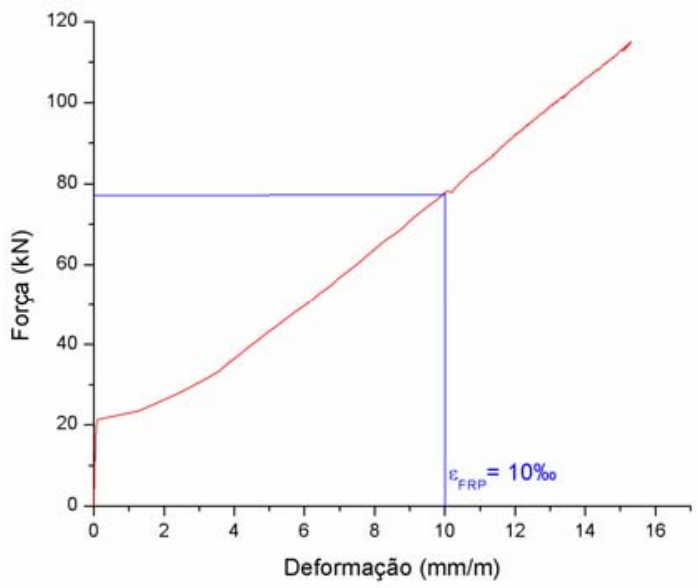

Barra da segunda camada

b) Viga 06

Figura 5.10 Diagramas Força X Deformação das barras dos modelos 04 e 06

Conforme os modelos foram dimensionados, a deformação limite de $10 \mathrm{~mm} / \mathrm{m}$ foi atingida aos $80 \mathrm{kN}$ de carregamento, exatamente no instante em que a viga armada com aço muda do estádio II para o estádio III de deformação. Por causa da diferença de módulo de elasticidade dos materiais, foi necessária uma área de armadura de GFRP muito maior que de aço para atingir a mesma deformação limite.

Por essa análise dos diagramas Força X Deformação, fica claro que a grande deformabilidade das barras de GFRP, leva as vigas armadas sob o critério de mesma resistência a atingirem a deformação limite com a metade do carregamento. Portanto a deformação da armadura é uma variável muito mais significativa para o 
dimensionamento de elementos com GFRP que para elementos usuais de concreto armados com aço. Esta diferença de comportamento acena para a possibilidade de aplicação da protensão como um fator de minimização das conseqüências das altas deformações apresentadas em barras de GFRP em vigas submetidas a forças de tração.

A Figura 5.11 apresenta uma comparação entre os modelos, mostrando o carregamento atingido para a deformação de $10 \mathrm{~mm} / \mathrm{m}$.

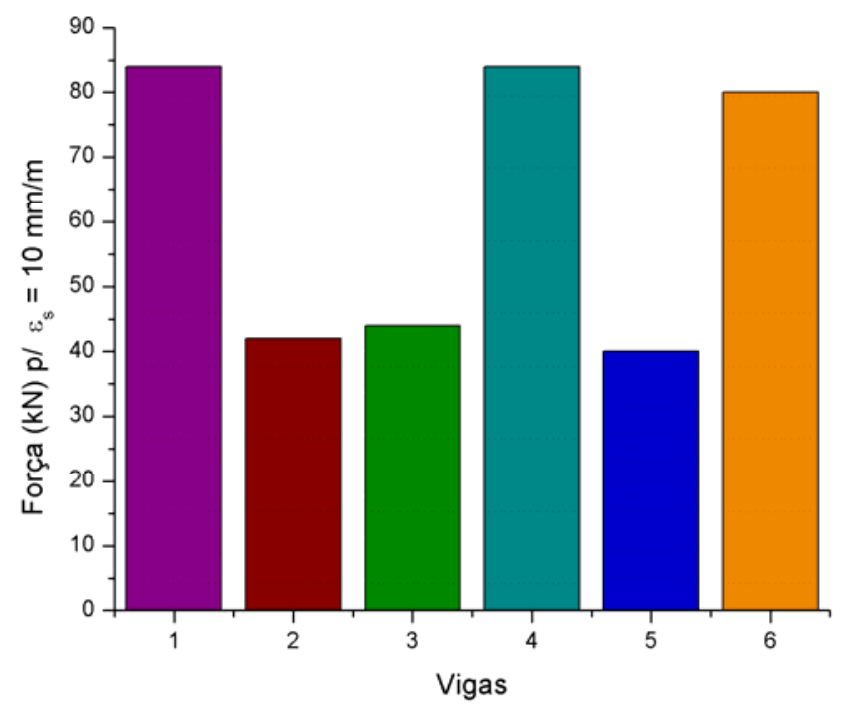

Figura 5.11 Diagrama de comparação dos modelos

\subsubsection{Deslocamentos observados nos modelos.}

As diretrizes de dimensionamento de elementos de concreto armado com GFRP colocam como principal fator de limitação, os deslocamentos e aberturas de fissuras. Nos ensaios isso ficou muito claro, os modelos de GFRP apresentam deslocamentos extremamente superiores aos da viga armada com barras de aço. $\mathrm{Na}$ Figura 5.12 pode-se observar os modelos durante o ensaio e o seu deslocamento visual. As fotos estão dispostas na ordem numérica dos modelos. 

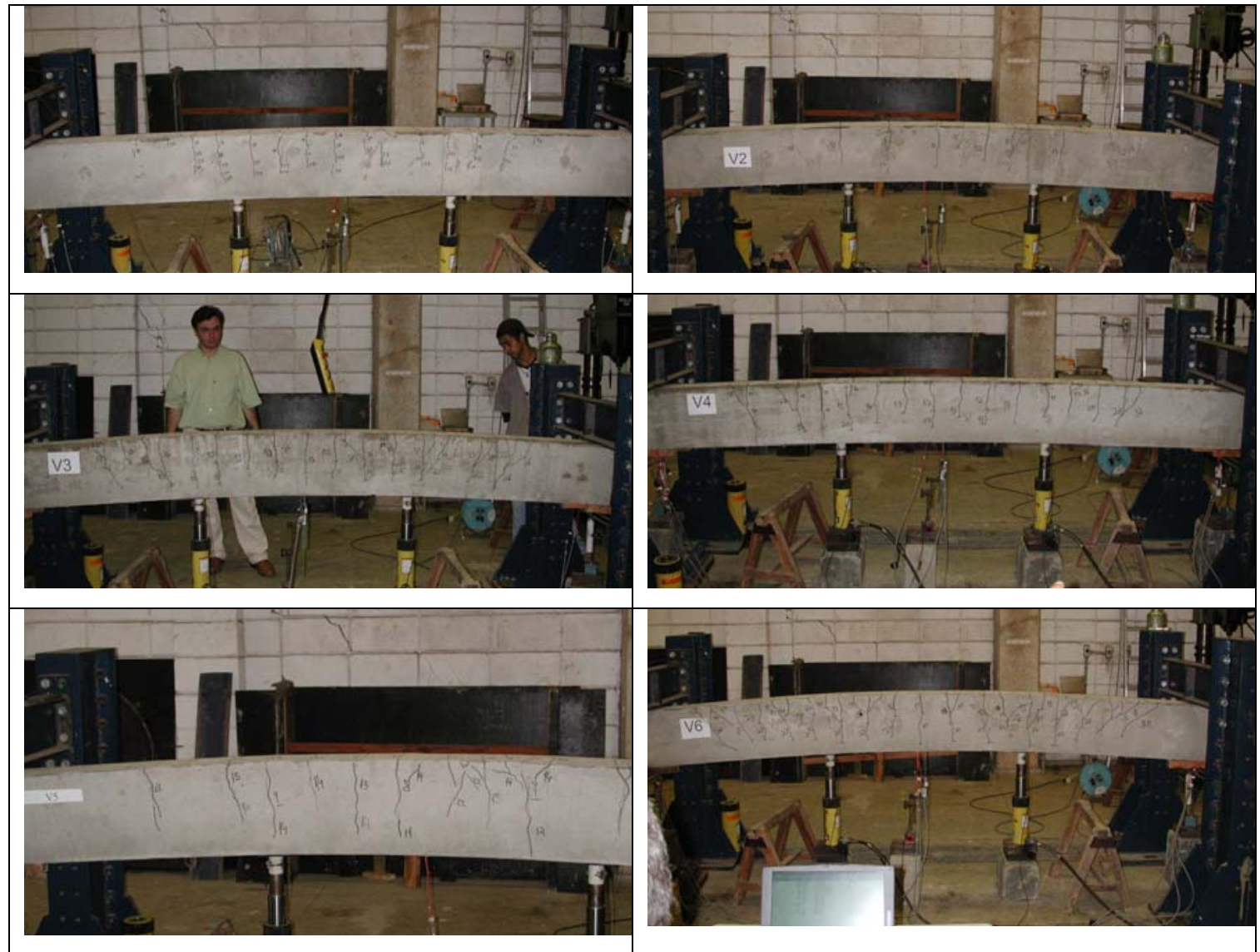

Figura 5.12 Deslocamento visual dos modelos durante o ensaio

Viga com barras de aço

Adotou-se como limite de deslocamento, aquele proposto na NBR 6118:2003, com valor limite obtido dividindo-se o vão efetivo por 350. Na Figura 5.13 pode-se observar que no modelo armado com aço o deslocamento máximo adotado foi atingido a uma força superior a $60 \mathrm{kN}$.

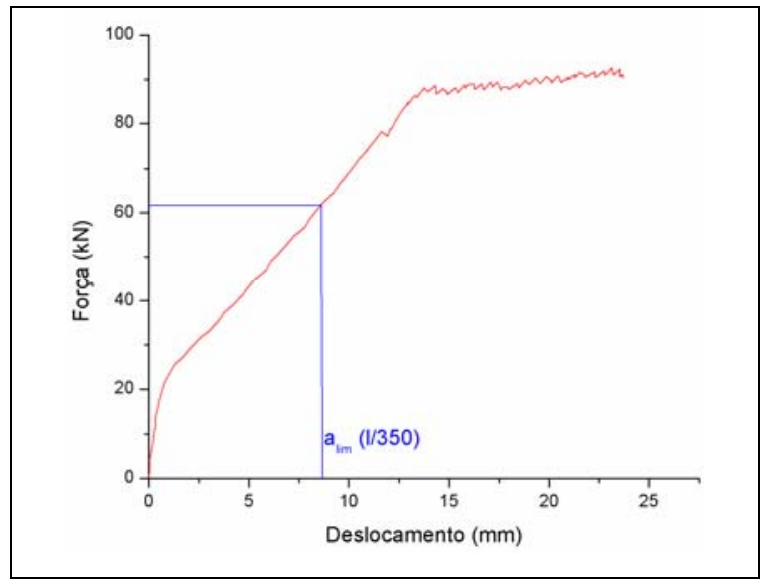

Figura 5.13 Diagrama Força X Deslocamento para o modelo 01 
Vigas com equivalência de resistência

Como se pode observar na Figura 5.14, as vigas armadas com barras de GFRP para a equivalência de resistência apresentam o deslocamento limite a um carregamento próximo de $24 \mathrm{kN}$. A força obtida para o mesmo deslocamento não atinge nem a metade do valor do carregamento da viga com barras de aço. As variações entre as armaduras das vigas não se mostraram mudanças significativas no que se refere ao deslocamento, sendo que todos os modelos de equivalência de resistência comportaram-se da mesma forma. $O$ fato de se ter uma armadura mais distribuída, ou a existência de ganchos, não influenciou nos resultados obtidos.

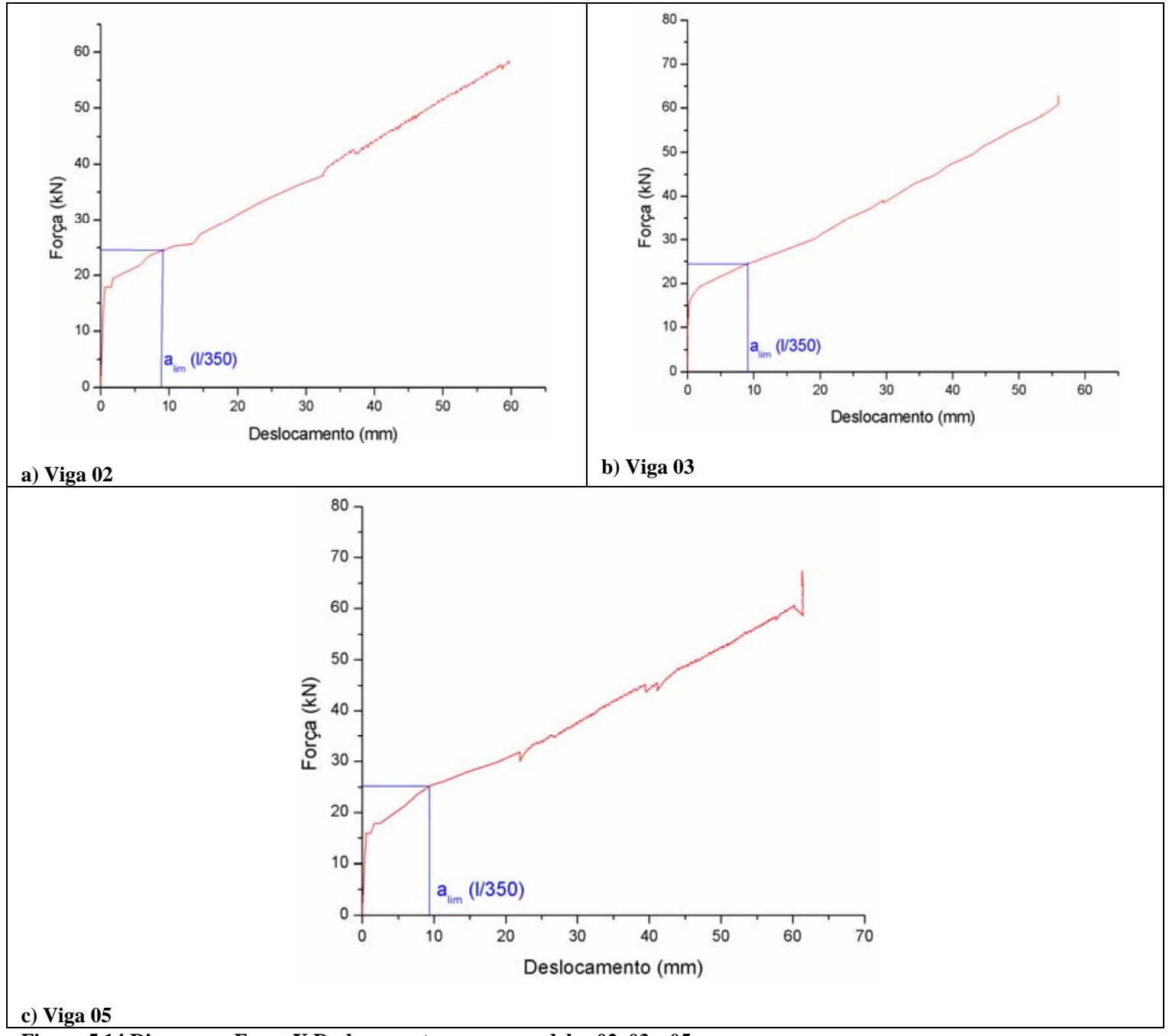

Figura 5.14 Diagramas Força X Deslocamento para os modelos 02, 03 e 05

Vigas com equivalência de deformação

Mesmo as vigas de GFRP armadas para equivalência de deformação atingiram o deslocamento imposto como limite submetidas a um carregamento inferior ao alcançado pela viga de referência. Ambos os modelos atingiram o limite de 
deslocamento com carregamento próximo de $30 \mathrm{kN}$, metade daquele observado na viga armada com aço. $O$ fato da existência ou não de gancho não influenciou o deslocamento das vigas, mostrando o gancho ser novamente uma variável sem importância nesta análise, como apresentado na Figura 5.15.

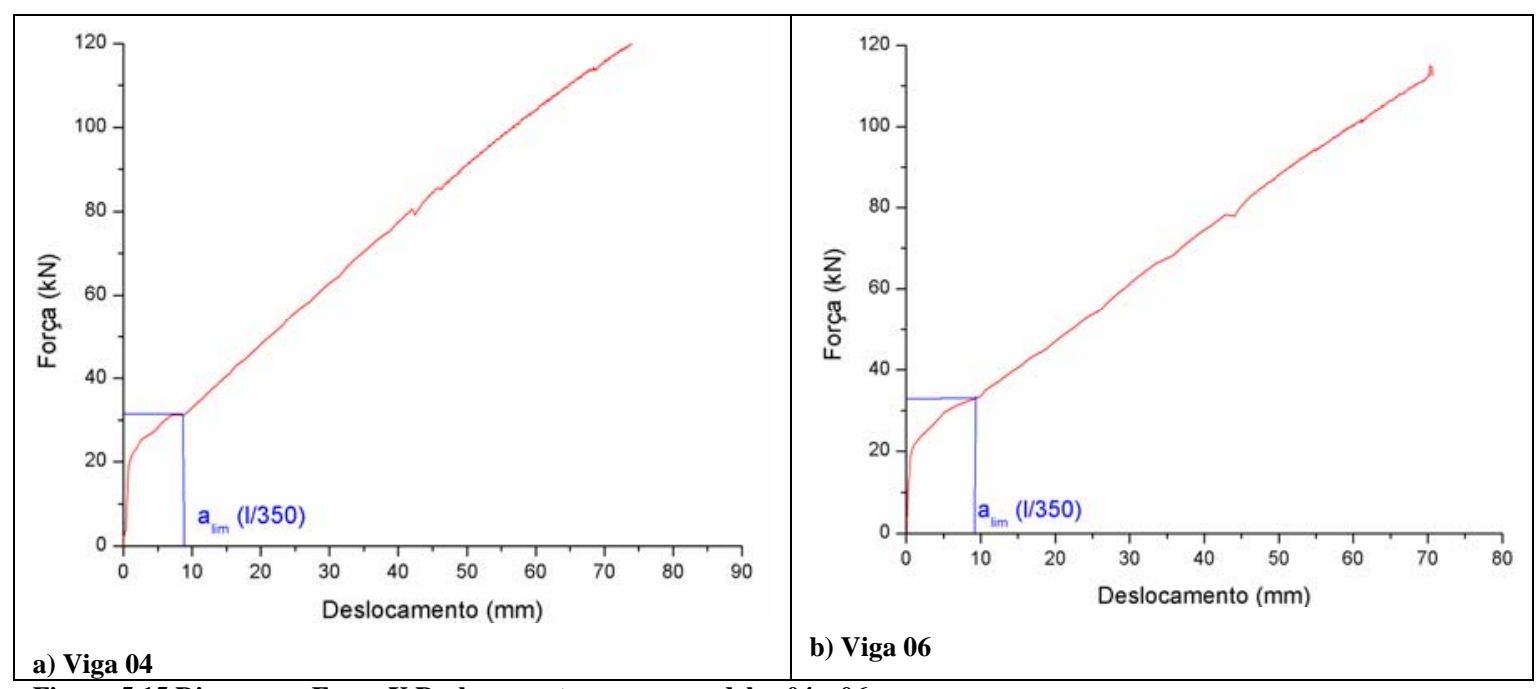

Figura 5.15 Diagramas Força X Deslocamento para os modelos 04 e 06

Observando o deslocamento dos seis modelos, conclui-se claramente que mesmo dimensionando os elementos pelo critério de ruína - ELU, no caso de elementos armados com GFRP, o deslocamento é uma propriedade muito significativa para determinação dos elementos. Além disso conforme observado no critério de deformação da armadura, houve uma equivalência entre a viga de referência e as dimensionadas pelo critério de deformação. Isto poderia consequentemente levar a um comportamento semelhante no que tange o deslocamento dos modelos, não foi o observado. Claro que essa afirmação seria sempre verdadeira se a aderência ou outros fatores que influem o deslocamento da viga não fossem modificados pela mudança do material das barras.

A Figura 5.16 mostra uma comparação entre os deslocamentos máximos apresentados nas vigas durante o ensaio e do carregamento alcançado para o deslocamento $1 / 350$. 

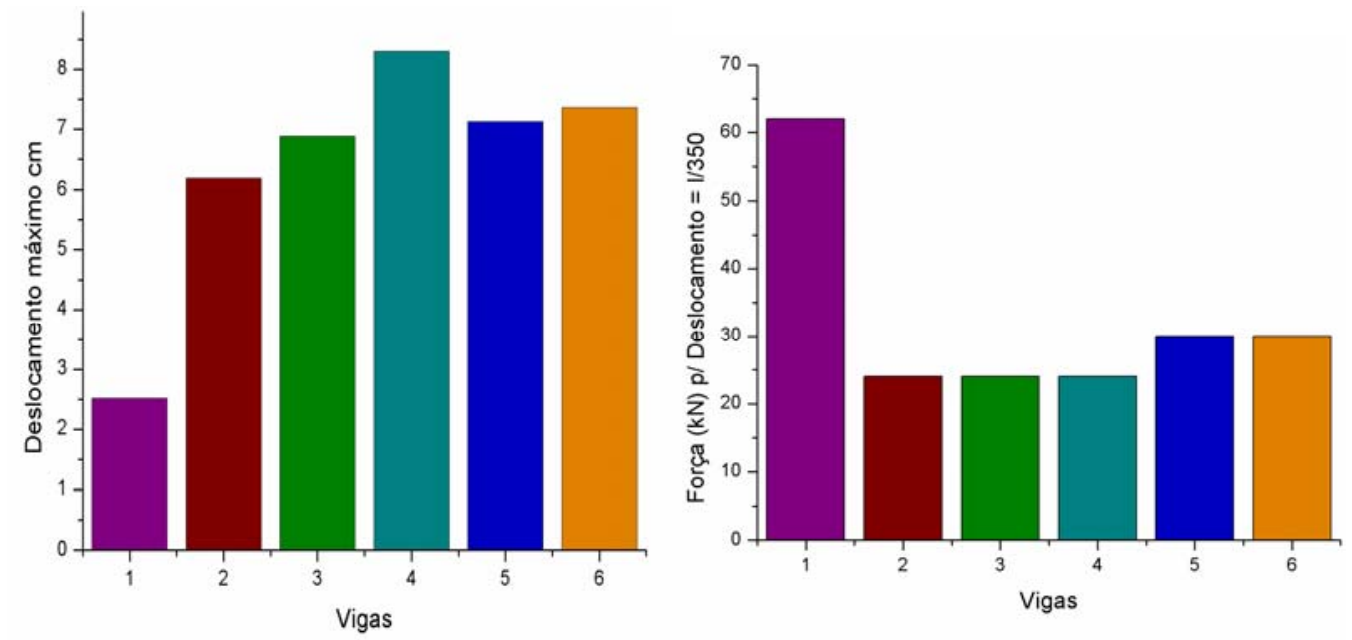

Figura 5.16 Diagramas de comparação dos deslocamentos entre os modelos

\subsubsection{Deformações nas extremidades das barras dos modelos e efetividade dos ganchos}

Diante da comparação do comportamento dos modelos munidos de ganchos nas extremidades com aqueles com a extremidade da barra reta, pôde-se avaliar a influência dos ganchos no comportamento das vigas armadas com GFRP. Fator que diante das variáveis analisadas anteriormente não demonstrou influência.

A Figura 5.17 mostra a localização dos extensômetros nos ganchos para facilitar o entendimento dos resultados.

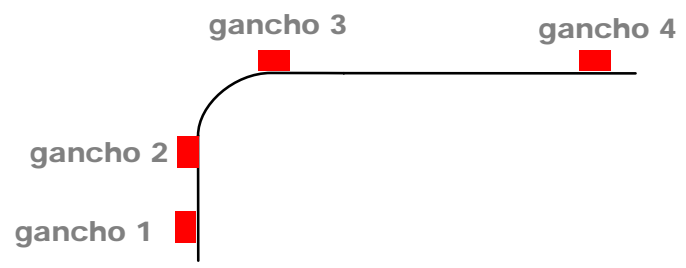

Figura 5.17 Localização dos extênsômetros nos ganchos

Viga armada com aço

Como o gancho na extremidade da barra de aço não pode ser comparado com o gancho de GFRP, por causa das diferenças na montagem (os ganchos longitudinais das barras de GFRP são peças a parte e incluídas com a sua fixação nas barras longitudinais), este não foi instrumentado para análise. Mas a deformação das barras na extremidade pode ser um fator de comparação para avaliação da aderência do conjunto concreto e armadura. 

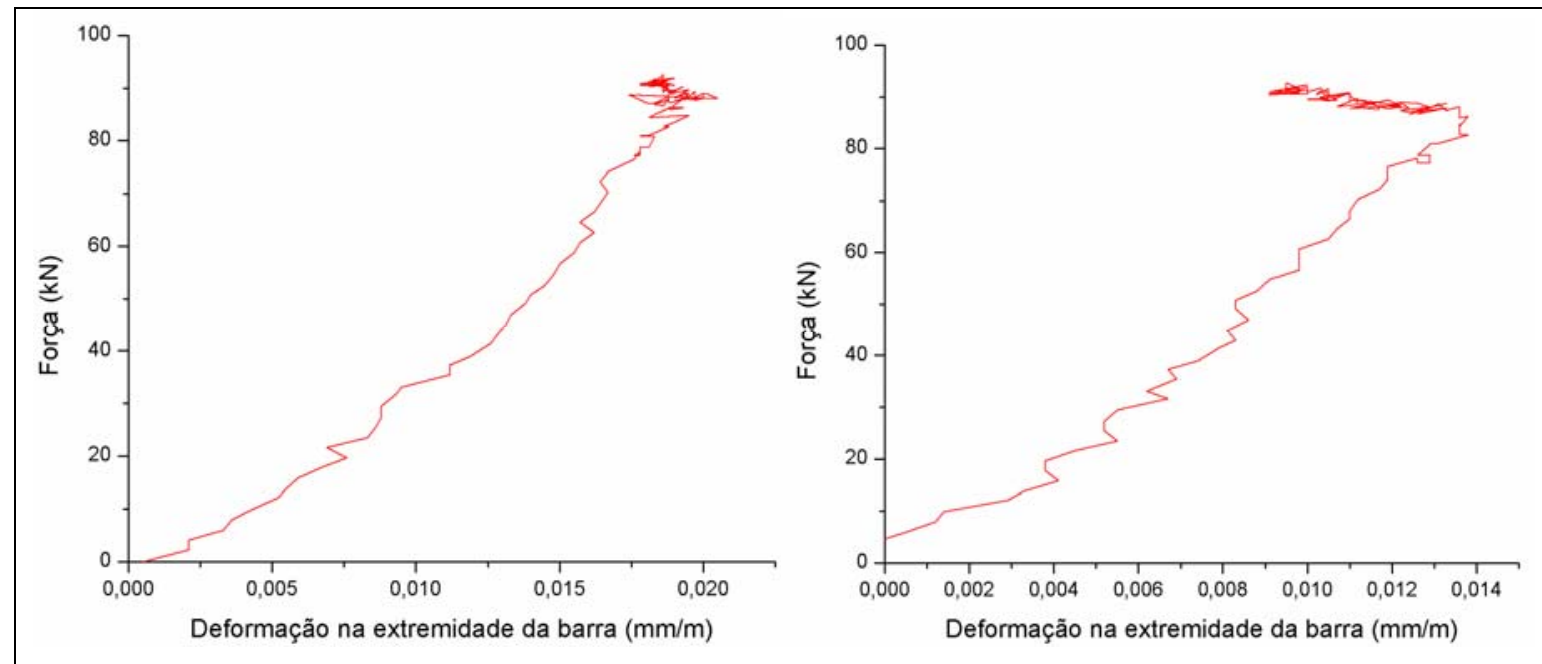

Figura 5.18 Diagrama Força X Deformação na extremidade da barra para o modelo 01

As deformações nas extremidades das duas barras de aço mostraram-se ser muito pequenas, com boa aderência entre os dois materiais.

Viga de GFRP armada com equivalência de capacidade resistente

A Figura 5.19 traz os diagramas de força com a deformação na extremidade das barras dos modelos. A primeira observação a se fazer diz respeito à comparação entre barras de aço e GFRP, é fácil notar que a deformação é maior na extremidade das barras de GFRP. Aos $20 \mathrm{kN}$, por exemplo, essa diferença é de 100\%. Mas ao atingir o carregamento de $40 \mathrm{kN}$ essa diferença cai para menos de $50 \%$. Aos $60 \mathrm{kN}$ a diferença aumenta novamente. Isso mostra não apenas a aderência entre as barras de GFRP é menor que a do aço com o concreto, mas também que o comportamento não pode ser linearmente comparado, ou seja, as deformações não crescem nas mesmas proporções. 


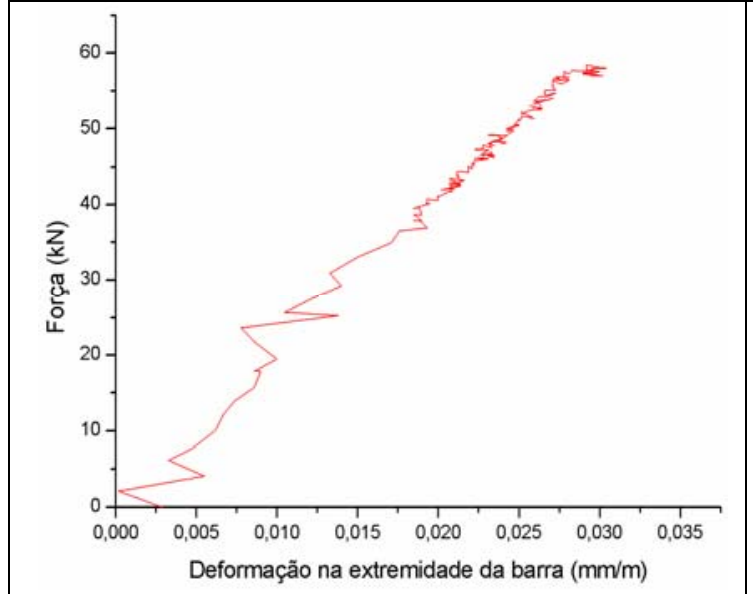

a) Viga 02

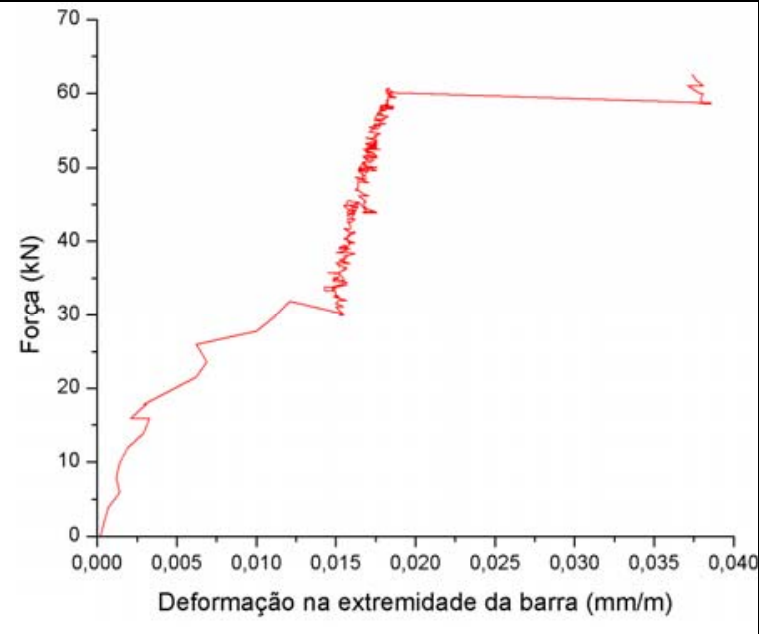

b) Viga 05

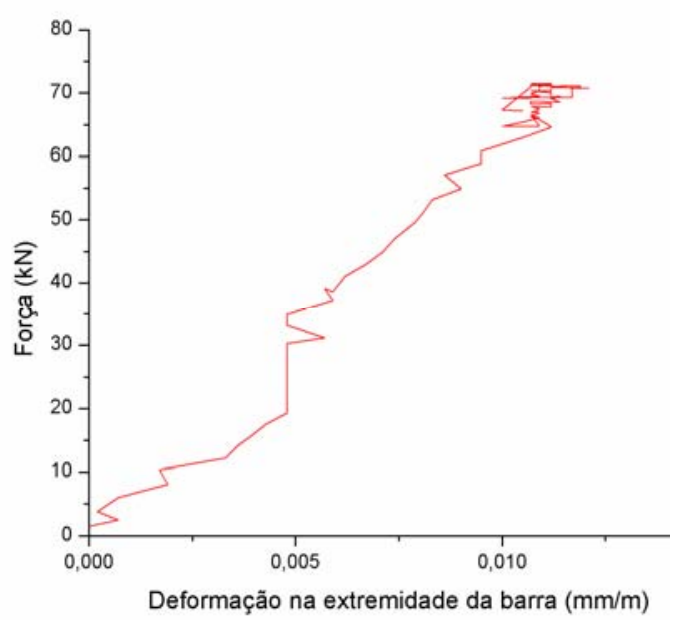

c) Viga 03

Figura 5.19 Diagramas Força X Deformação na extremidade da barra para os modelos 02, 05 e 03

No caso da comparação entre os modelos armados com GFRP, percebe-se que as barras munidas de ganchos nas extremidades possuem um comportamento bem mais linear que o modelo de barra reta. A Viga 05 apresenta um comportamento curioso com períodos de crescimento específicos a cada aumento de carregamento. Aos $30 \mathrm{kN}$ existe uma queda na taxa de deformação por carregamento que se mantém em $0,005 \mathrm{~mm} / \mathrm{m}$ até os $60 \mathrm{kN}$. Nesse carregamento há um aumento muito brusco na deformação, ou uma grande perda na aderência a partir deste carregamento. Claro que quando esses modelos atingiram o carregamento de $60 \mathrm{kN}$ os limites anteriormente impostos de deformação limite e deslocamento limite já haviam sido atingidos. Portanto, no caso das vigas armadas para equivalência da capacidade resistente, o gancho se mostrou uma variável significativa apenas para as seguintes situações: tornar o comportamento da deformação nas extremidades das barras mais linear, ou para manter a aderência a carregamentos mais altos que os impostos por limites de deformação última da armadura e deslocamento do modelo. 


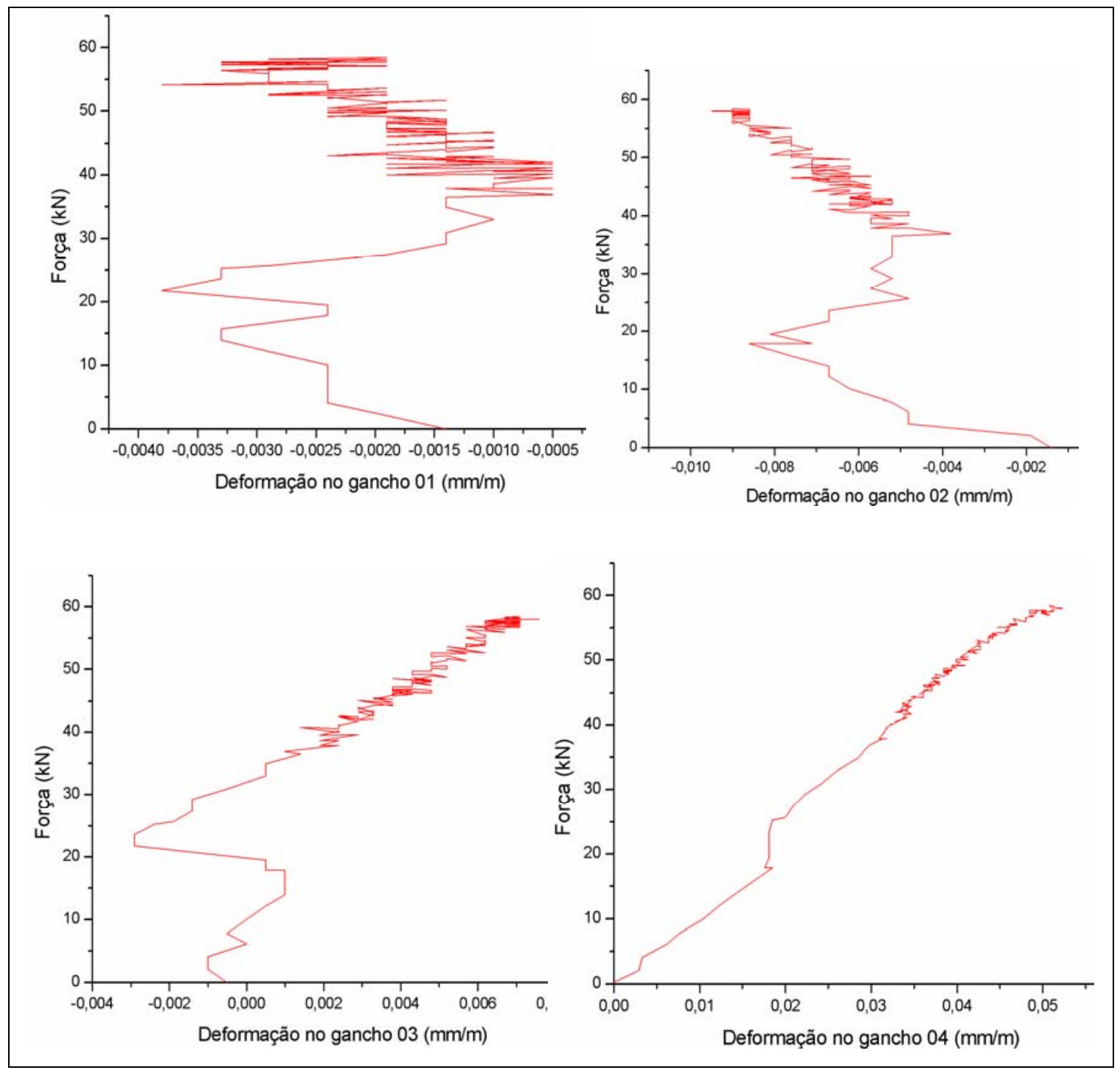

Figura 5.20 Diagramas Força X Deformação no gancho do modelo 02

Na Figura 5.20 é possível verificar como são baixas as deformações no gancho da Viga 02, o que demonstra a sua falta de efetividade no que diz respeito à melhora na ancoragem das barras de GFRP. As maiores deformações não ultrapassam o valor de $0,01 \mathrm{~mm} / \mathrm{m}$. Além disso, é possível observar por meio da análise das deformações negativas das barras na extremidade transversal do gancho, a formação da biela de compressão no apoio da viga. 

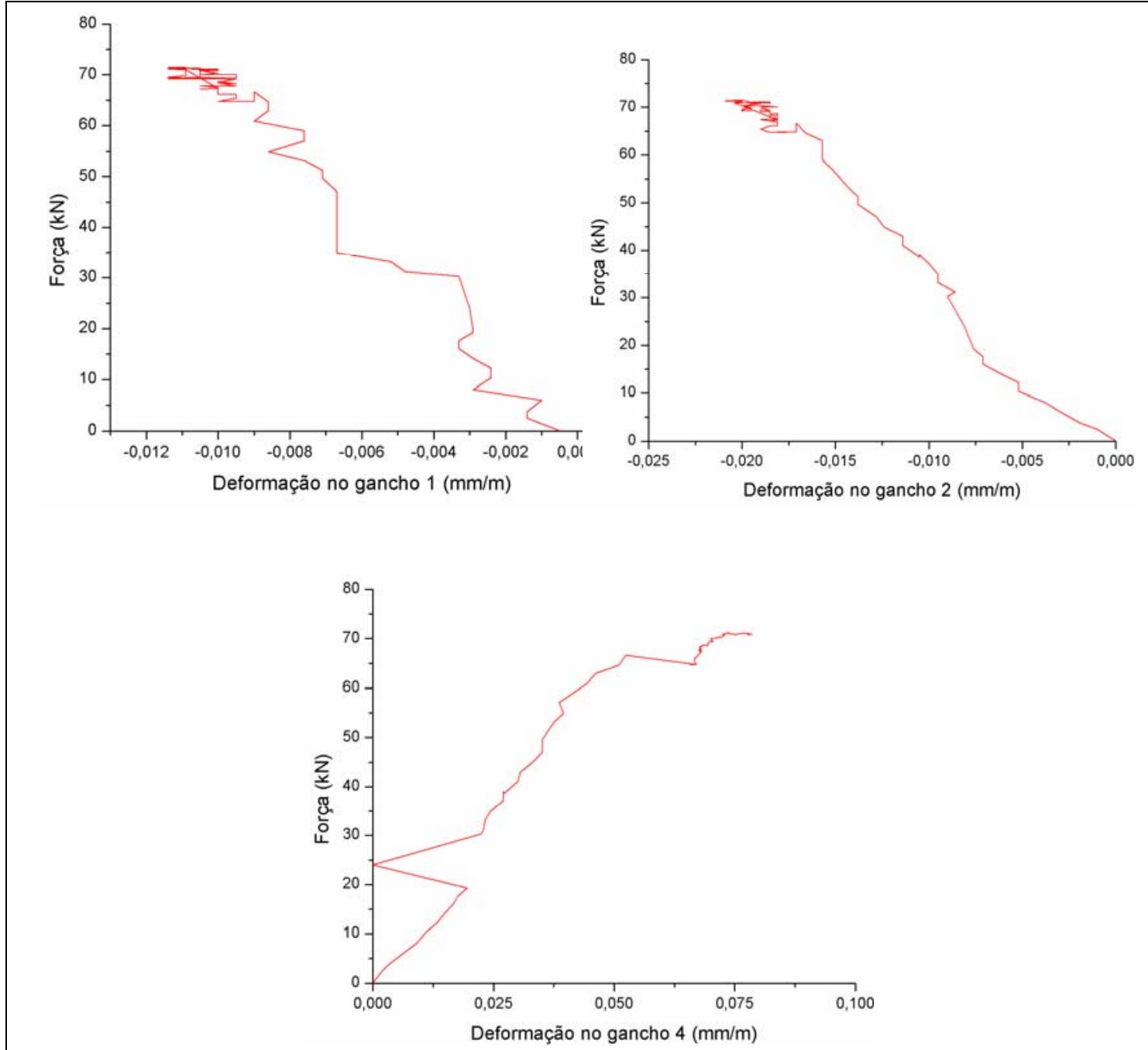

Figura 5.21 Diagramas Força X Deformação no gancho do modelo 03

A Figura 5.21 por sua vez mostra o comportamento do gancho na Viga 03, nesse caso as deformações atingiram valores maiores que na Viga 02, mas ainda assim estes não ultrapassam o valor de $0,05 \mathrm{~mm} / \mathrm{m}$ antes de o carregamento atingir os valores impostos pelos fatores limitantes citados anteriormente.

Viga de GFRP armada com equivalência de deformação última

Na Figura 5.22 pode-se observar as deformações nas extremidades das barras de GFRP naqueles modelos dimensionados com equivalência de deformação última. Mesmo havendo uma maior proximidade de comportamento quanto a deformação destes modelos com o armado com aço, percebe-se um aumento das deformações nas extremidades das barras. Aos $20 \mathrm{kN}$, por exemplo, essa diferença é de menos de $0,0025 \mathrm{~mm} / \mathrm{m}$. Aos $40 \mathrm{kN}$ essa diferença aumenta, mas não chega a $0,005 \mathrm{~mm} / \mathrm{m}$. 
Como a deformação última no meio das barras se mostrou praticamente a mesma, essa diferença de deformação na extremidade destas barras só pode ser explicada pela diferença de comportamento do conjunto GFRP - concreto.

$\mathrm{Na}$ comparação entre o modelo munido de gancho e o outro com extremidade reta, as deformações não apresentaram um crescimento significativo. Na verdade, o comportamento dos dois modelos é muito semelhante, e como nos modelos anteriores, a única contribuição do gancho é evitar um comportamento não linear da deformação na extremidade da barra.

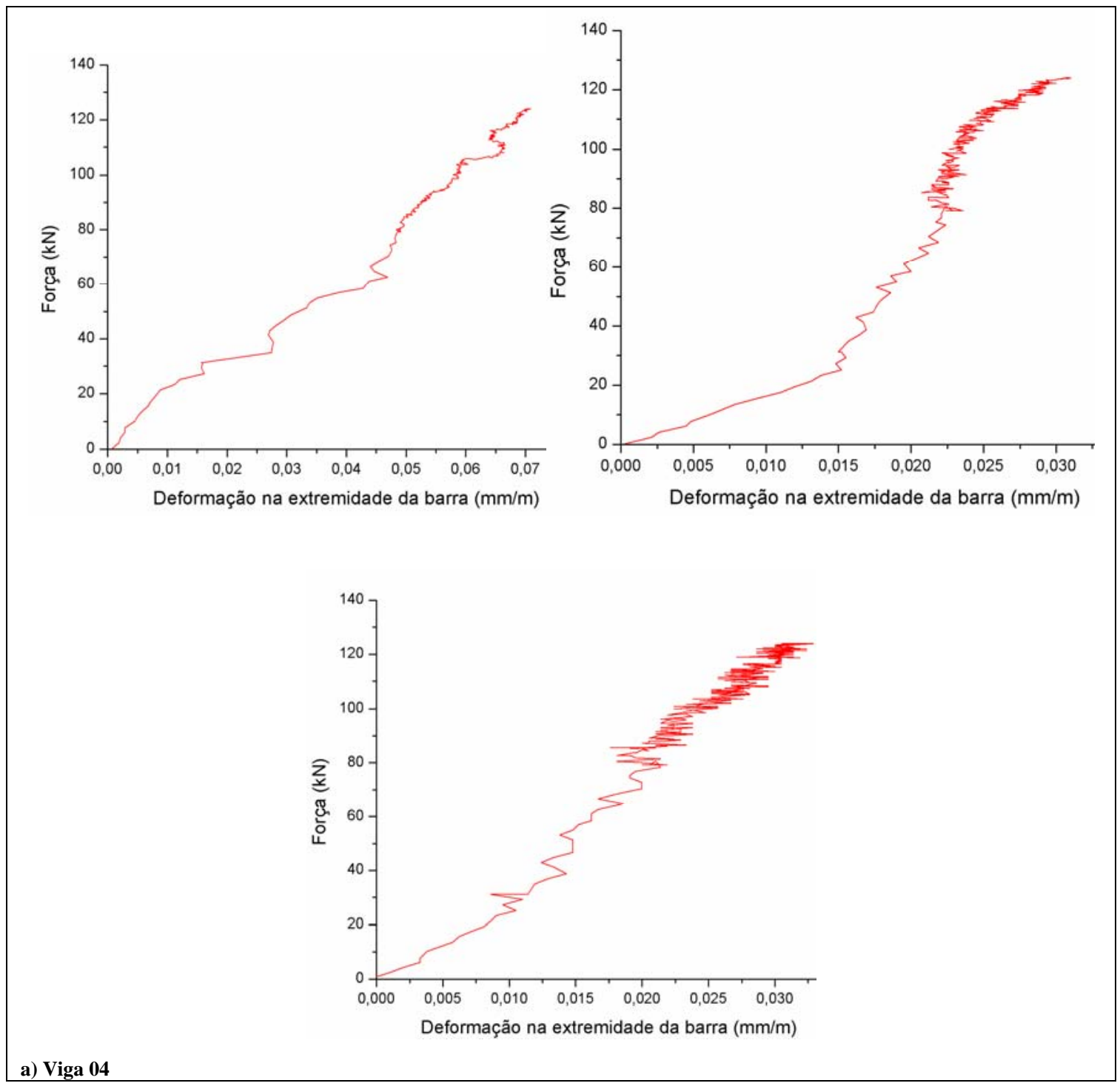



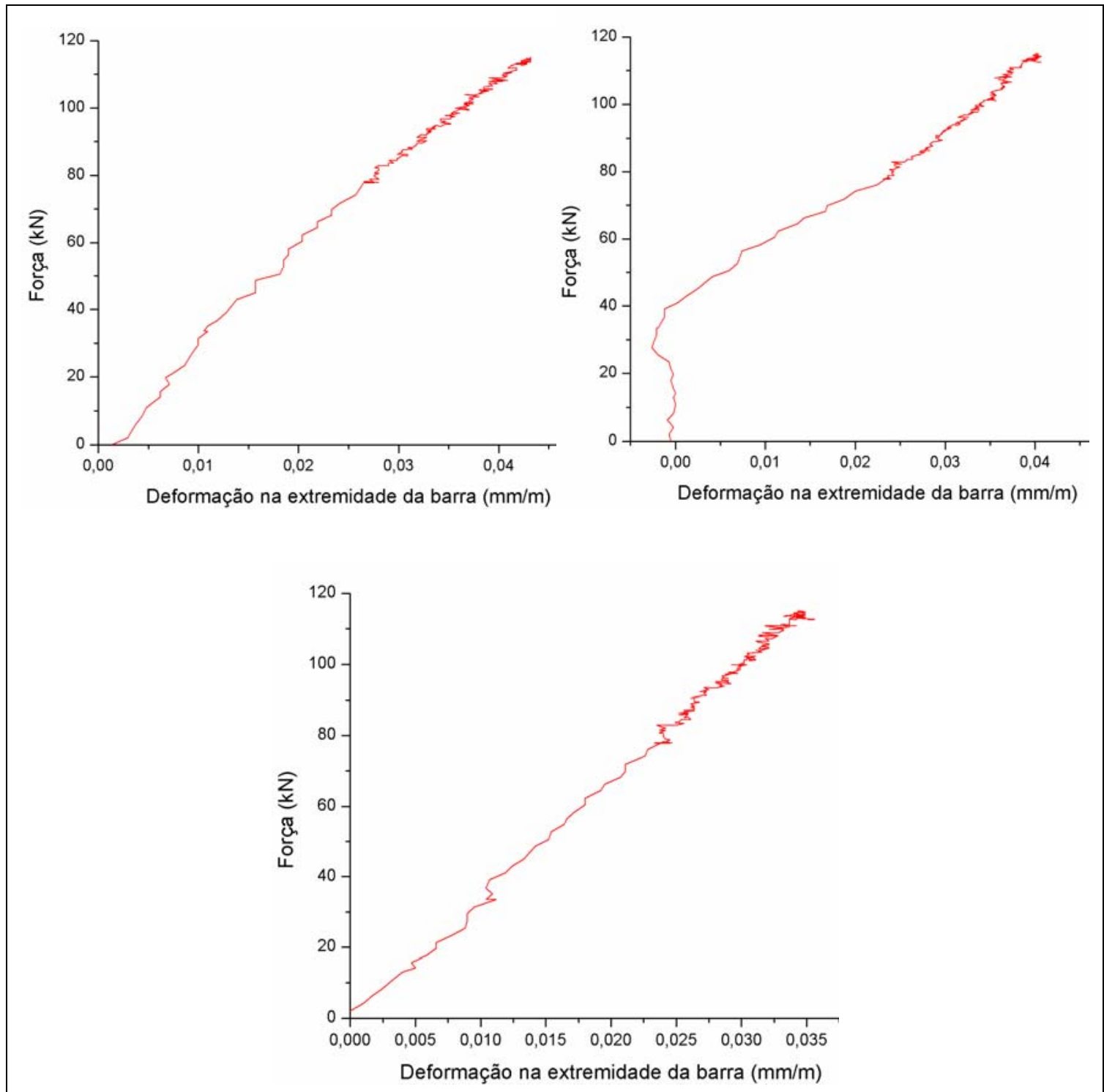

b) Viga 06

Figura 5.22 Diagramas Força X Deformação na extremidade da barra para os modelos 04 e 06

A Figura 5.23 se refere ao comportamento dos ganchos para a Viga 04. Notase a continuidade no padrão do comportamento do modelo. Pequenas deformações e a formação da biela de compressão no apoio. 

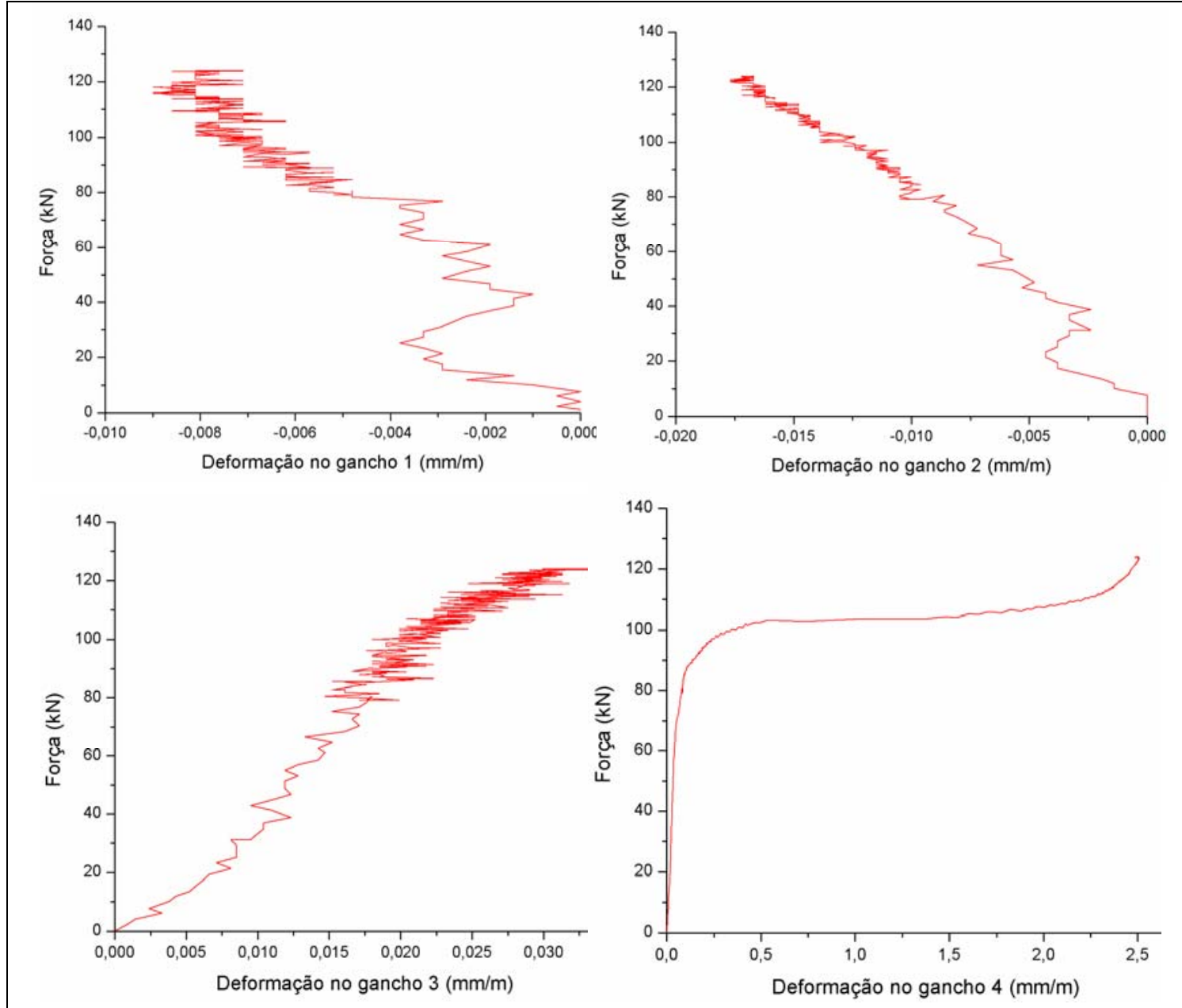

Figura 5.23 Diagramas Força X Deformação no gancho do modelo 04

\subsubsection{Fissuração}

As fissuras de todos os modelos foram mapeadas conforme a Figura 5.24 e pode-se perceber que os modelos dimensionados para equivalência de resistência possuem fissuras mais espaçadas e em menor quantidade que os outros modelos. Já aqueles dimensionados para equivalência de deformação última, as fissuras são mais numerosas do que a encontrada na viga armada com aço. Na Figura 5.24 os modelos estão dispostos em ordem numérica. 


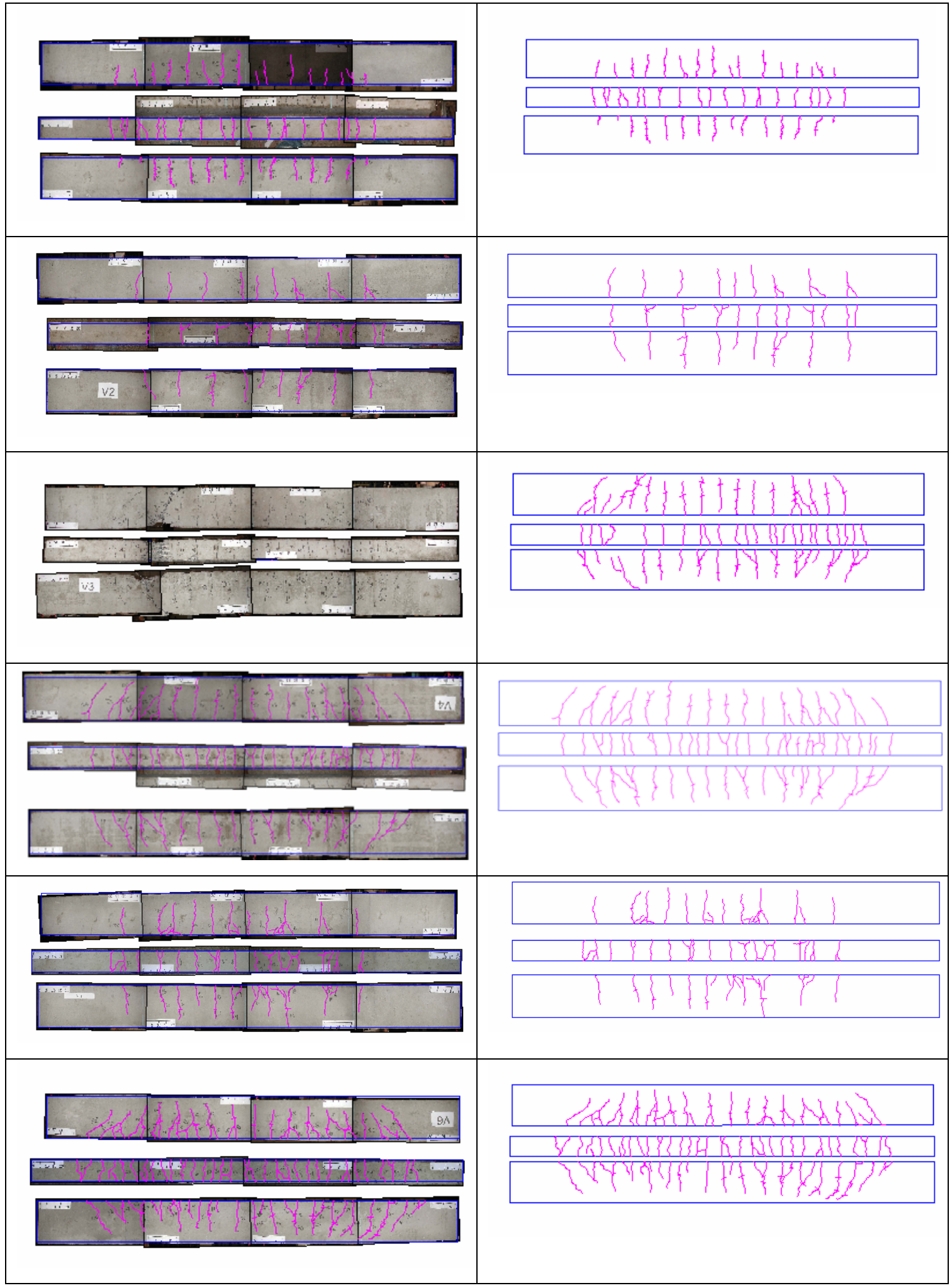

Figura 5.24 Mapeamento e configuração das fissuras dos odelos ensaiados

No ensaio do modelo 03, acompanhou-se também a abertura de fissuras do modelo. Na Tabela 5.7 e Figura 5.25 são apresentados os resultados do ensaio da 
viga 03 e os valores calculados teoricamente pela equação de Gegely-Lutz (1973) adaptada pelo ACl 440.1R-03 e apresentada no capítulo 3 desse trabalho.

$$
w=\frac{2,2}{E_{F R P}} \cdot \gamma \cdot k_{b} \cdot f_{F R P} \cdot \sqrt[3]{d^{\prime} \cdot A_{c c}}
$$

Tabela 5.7 Abertura da fissura na viga 03

\begin{tabular}{|c|c|c|}
\hline $\begin{array}{c}\text { Força } \\
(\mathrm{kN})\end{array}$ & $\begin{array}{c}\text { Abertura da fissura } \\
\text { experimental }(\mathrm{mm})\end{array}$ & $\begin{array}{c}\text { Abertura da fissura } \\
\text { teórica }(\mathrm{mm})\end{array}$ \\
\hline 10 & 0,2 & 0,10 \\
\hline 12 & 0,2 & 0,20 \\
\hline 14 & 0,3 & 0,20 \\
\hline 16 & 0,4 & 0,58 \\
\hline 18 & 0,4 & 0,31 \\
\hline 20 & 0,45 & 0,63 \\
\hline 22 & 0,5 & 0,75 \\
\hline 24 & 0,6 & 0,79 \\
\hline 26 & 0,8 & 1,29 \\
\hline 28 & 0,95 & 1,74 \\
\hline 30 & 1,1 & 1,79 \\
\hline 32 & 1,2 & 1,83 \\
\hline 34 & 1,4 & 1,82 \\
\hline
\end{tabular}

Como se pode observar, o valor da abertura das fissuras teórico é sempre superior ao obtido experimentalmente, com exceção da abertura para $10 \mathrm{kN}$, que por ser muito pequena ainda é de difícil leitura durante o experimento. Portanto, segundo o que foi observado durante o ensaio da viga V03, o modelo teórico de abertura de fissuras é muito conservativo resultando em valores muito distantes daqueles observados no ensaio. 

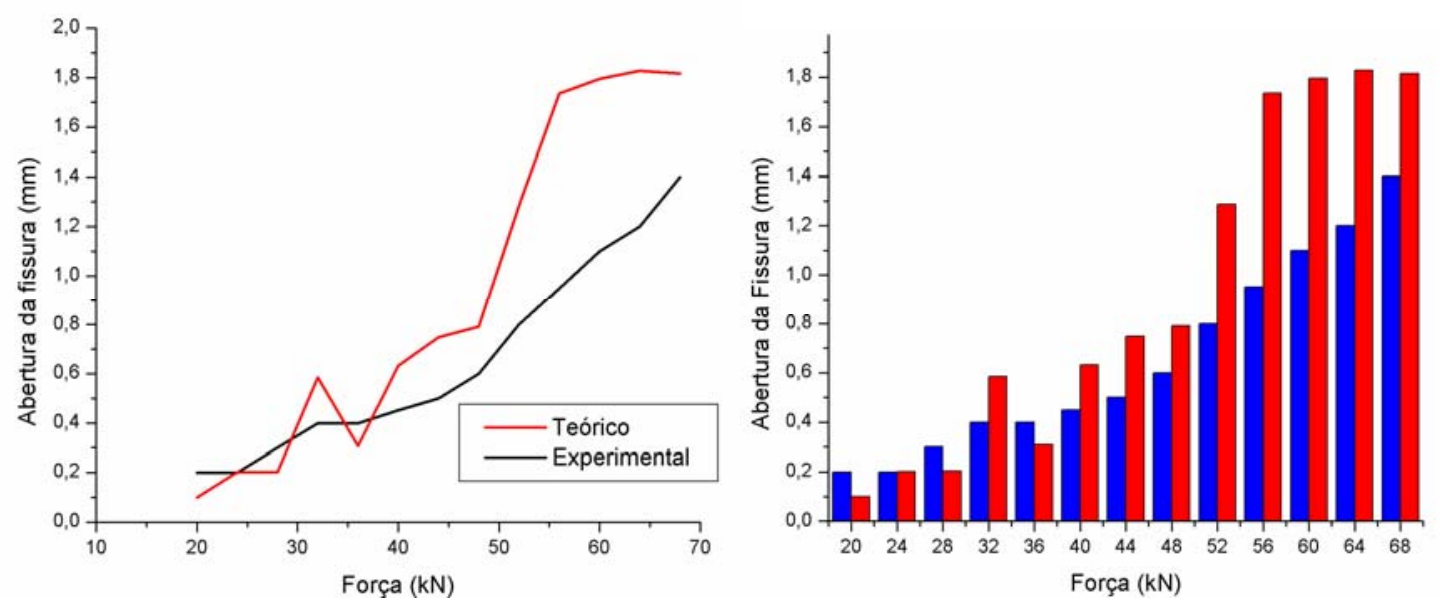

Figura 5.25 Comparação Teórica e Experimental da Abertura de fissuras

Os limites de abertura de fissuras para barras de GFRP impostos na norma japonesa (JSCE, 1997) são de 0,5 mm para ambientes externos e de 0,7 mm para ambientes internos. Na Figura 5.25 é fácil perceber que para uma força de 48 kN , o valor da abertura de fissuras ultrapassa o limite, tanto no caso do valor obtido experimentalmente como no caso do valor calculado teoricamente.

\subsubsection{Comparação entre $M_{R}$ e $M_{S}$}

Para avaliar o comportamento de um elemento estrutural é de fundamental importância a avaliação da sua capacidade resistente. Neste estudo as vigas foram avaliadas por meio da determinação do seu momento resistente $\left(M_{R}\right)$ diante de um momento fletor solicitante $\left(\mathrm{M}_{\mathrm{S}}\right)$.

Para realizar esta avaliação, foram primeiramente determinadas as deformações na armadura da viga e no concreto. As deformações das barras foram medidas experimentalmente e as deformações no concreto foram obtidas utilizando um procedimento teórico baseado na curvatura do modelo apresentado por Park e Paulay (1974) e Fusco (1995).

A curvatura $1 / R$ foi determinada pela medida do deslocamento dos modelos nos apoios e no centro da viga. Partindo dessas medidas, o raio da curvatura foi encontrado pelo arco traçado nestes três pontos.

A Figura 5.26 mostra um elemento de concreto armado inicialmente de seção plana com momentos e forças axiais em equilíbrio. $O$ raio de curvatura $R$ é medido até a linha neutra - LN. 

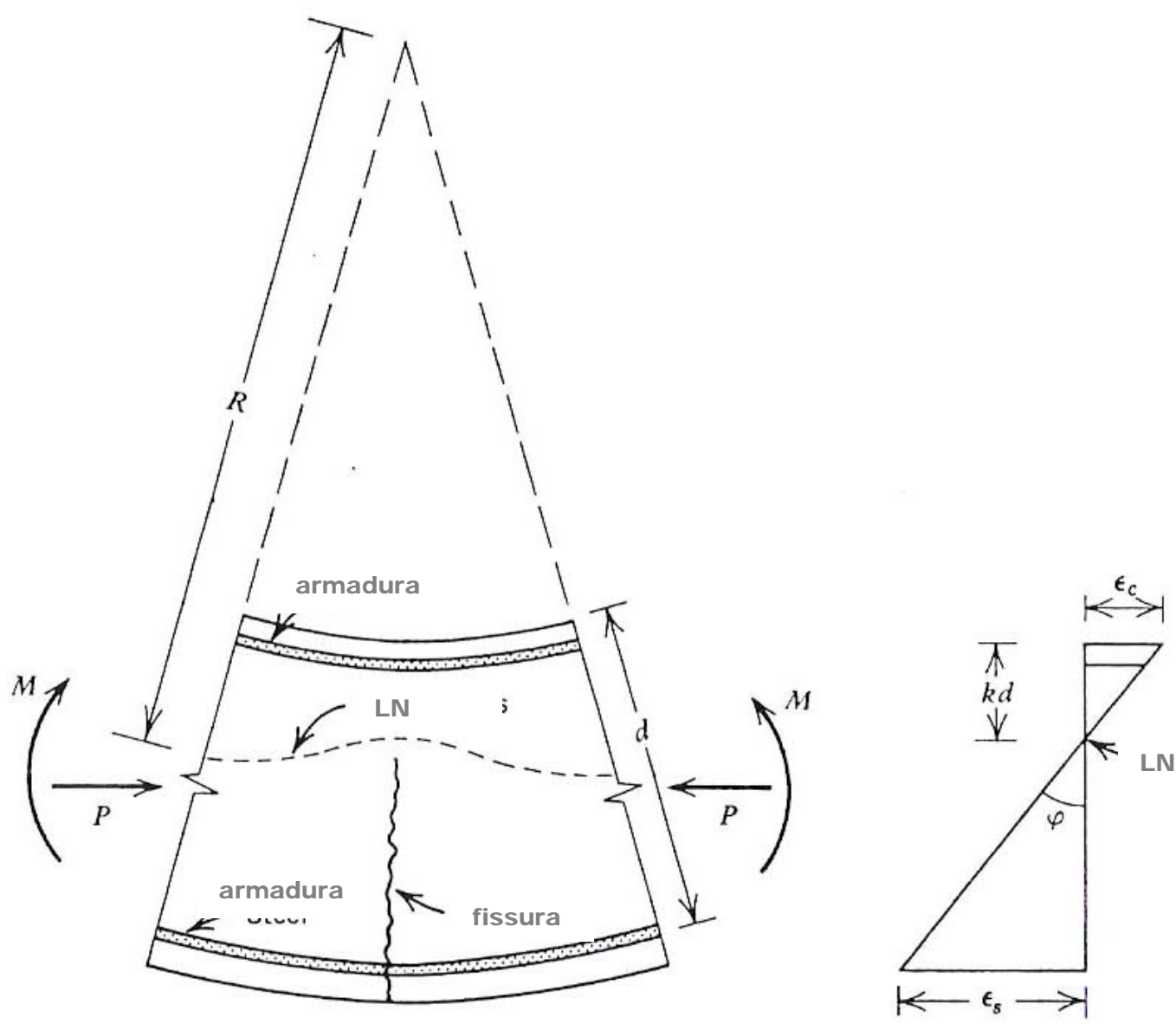

Figura 5.26 - Deformação de um elemento submetido à flexão

Da literatura (FUSCO, 1995 e PARK e PAULAY, 1974) a curvatura e a deformação do concreto e da armadura variam ao longo do comprimento, pois, existe tensão entre as fissuras de concreto. Mas, considerando um elemento de pequeno comprimento pode-se dizer que:

A razão entre o raio de curvatura e o comprimento do elemento ( $d x$ ) é proporcional à razão entre a deformação do concreto neste comprimento $\mathrm{dx}$ e a altura da linha neutra definida pela multiplicação entre a altura útil e um coeficiente $k$. A razão é também proporcional à deformação na armadura no comprimento $d x$ e a distância do seu centro de inércia e a linha neutra.

$\frac{d_{x}}{R}=\frac{\varepsilon_{c} d_{x}}{k d}=\frac{\varepsilon_{s} d_{x}}{d(1-k)}$

Portanto: 
$\frac{1}{R}=\frac{\varepsilon_{c}}{k d}=\frac{\varepsilon_{s}}{d(1-k)}$

Eliminando o fator $k$ têm-se que:

$\frac{1}{R}=\frac{\varepsilon_{c}+\varepsilon_{s}}{d}$

5-2

Determinando dessa forma, a deformação no concreto, uma vez que a curvatura é conhecida bem como a deformação na armadura e a altura útil do elemento. Os pontos escolhidos foram: o instante em que o deslocamento atingiu o valor do vão/350 e o último valor registrado no ensaio ou em etapa de carga anterior à ruptura.

A Tabela 5.8 mostra o valor das variáveis envolvidas no procedimento.

Tabela 5.8 Definição da deformação do concreto na borda comprimida

\begin{tabular}{c|ccccccc}
\hline viga & \multicolumn{2}{|c}{$\begin{array}{c}F \\
(\mathrm{kN})\end{array}$} & $\begin{array}{c}\text { Momento } \\
\text { Solicitante } \\
(\mathrm{kN} \mathrm{cm})\end{array}$ & $\begin{array}{c}\varepsilon_{s} \\
(\%)\end{array}$ & $\begin{array}{c}d \\
(\mathrm{~cm})\end{array}$ & $\begin{array}{c}\text { Deslocamento } \\
(\mathrm{cm})\end{array}$ & $\begin{array}{c}\varepsilon_{c c} \\
(\%)\end{array}$ \\
\hline 01 & $\mathrm{~F}(\mathrm{I} / 300)$ & 64,4 & 3038,22 & 2,13 & 26,88 & 9,3 & 0,28 \\
& $\mathrm{Fu}$ & 90,28 & 4355,16 & 3,49 & 26,88 & 23,2 & 0,54 \\
02 & $\mathrm{~F}(\mathrm{I} / 300)$ & 25,2 & 1187,08 & 4,02 & 27,02 & 10,7 & 0,49 \\
& $\mathrm{Fu}$ & 58 & 2745,98 & 15,00 & 27,02 & 59,7 & 0,32 \\
03 & $\mathrm{~F}(\mathrm{I} / 300)$ & 30,4 & 1422,31 & 5,43 & 27,18 & 19,3 & 0,72 \\
& $\mathrm{Fu}$ & 69,8 & 3289,44 & 15,00 & 27,18 & 64,5 & 1,74 \\
04 & $\mathrm{~F}(\mathrm{I} / 300)$ & 31,2 & 1468,61 & 3,19 & 27,02 & 8,9 & 1,51 \\
& $\mathrm{Fu}$ & 123,4 & 5802,15 & 15,00 & 27,02 & 77,4 & 3,80 \\
& $\mathrm{~F}(\mathrm{I} / 300)$ & 25,4 & 1196,48 & 4,97 & 27,02 & 9,8 & 0,90 \\
& $\mathrm{Fu}$ & 62,4 & 2939,19 & 15,00 & 27,02 & 61,4 & 1,05 \\
06 & $\mathrm{~F}(\mathrm{I} / 300)$ & 33,4 & 1577,09 & 2,62 & 27,02 & 10,0 & 1,04 \\
& $\mathrm{Fu}$ & 113,5 & 5286,51 & 15,00 & 27,02 & 70,2 & 3,34 \\
\hline
\end{tabular}

Definidas as deformações dos materiais envolvidos, a determinação da capacidade resistente do elemento é feita com as das diretrizes de cálculo definidas na NBR 6118:2003 para a viga com barras de aço e com as indicações apresentadas 
no capítulo 3 para as vigas de GFRP. A Figura 5.27 esquematiza como foi realizada a avaliação da capacidade resistente para os modelos de viga adotados neste estudo.

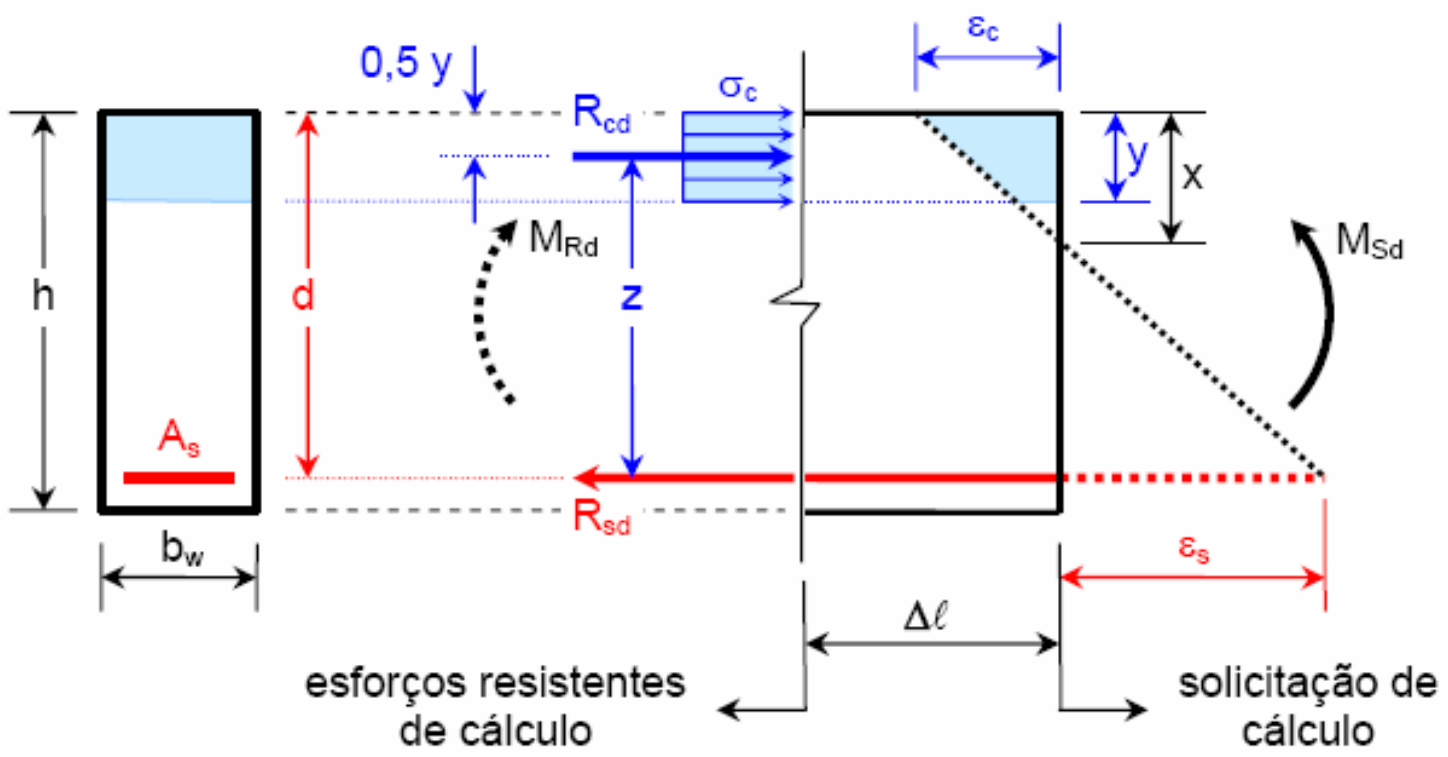

Figura 5.27 Seção transversal típica de uma viga de concreto simplesmente armada

Portanto, é fácil perceber a semelhança entre os triângulos formados pelas deformações dos materiais e a posição da linha neutra é definida pela compatibilidade de deformações.

$$
\frac{\varepsilon_{c}}{x}=\frac{\varepsilon_{s}}{d-x}
$$

As tensões do concreto e da armadura foram definidas a partir dos diagramas tensão $x$ deformação apresentados nos items 5.1 e 5.2 deste capítulo. A Tabela 5.9 traz os valores das tensões e da posição da linha neutra. 
Tabela 5.9 Determinação da posição da linha neutra e das tensões nos materiais

\begin{tabular}{c|cccccccc}
\hline viga & $F$ & $\varepsilon_{s}$ & $\varepsilon_{c c}$ & $x$ & $Y$ & $\sigma_{c}$ & $A_{c}$ & $f_{s}$ \\
& $(k N)$ & $(\% \circ)$ & $(\% o)$ & $(\mathrm{cm})$ & $(\mathrm{cm})$ & $\left(\mathrm{kN} / \mathrm{cm}^{2}\right)$ & $\mathrm{cm}^{2}$ & $\left(\mathrm{kN} / \mathrm{cm}^{2}\right)$ \\
\hline 01 & $\mathrm{~F}(1 / 300)$ & 2,13 & 0,28 & 3,2 & 2,6 & 1,03 & 38,70 & 34,13 \\
& $\mathrm{Fu}$ & 3,49 & 0,54 & 3,2 & 2,5 & 1,93 & 38,00 & 56,00 \\
02 & $\mathrm{~F}(1 / 300)$ & 4,02 & 0,49 & 2,9 & 2,0 & 1,73 & 29,88 & 15,33 \\
& $\mathrm{Fu}$ & 15,00 & 0,32 & 0,6 & 0,4 & 1,15 & 5,67 & 57,24 \\
03 & $\mathrm{~F}(1 / 300)$ & 5,43 & 0,72 & 2,9 & 2,0 & 2,35 & 29,42 & 20,19 \\
& $\mathrm{Fu}$ & 15,00 & 1,74 & 2,9 & 2,1 & 3,91 & 31,40 & 55,76 \\
04 & $\mathrm{~F}(1 / 300)$ & 3,19 & 1,51 & 8,8 & 6,4 & 3,74 & 95,77 & 12,19 \\
& $\mathrm{Fu}$ & 15,00 & 3,80 & 5,6 & 4,7 & 3,99 & 71,19 & 57,24 \\
05 & $\mathrm{~F}(1 / 300)$ & 4,97 & 0,90 & 4,2 & 2,9 & 0,34 & 44,14 & 18,95 \\
& $\mathrm{Fu}$ & 15,00 & 1,05 & 1,8 & 1,3 & 0,39 & 18,93 & 57,24 \\
\multirow{2}{*}{06} & $\mathrm{~F}(\mathrm{l} / 300)$ & 2,62 & 1,04 & 7,8 & 5,5 & 3,31 & 82,49 & 10,01 \\
& $\mathrm{Fu}$ & 15,00 & 3,34 & 5,0 & 4,1 & 3,47 & 61,81 & 57,24 \\
\hline
\end{tabular}

As forças resultantes na viga armada com barras de aço segundo a NBR 6118:2003 são dadas por:

$$
\begin{aligned}
& R_{c c}=A_{c c} \cdot \sigma_{c} \quad y=0,8 \cdot x \\
& A_{c c}=b_{w} \cdot y \quad \sigma_{c}=0,85 \cdot f_{c} \\
& R_{s}=A_{s} \cdot f_{s}=A_{s} \cdot \varepsilon_{s} \cdot E_{s}
\end{aligned}
$$

As forças resultantes na viga armada com barras de aço segundo as diretrizes do capítulo 3 são dadas por:

$$
\begin{aligned}
& R_{c c}=A_{c c} \cdot \sigma_{c d} \\
& A_{c c}=b_{w} \cdot y \\
& y=\gamma \cdot x \\
& \sigma_{c d}=\alpha \cdot f_{c d} \quad \alpha=-68711 \cdot \varepsilon_{c}^{2}+464,79 \cdot \varepsilon_{c}+0,01
\end{aligned}
$$




$$
\begin{aligned}
& \gamma=2 \cdot\left(1962,6 \cdot \varepsilon_{c}^{2}+17,89 \cdot \varepsilon_{c}+0,33\right) \\
& R_{F R P}=A_{F R P} \cdot f_{F R P}=A_{F R P} \cdot \varepsilon_{F R P} \cdot E_{F R P}
\end{aligned}
$$

Como as deformações no concreto foram determinadas pelo processo do raio de curvatura, optou-se por utilizar as deformações nas armaduras e, consequentemente, as forças resultantes por elas definidas para determinação da capacidade resistente.

Com as forças resultantes e o braço de alavanca, o momento resistente é facilmente calculado. Tabela 5.10 apresenta os momentos resistentes e os respectivos solicitantes para cada viga.

Tabela 5.10 definição do momento resistente das vigas

\begin{tabular}{c|cccccc}
\hline viga & & $R_{s}$ & $d$ & $z$ & $M_{R}$ & $M_{S}$ \\
& & $(k N)$ & $c m$ & $c m$ & $k N . c m$ & $k N . c m$ \\
\hline 01 & $\mathrm{~F}(1 / 300)$ & 83,73 & 26,88 & 26,02 & 2178,26 & 3038,22 \\
& $\mathrm{Fu}$ & 137,37 & 26,88 & 26,03 & 3575,86 & 4355,16 \\
02 & $\mathrm{~F}(1 / 300)$ & 21,85 & 27,02 & 26,03 & 568,75 & 1187,08 \\
& $\mathrm{Fu}$ & 81,62 & 27,02 & 26,83 & 2190,16 & 2745,98 \\
03 & $\mathrm{~F}(1 / 300)$ & 31,95 & 27,18 & 26,20 & 837,13 & 1422,31 \\
& $\mathrm{Fu}$ & 88,24 & 27,18 & 26,14 & 2306,24 & 3289,44 \\
04 & $\mathrm{~F}(1 / 300)$ & 37,64 & 27,02 & 23,83 & 897,06 & 1468,61 \\
& $\mathrm{Fu}$ & 176,78 & 27,02 & 24,65 & 4357,78 & 5802,15 \\
05 & $\mathrm{~F}(1 / 300)$ & 27,03 & 27,02 & 25,55 & 690,58 & 1196,48 \\
& $\mathrm{Fu}$ & 81,62 & 27,02 & 26,39 & 2154,10 & 2939,19 \\
\multirow{2}{*}{06} & $\mathrm{~F}(1 / 300)$ & 30,90 & 27,02 & 24,27 & 750,09 & 1577,09 \\
& $\mathrm{Fu}$ & 176,78 & 27,02 & 24,96 & 4413,03 & 5286,51 \\
\hline
\end{tabular}

A Figura 5.28 traz uma comparação entre os valores dos momentos resistentes e os momentos fletores solicitantes nas vigas para o instante em que o valor dos deslocamentos atingiu o limite do vão efetivo dividido por 350, imposto na NBR 6118:2003.. 


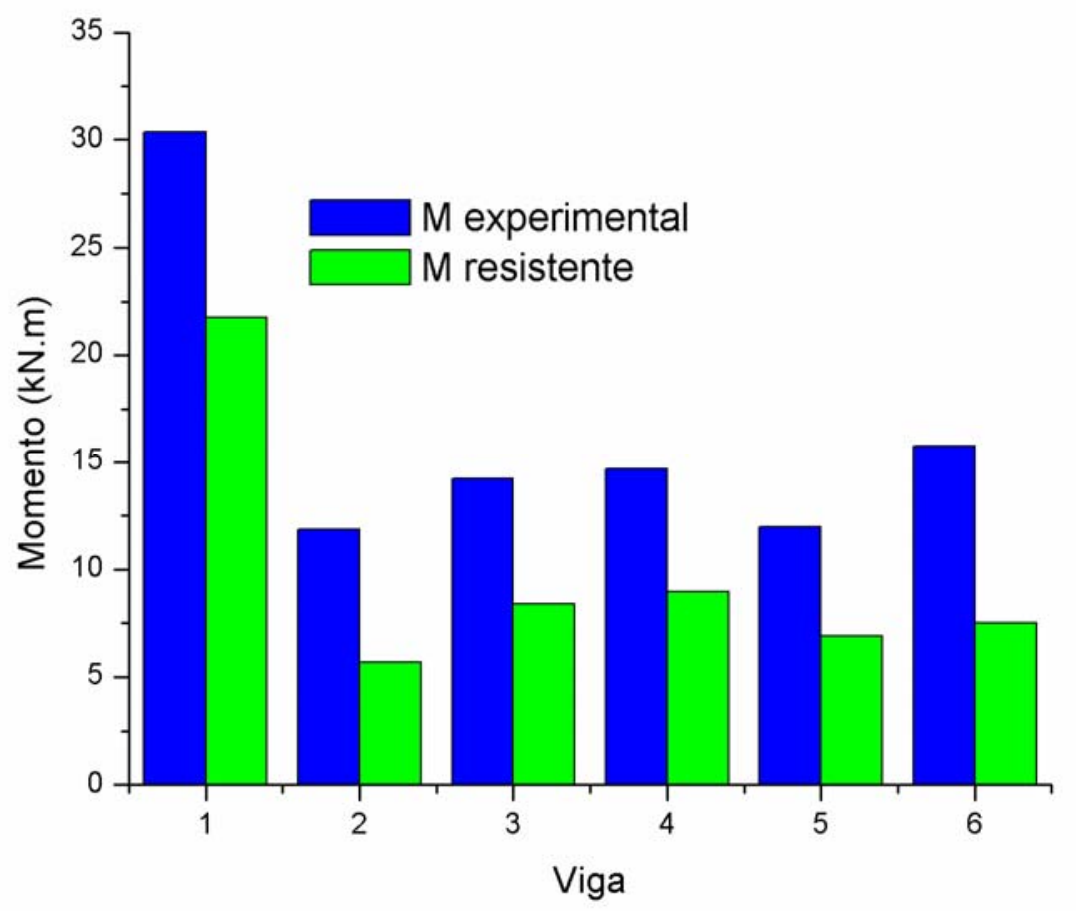

Figura 5.28 Comparação entre Momentos para o Estado Limite de Serviço

A diferença entre os dois resultados pode ser explicada, pela aproximação das deformações do concreto calculadas pelo procedimento descrito e não medidas durante o ensaio. A diferença em alguns casos chega a ser superior a $50 \%$. Além desta variável, há também o problema das hipóteses de dimensionamento utilizadas para se encontrar o valor do momento resistente.

O baixo módulo de elasticidade das barras de GFRP foi uma variável de extrema importância na determinação dos momentos. Para este deslocamento os modelos armados com barras de GFRP atingiram momentos muito inferiores àqueles atingidos pelo armado com barras de aço CA-50. Mesmo os modelos armados com equivalência de deformação última, apresentaram uma capacidade resistente muito inferior à do modelo armado com barras de aço.

A Figura 5.29 mostra os momentos: resistente último, fletor solicitante último e o valor do momento último encontrado teoricamente na determinação dos modelos. Lembrando que os valores últimos para os modelos 02, 05 e 06, representam apenas a última leitura obtida dos modelos, pois estes não foram levados à ruína. 


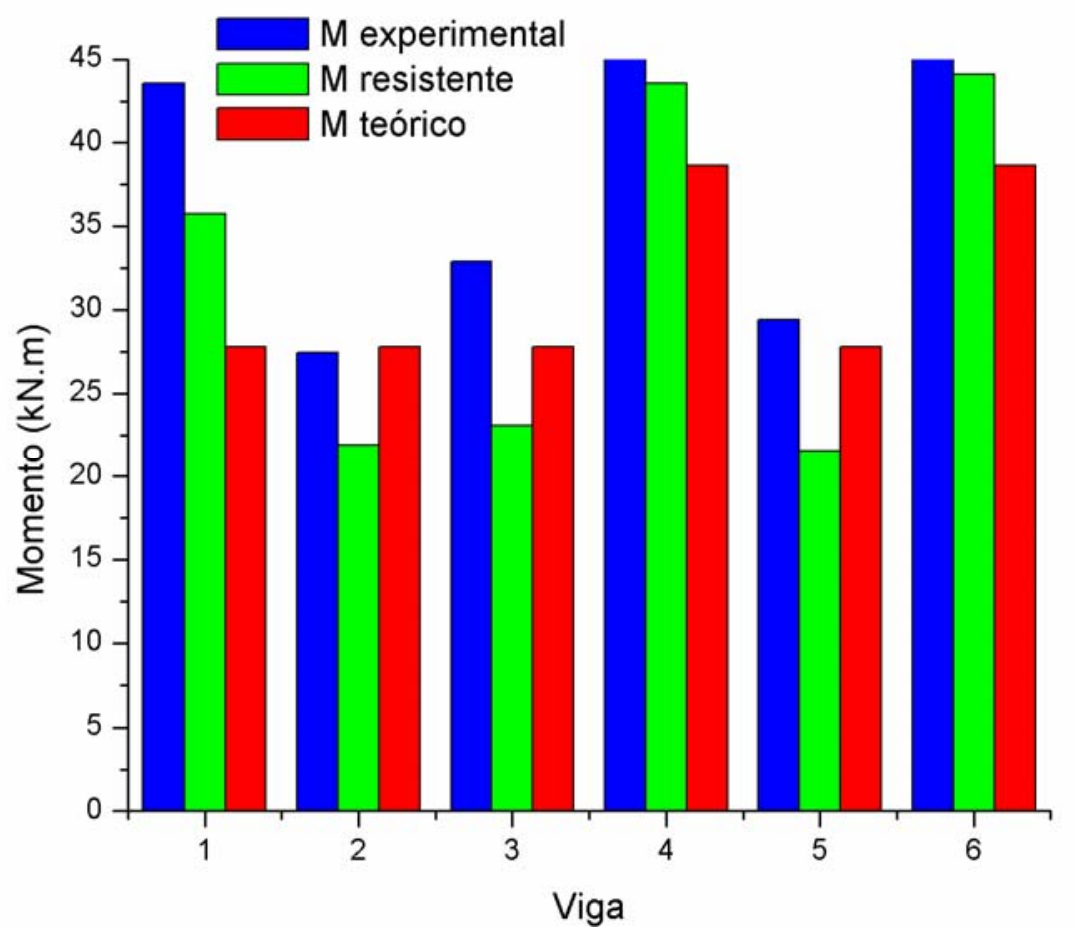

Figura 5.29 Comparação dos Momentos para o Estado Limite Ultimo

Para a viga 01, a diferença entre o valor dos momentos explica-se tanto pela resistência do concreto que apresentou valor superior ao previsto, no caso da diferença entre o teórico e o experimental, quanto pela deformação do concreto que foi uma variável obtida analiticamente.

Os modelos 02, 03 e 05, apresentaram pouca diferença entre o teórico e o experimentalmente obtido. Porém, a diferença da capacidade resistente entre esses modelos e o modelo armado com barras de aço é preocupante. Mesmo com as diferenças no concreto, comparando-se os valores, se existiu um aumento de resistência do concreto não previsto, este aumento não foi verificado para estes modelos.

Portanto, pode-se afirmar que esses modelos dimensionados para equivalência de capacidade resistente foram dimensionados de tal modo a não atingir a resistência do modelo armado com barras de aço conforme era previsto. Claro que esta afirmação não poderia ser feita analisando-se apenas os resultados obtidos para os modelos 02 e 05, pois eles não foram rompidos, mas o comportamento do modelo 03 admite esta afirmação como verdadeira.

Já os modelos dimensionados para equivalência de deformações, modelos 04 e 06 apresentaram resistências iguais ou superiores àquelas da viga armada com 
barras de aço. Não foi com este objetivo que elas foram dimensionadas, mas como o rompimento da viga 06 se deu pelo esmagamento do concreto comprimido, pode-se explicar essa semelhança, em função do limite da capacidade resistente do concreto.

Dessa análise é possível concluir que o dimensionamento de elementos de viga armados com GFRP deve ser feito para se utilizar a totalidade da capacidade resistente do concreto e tentar utilizar o máximo da capacidade resistente das armaduras de GFRP, sem que essa seja o tipo de ruína governante no comportamento da estrutura. 


\section{CONSIDERAÇÕES FINAIS}

Em qualquer construção, a estrutura é a parte responsável por manter o todo, ela é o esqueleto do corpo. Os materiais utilizados devem ser confiáveis, para isso é necessário o conhecimento de suas propriedades e comportamento quando inserido em um elemento estrutural. Para armaduras não metálicas de GFRP, este trabalho significa a primeira de muitas outras pesquisas a serem realizadas no Departamento de Estruturas e em outros na Universidade.

Este pioneirismo na área vem abrir um amplo leque de possibilidades de estudos em barras de FRP e mais especificamente de GFRP. As propriedades do material e seu comportamento continuam sendo desconhecidos, mas agora não totalmente. As dificuldades de se lidar com o novo, são os desafios de adaptação de equipamentos e do raciocínio frente ao diferente.

A primeira dificuldade enfrentada nesta pesquisa refere-se ao fato de que não se sabia qual a aparência das barras de GFRP, o seu comprimento real e ainda como seriam adicionados os ganchos nas extremidades. Definir um cronograma de trabalho efetivo sem saber com o que se está lidando e dependendo de materiais vindos de outro país é praticamente impossível.

O ensaio de tração das barras de GFRP ainda é um desafio a ser superado em pesquisas futuras. Utilizando-se as diretrizes do ASTM D 3916-02 pôde-se determinar com sucesso o digrama tensão $x$ deformação das barras, mas ainda não foi possível determinar com eficiência a capacidade resistente destas barras na tração. 
Na montagem dos elementos foi bastante difícil lidar com a grande flexibilidade do material. $\mathrm{Na}$ amarração das barras de GFRP e dos estribos de aço a viga apresentava um deslocamento, pois, os estribos em virtude do sua massa flexionavam as barras. Na concretagem era difícil manter o elemento imóvel na fôrma, para isso foi necessário um maior número de espaçadores e de pesos para evitar que a armadura saísse do fundo da fôrma.

As incertezas do comportamento das vigas durante o ensaio, juntamente com uma preocupação quanto à segurança dos equipamentos e dos técnicos envolvidos foram os principais motivos de se limitar a maioria dos ensaios das vigas armadas com GFRP para a capacidade de deformação dos extensômetros nas barras. Os ensaios das duas últimas vigas, V03 e V04, foram executados até a ruína das vigas. A viga V04 ruiu por esmagamento do concreto, e a viga V03 pela ruptura da armadura. Em ambos os modelos, as rupturas foram repentinas, mas, como relatado por outros pesquisadores, a ruptura da barra de GFRP, leva o elemento a uma ruína mais caótica e repentina do que aquela definida pelo esmagamento do concreto.

O comportamento das vigas armadas com GFRP desenvolveu-se da maneira esperada, considerando-se a natureza das barras. Durante os ensaios eram visíveis as fortes influências de algumas propriedades como o pequeno módulo de elasticidade comparando com o do aço e o comportamento elástico diante dos esforços solicitantes. Os únicos valores que resultaram fora do esperado foram os da resistência das vigas armadas para equivalência da capacidade resistente do modelo armado com barras de aço. O modelo armado com barras de aço surpreendeu no que se refere ao aumento de resistência em virtude do aumento da capacidade resistente do concreto empregado no modelo.

O comportamento elástico das barras leva à sensação que, depois de descarregada a viga volta à sua geometria inicial, dando a impressão de que as deformações diminuem com a diminuição das forças aplicadas. Mas, é fato que o concreto possui um comportamento elasto-plástico, tornando impossível essa situação extrema. A ilusão é provocada pela propriedade de comportamento elástico da barra que pode sim, anular suas deformações após o seu carregamento, excluindo-se as barras rompidas ou com deformações extremamente avançadas.

O pequeno módulo de elasticidade leva o deslocamento da viga a intensidades muito mais elevadas para uma mesma força, como foi claramente explicitado nos 
diagramas Força x Deslocamentos de cada viga, demonstrando que este normalmente é o fator limitante no dimensionamento de vigas simplesmente armadas. Este baixo módulo de elasticidade aumenta muito a taxa de armadura de GFRP necessária para que uma viga simplesmente armada obedeça aos Estados Limites Último e de Serviço definidos nas normas de dimensionamento nacionais e internacionais.

Essa mesma conclusão abre a oportunidade de novas pesquisas para constatar outras aplicações das barras de GFRP que possam se favorecer do fato da barra ter módulo de elasticidade pequeno e comportamento elástico.

Isto é, esta pesquisa é o início de um estudo maior que num futuro próximo pode englobar outros assuntos envolvidos. Pode-se sugerir trabalhos que levem em conta as tensões tangenciais, protensão das barras (potencializando as suas propriedades) e a sua ancoragem (fator limitante de fabricação pelo processo de pultrusão). Avançando para estudo da fadiga nas barras, deslocamentos e deformação de longo termo para elementos de concreto armados simplesmente, ou envolvendo protensão da armadura não metálica. E ainda trabalhos designados para o melhoramento do compósito de fibra e matriz, como por exemplo, estudos da durabilidade das fibras e da matriz polimérica, de melhoramento das propriedades das fibras (resistência à ataques ambientais) e da capacidade de proteção da matriz. 


\section{REFERÊNCIAS}

ALVES, A. B.; CASTRO, P. F. (1998) Barras de armação em FRP: Discussão de parâmetros para normalização. In: III Congresso de Engenharia Civil. Anais do congresso. Juiz de Fora, Agosto de 1998.

AMERICAN CONCRETE INSTITUTE (1994). ACI 318 - Building code requirements for reinforced concrete. Detroit, USA.

AMERICAN CONCRETE INSTITUTE (1996) ACI COMMITTEE 440R State-of-Report on Fiber Reinforced Plastic (FRP) Reinforcement for Concrete Structures.

AMERICAN CONCRETE INSTITUTE (2003). ACI COMMITTEE 440.1R Guide for the Design and Construction of Concrete Reinforced with FRP Bars.

ASSOCIAÇÃO BRASILEIRA DE NORMA TÉCNICAS (1994). NBR 5739:1994 Concreto - Ensaio de compressão de corpos-de-prova cilíndricos - Método de ensaio. Rio de Janeiro.

ASSOCIAÇÃO BRASILEIRA DE NORMA TÉCNICAS (2003). NBR 6118:2003 Projeto de estruturas de concreto. Rio de Janeiro.

ASSOCIAÇÃO BRASILEIRA DE NORMA TÉCNICAS (1991). NBR 6349:1991 - Fios, barras e cordoalhas de aço para armaduras de protensão - Ensaio de tração - Método de ensaio. Rio de Janeiro.

ASSOCIAÇÃO BRASILEIRA DE NORMA TÉCNICAS (1994). NBR 7222:2003 Argamassa e concreto - Determinação da resist6encia à tração por compressão diametral de corpos-de-prova cilíndricos - Método de ensaio. Rio de Janeiro. 
ASSOCIAÇÃO BRASILEIRA DE NORMA TÉCNICAS (1984). NBR 8522:1884 Concreto - Determinação do módulo de deformação estática e diagrama tensão deformação - Método de ensaio. Rio de Janeiro.

BAKHT, B. et al. (2000). Canadian Bridge Design Code Provisions for Fiber-Reinforced Structures. Journal of Composites for Construction, vol. 4, n. 1. February, 2000

BAKIS, C. E. et al. (2002). Fiber-Reinforced Polymer Composites for Construction State-of-the-Art Review. Journal of Composites for Construction, v. 06, n. 2. Maio 2002.

BENMOKRANE, B. et al. (2002). Durability of Glass Fiber-Reinforced Polymer Reinforcing Bars in Concrete Environment. Journal of Composites for Construction, vol. 06, n. 3. Agosto 2002.

COMITE EURO-INTERNACIONAL DU BÉTON (1990). CEB-FIP Model code for concrete structures. Bulletin D'Information, Paris, July;

FUSCO, P. B. (1994). Técnicas de armar estruturas de concreto. Editora Pini Ltda., São Paulo;

GAO, D.; BENMOKRANE, B.; e MASMOUDI, R. (1998) A Calculating Method of Flexural Properties of FRP-Reinforced Concrete Beam, Technical Report, Department of Civil Engineering, University of Sherbrooke, Sherbrooke, Quebec, Canada, $24 \mathrm{pp}$.

GONÇALVES, R. M. et al. (2005) Segurança nas estruturas: teoria e exemplos. SET/EESC/USP, São Carlos.

HUGHES BROS. INC. (2001). Mechanical Properties of GFRP rebar. Seward, NE. http://www.hughesbros.com

HULATT, J.; HOLLAWAY, L.; THORNE, A. (2002). Preliminary investigations on the environmental effects on new heavyweight fabrics for use in civil engineering. Composites Part B: Engineering, vol. 33, n. 6. Setembro 2002.

KAJORNCHEAPPUNNGAM, S.; GUPTA, R. K.; GANGARAO, H. V. S. (2002). Effect of Aging Environment on Degradation of Glass-Reinforced Epoxy. Journal of Composites for Construction, vol. 06, n. 1. Fevereiro 2002. 
LEONARDT, F.; MÖNNING, E. (1977). Construções de concreto. Ed. Interciência, v. 01, 02, 03 e 04, Rio de Janeiro;

METHA, P. K.; MONTEIRO, P. J. M. (1994). Concreto: estrutura, propriedades e materiais. Ed. Pini, São Paulo.

MICELLI, F.; NANNI, A. (2004). Durability of FRP rods for concrete structures. Construction and Building Materials, vol. 18, n. 7. Setembro 2004.

NEOCLEOUS, K. (2005). Publicação eletrônica [mensagem pessoal]. Recebido por <danusaht@sc.usp.br> em 24 março.

PARK, R.;PAULAY, T. (1974) Reinforced Concrete Structures. New York, John Wiley \& Sons, 1975.

PILAKOUTAS, K.; NEOCLEOUS, K.; GUADAGNINI, M. (2002). Design Philosophy Issues of Fiber Reinfored Polymer Reinforced Concrete Structures. Journal of Composites for Construction, vol. 06, n. 3. Agosto 2002.

RAYOL, J. O.; MELO, G. S. (1998) Comportamento de vigas de concreto de alta resistência com armadura não metálica tipo FRP. In: III Congresso de Engenharia Civil. Anais do congresso. Juiz de Fora, Agosto de 1998.

SEN, R.; MARISCAL, D.; SHAHAWY, M. (1993). Investigation of S-2 Glass/ Epoxy Strands in Concrete. In: International Symposium on Fiber Reinforced Plastic Reinforcement for Concrete Structures. Fiber reinforced plastic reinforcement for concrete structures. Detroit, ACI, 1994.

SONOBE, Y. (1993) Outline of the National Research Project on the Use of FRP Reinforcement in Concrete Building Structures in Japan. In: International Symposium on Fiber Reinforced Plastic Reinforcement for Concrete Structures. Fiber reinforced plastic reinforcement for concrete structures. Detroit, $\mathrm{ACl}, 1994$.

TANNOUS, F. E.; SAADATMANESH, H. (1998). Durability of AR Glass Fiber Plastic Bars. Journal of Composites for Construction, vol. 03, n. 1. Fevereiro 1999.

THERIAULT, M., e BENMOKRANE, B. (1998) Effects of FRP Reinforcement Ratio and Concrete Strength on Flexural Behavior of Concrete Beams. Journal of Composites for Construction, V. 2, No. 1, pp. 7-16. 
TIGHIOUART, B.; BENMOKRANE, B.; GAO, D.; Investigation of bond in concrete member with fiber reinforced polymer (FRP) bars. Construction and Building Materials, vol. 12, n. 8. Dezembro 2004

UOMOTO, T. et al.(2002). Use of Fiber Reinforced Polymer Composites as reinforcing Material for Concrete. Journal of Materials in Civil Engineering, vol. 14, n. 3. Maio, junho 2002.

YAMASAKI, Y. et al (1993). Fundamental Properties of Continuous Fiber Bars. In: International Symposium on Fiber Reinforced Plastic Reinforcement for Concrete Structures. Fiber reinforced plastic reinforcement for concrete structures. Detroit, $\mathrm{ACl}, 1994$. 